\title{
Concepción de Marketing para la Exportación de Flores Frescas Cortadas de Origen Colombiano a la República Argentina.
}

Trabajo Científico libre para la obtención del grado de Magister en Marketing Internacional de la Escuela de Postgrado de Marketing Internacional -Facultad de Ciencias Económicas

- Universidad Nacional de La Plata -

Profesor Director de Tesis:

Prof. Lic. Reinaldo Horacio Kopp
Presentado por:

Oscar Iván Prieto Amaya

Dirección: Transversal 56 № $108-50$

Apto 402 Bogotá - Colombia.

Tel. (571) 3112027824 


\section{PROLOGO}

Más allá o más acá de su significado romántico, las flores se han transformado en los últimos años en un suculento negocio que mueve en el mundo unos 35.000 millones de dólares por año. Se trata de uno de los rubros más dinámicos de la economía mundial -con una tasa de crecimiento de alrededor del 6 por ciento ${ }^{1}$ - y un gran generador de puestos de trabajo ${ }^{2}$.

Pese a tener las condiciones climáticas y fitosanitarias necesarias para participar de ese atractivo negocio, la Argentina es, todavía, una espectadora pasiva y distante. Al contrario, Colombia, Ecuador, Israel, Tailandia, Kenia, Nueva Zelanda y Australia, que en la década del 80 ni siquiera figuraban entre los productores, son hoy grandes exportadores. Más próximos, Brasil y Chile -que se subieron tarde al negocio- han logrado un posicionamiento más que interesante.

El mercado de la floricultura está en constante movimiento. El público cambia sus patrones de consumo de modo constante y está abierto a nuevas especies, variedades, colores. Y está dispuesto a pagar más por eso.

Como típico bien suntuario, su consumo guarda directa relación con el poder adquisitivo de la población y, por lo tanto, la expansión del negocio está ligada de modo estrecho al mejoramiento de las condiciones económicas, sociales y culturales de los pueblos.

De acuerdo con estimaciones realizadas por el INTA, el sector nacional de producción de flores de corte está posicionado para transformarse en una industria sustentable y cuenta con potencial para su expansión ${ }^{3}$ mediante la innovación, adaptación de tecnología y mayor eficiencia del sistema comercial.

Considerando la importancia económica de la floricultura a nivel local y asumiendo el potencial de crecimiento proyectado desde las instituciones públicas ${ }^{4}$, este estudio

\footnotetext{
${ }^{1}$ Cámara de Importadores y Exportadores de Flores, plantas y afines de la República Argentina Publicación mensual Confederación Argentina de la Mediana Empresa CAME - Abril/2009.

${ }^{2}$ International Trade Centre. Product Profile: Cut Flowers and Foliage, 2001 en JICA-INTA, 2003

3 INTA, "Programa Nacional Hortalizas y Flores", 2002.

${ }^{4}$ INTA, Concejo Federal de Inversiones (CFI), Universidad de Buenos Aires (UBA), etc.
} 
plantea establecer aspectos relevantes del marketing para la importación y comercialización de flores frescas de corte originarias de Colombia.

Por ello, se analizará y evaluará la oportunidad desde el punto de vista estratégico. En términos generales se asume la posibilidad de crecimiento del mercado, así como las tendencias relacionadas con la calidad (durabilidad, diversidad, etc.). Asimismo, cuanto más imperfecto es el mercado, más interesante es la oportunidad. Esto conlleva una serie de estrategias encaminadas a satisfacer las necesidades de los clientes, brindando productos con los más altos niveles de calidad y servicio.

Para tal fin, este trabajo se organiza en capítulos donde inicialmente, se propone una figura para el establecimiento de una posible operación de importación de flores frescas desde Colombia, pasando luego por un análisis de cifras del comercio internacional tanto de Argentina como Colombia, realizando un análisis DOFA para evaluar la oportunidad de llevar a la realidad un negocio con este producto entre los 2 países, y finalmente, se propone un plan de mercadeo donde se definirá claramente el Producto a comercializar, el precio estimado, su forma de distribución, y sus mecanismo para el impulso y promoción. Posteriormente se cierra con un análisis financiero el cual tiene como objetivo establecer la viabilidad financiera que tendría la propuesta del presente proyecto, bajo un esquema de variables supuestas que pueden influir en su desarrollo. Finalmente se entregan conclusiones generales del análisis realizado en cada capítulo.

Para alcanzar estas conclusiones, se llevaron a cabo actividades de investigación de diversas fuentes, iniciando con características amplias, para luego, ir focalizando la información según el interés para este estudio. Vale la pena mencionar los documentos elaborados por el INTA y la Agencia de Cooperación Internacional del Japón (JICA), cuyos títulos se detallan en la bibliografía, al igual que los documentos elaborados por el Concejo Federal de Inversiones (CFI) y el texto "Floricultura en la Argentina" de la Facultad de Agronomía de la Universidad de Buenos Aires (UBA), entre otros. Asimismo, se revisó y analizó la información de mercado, tomando como dato de interés, la información citada por el estudio preliminar "Estudio de Mercado Interno e Internacional de Flores de Corte, Plantas Ornamentales y Follajes" del CFI 
- Fundación fortalecer y otros documentos disponibles en internet publicados por la Asociación Colombiana de Productores de Flores (ASOCOLFLORES). 


\section{INDICE}

\section{ESTRATEGIA GENERAL PARA COMPOSICICIÓN DE LA EMPRESA}

1.1 Descripción y Filosofía del Plan de Marketing

1.2. Composición Organizacional

1.3 Concepción Financiera a Largo Plazo

1.4 Objetivos del Proyecto

1.5 Alcance del Proyecto

1.6 Estrategia General de Marketing

II. OPORTUNIDAD COMERCIAL

2.1 Oportunidad de Comercio Colombia-Argentina

\section{ANÁLISIS DE OPORTUNIDADES Y ANÁLISIS DE MERCADO}

3.1 Volumen de mercado y desarrollo del mercado

3.1.1 Posición Arancelaria

3.1.2 Evaluación del mercado meta

3.1.3 Análisis de Intercambio Comercial entre Argentina y Colombia

3.1.4 Análisis del Comercio del Sector de Flores

3.1.5 Mercado de las Flores en Argentina

3.1.6 Proceso de producción de flor local

3.1.7 Comercialización de flor en el Mercado Interno

3.2 Barreras de Acceso

3.2.1 Acuerdo de Complementación Económica

3.2.2 Programa de Liberación

3.2.3 Aranceles y otros impuestos a las importaciones

3.2.4 Regulaciones y Normas

3.2.5 Requerimientos de Etiquetado

3.2.6 Prohibiciones

3.3 Análisis de la Competencia

3.3.1 Oferta Local de Flores Frescas Cortadas

3.3.2 Oferta Extranjera de Flores Frescas de Corte

3.4 Análisis FODA y evaluación de oportunidad

IV. DETERMINACIÓN DE GRUPO OBJETIVO Y OBJETIVOS DE MERCADEO

4.1 Segmentación de Mercado y Cuantificación de la demanda

4.2 Unidad de Negocio

4.3 Objetivos del Plan de Mercadeo

4.4 Posicionamiento

V. ESTRATEGIA DE MARKETING Y PLAN DE ACTIVIDADES

5.1 Estrategia: Liderazgo, Diferenciación y Enfoque

5.2 Factores Claves de Éxito

5.3 Plan de Marketing (4P's): Definición del Marketing Mix

5.4 Cadena de Comercialización - Manejo de Producto

\section{PRESUPUESTO Y CONTROL}

6.1 Recursos e Inversiones

6.2 Factibilidad Técnica 
6.2.1 Ensayo e Investigación

6.2.2 Ubicación

6.2.3 Escalas de Producción

6.3 Proyecciones (Ventas y Costos)

6.5 Análisis Financiero

\section{CONCLUSIONES GENERALES}

\section{TABLAS}

- Tabla No. 1 Posición Arancelaria Productos a Importar

- Tabla No. 2 Argentina: Generalidades

- Tabla No. 3 Exportaciones e Importaciones Argentinas Totales 2006-2009

- Tabla No. 4 Intercambio Bilateral Argentina - Colombia

- Tabla No. 5 Exportaciones Colombianas de la Subpartida Arancelaria 060311 (Rosas), por destino durante los años 2008 y 2009.

- Tabla No.6 Importaciones del sector floricultor (Plantas Vivas y productos de la floricultura) en la Argentina (2006-2008)

- Tabla No. 7 Exportaciones del sector floricultor (Plantas Vivas y productos de la floricultura) de la Argentina (2006-2008)

- Tabla No. 8 Importaciones de flor fresca en la Argentina (2007-2008)

- Tabla No. 9 Importaciones de flor en la Argentina (2007-2008)

- Tabla No.10 Importadores de flor en la Argentina (2007-2008)

- Tabla No. 11 Cantidad de mujeres en el grupo de edad objetivo $2010-2015$

- Tabla No. 12 Cálculo de la Demanda y su proyección de crecimiento

- Tabla No. 13. Estructura de Costos y Gastos Proceso de Importación

- Tabla No. 14. Matriz de Precios y Márgenes de Ganancia por Canal

\section{ANEXOS}

- Anexo $N^{\circ}$ 1. Cronograma de Ejecución Plan de Marketing

- Anexo $N^{\circ}$ 2. Diagrama de Procesos para la Importación de Flor

- Anexo №3 Simulación del Embalaje y la Unidad de Carga

- Anexo No 4 Frecuencias de Vuelos de Carga Bogotá-Buenos Aires

- Anexo $N^{\circ} 5$. Análisis Financiero (Ventas y Costos Proyectados)

- Anexo $N^{\circ}$ 6. Presupuesto Financiero Proyectado (Flujo de Caja)

- Anexo $N^{\circ} 7$. Premisas y Estimaciones Utilizadas para la Proyección de los Flujos de Fondos Netos

- Anexo $N^{\circ}$ 8. Diseño Preliminar Página de Internet 


\section{RESUMEN EJECUTIVO}

El alcance de la presente investigación, será la de evaluar la viabilidad de establecer una operación radicada en la República Argentina que importará y comercializará flor fresca de corte de origen colombiano. Al inicio de la ejecución del proyecto se atenderá mercado de Buenos Aires, por ser el sector que presenta mayor escala de comercialización en este tipo de productos $^{5}$, teniendo como objetivo a corto plazo la incorporación de la provincia de Santafé por la cercanía en distancia. Los productos que de acuerdo con datos históricos de importación y con especialistas del sector son preferidos en Argentina son rosa, claveles y crisantemos, encontrando en menor medida mini rosa, mini clavel, alstroemerias y lirios. Todos estos tipos de flor con diversidad de colores, tamaños y variedades son producidos a gran escala en Colombia 6 .

El emprendimiento surge luego un análisis de mercado -in situ-, donde se evidenció la gran aceptación de bienes suntuosos en la medida que el crecimiento del país permite mayor disponibilidad de recursos monetarios en las personas. La tendencia creciente en la importación de flores en Argentina principalmente de origen ecuatoriano y colombiano (con un pequeño retroceso en 2008), muestra un gran dinamismo en los consumidores que encontraron nuevas aplicaciones para este tipo de bienes.

Las bases que garantizan el éxito del negocio están asentadas en la posibilidad de proporcionar flores de gran calidad, aspectos que se verán reflejados en mayores tiempos de duración en florero, diversidad en tipos, colores y variedades de flores. Además, el menor tiempo de reabastecimiento comparado con otros importadores ${ }^{7}$ generará un indicio de eficiencia y confianza en los clientes.

\footnotetext{
${ }^{5}$ Cámara de Importadores y Exportadores de la República Argentina - Publicación Mensual Cámara de la Mediana Empresa (CAME) - Junio 2010.

${ }^{6} 7.200$ hectáreas cultivadas - Asociación Colombiana de Floricultores (ASOCOLFLORES)

${ }^{7}$ Promedio de tiempo de reabastecimiento de flor importada desde Ecuador: 5-6 días (consulta personal en el mercado de las flores ubicado en Almagro - Capital Federal - Argentina)
} 
El negocio apunta a satisfacer las necesidades de clientes que requieren flores de gran calidad y exclusivas, de manera que se dirige a un sector especializado donde los consumidores finales son personas de poder adquisitivo medio, medio alto y alto. De igual forma, los clientes de la importadora serán mayoristas y florerías exclusivas ubicadas en las zonas que concentran los consumidores con las características anteriormente mencionadas. Asimismo, se pretende mantener un portafolio de productos para hoteles y restaurantes, quienes debido a sus actividades requieren el suministro de este tipo de bienes bajo las premisas de durabilidad y variabilidad con un sistema de aprovisionamiento adecuado.

El auge de la integración y cooperación entre países que en la última década se viene dando de forma positiva, genera un factor competitivo para el intercambio de bienes. Los acuerdos de cooperación en términos de rapidez en los trámites y estandarización de normas fitosanitarias para productos agroindustriales suscritos entre Colombia y Argentina, hacen que la trazabilidad sea mayor gracias a la disminución de barreras no arancelarias que durante mucho tiempo afectó el comercio de este tipo de bienes entre los dos países.

La gran relevancia que tienen actualmente las flores ecuatorianas en el mercado argentino es reflejo del escaso emprendimiento que se ha tenido con los productos florícolas colombianos, ya que los costos de importación desde Ecuador son en algunos casos inferiores, y, en términos de calidad, la flor colombiana dista favorablemente en buena proporción de los productos de su principal competidor ${ }^{8}$. De manera que mostrar al mercado flores de mejor calidad e incluso con precios inferiores serán las mejores herramientas para establecer en la mente de los consumidores la flor colombiana como su primera opción.

\footnotetext{
${ }^{8}$ Consultas a florerías ubicadas en Capital Federal durante el año 2009.
} 


\section{ESTRATEGIA GENERAL PARA COMPOSICICIÓN DE LA EMPRESA}

\subsection{Descripción y Filosofía del Plan de Marketing}

Se busca consolidar una operación dedicada a la importación y comercialización de flores frescas de origen Colombiano en el mercado Argentino. Como ya se mencionó, inicialmente, el desarrollo del proyecto apunta específicamente a la consolidación de las operaciones de importación, comercialización y distribución en las provincias de Buenos Aires y Santa Fe. En virtud de lo anteriormente expuesto, uno de los pilares fundamentales y factor clave de éxito será el establecimiento de una completa red de proveedores que proporcionen flores de excelente calidad, los cuales, además, se ajusten a los requerimientos en materia fitosanitaria que para tal fin tienen establecidos los organismos gubernamentales de la República Argentina.

En cuanto a la cadena de comercialización, se puede decir que la importadora trabajará con distribuidores mayoristas especializados en abastecer floristerías que manejan el sector exclusivo del mercado. Asimismo, se pretende mantener negociaciones con algunos detallistas (floristerías exclusivas) que por políticas corporativas sólo mantienen relación directa con los importadores. De igual forma, se quiere ampliar la red de clientes conformados en hoteles y restaurantes, que dentro de las necesidades de sus negocios requieren que se les proporcionen flores de la mejor calidad y durabilidad.

Por otro lado, la diversidad en tipo de flor, así como los colores, variedades y largo de tallo, marcarán un amplio campo de acción. Además, tendrá dentro de su portafolio de productos no solo ramos Bulk ${ }^{9}$ sino también Assortment y Bouquets ${ }^{10}$. Lo anterior le permitirá obtener a los clientes la flexibilidad que se necesita para cumplir con las exigencias del mercado de flores argentino, los cuales, se basan principalmente en calidad, ciclos estacionales (San Valentín, Día de la madre, Día de la primavera) y tendencias del momento (colores naranjas y amarillos en otoño, rojos y blancos en navidad).

\footnotetext{
${ }^{9}$ Bulk: Ramos de un solo tipo de flor y color; Assortment: Ramos de un solo tipo de flor y diferentes colores.

${ }^{10}$ Bouquets: Ramos de diferentes flores y colores.
} 


\section{Propuesta de Misión y Visión.}

MISIÓN: Satisfacer las necesidades de nuestros clientes a través de la oferta de una selecta variedad de flor con parámetros exigentes de calidad, precios competitivos y colocando todos nuestros recursos disponibles para brindar uno de los mejores servicios.

VISIÓN: Constituirse en 5 años entre las primeras importadoras radicadas en la República Argentina de flores frescas cortadas, siendo reconocidos como la mejor alternativa para ofrecer las flores Colombianas, como una innovadora opción que responde a las necesidades y tendencias del momento, apoyados en un excelente servicio y ofreciendo productos con unos altos estándares de calidad.

\subsection{Composición Organizacional}

El equipo de trabajo, inicialmente, estará conformado por tres (3) personas:

1. Encargado administrativo y contable: Gestión de Pagos y Cobros, Pago de impuestos, Registros.

2. Encargado de Marketing: Contacto directo con los clientes, recepción de órdenes de compra, promoción y gestión de contratos.

3. La tercera persona estará a cargo de la distribución, será quien se encargue de distribuir a cada uno de los clientes en sus puntos de venta o lugar de utilización.

En las primeras etapas de puesta en marcha del proyecto, se requerirá de asesores externos en evaluación de calidad de flor, establecimiento de sociedades (conveniencia por tipo de negocio, estructura y tamaño - S.R.L/Sociedad de hecho/S.C.A, etc.), y gestión impositiva (IVA, ingresos brutos, habilitaciones y demás normativas aplicables).

Adicionalmente, en Colombia se tendría el apoyo de un inspector de calidad, quien hará una revisión en los cultivos de flores y será quien defina si es viable o no el despacho de los productos. 


\subsection{Concepción Financiera a Largo Plazo}

La estructura financiera que adoptará el emprendimiento objeto de la presente investigación, se propone bajo una composición de capital propio y préstamos de terceros.

Los aportes de capital tendrán una estructura de largo plazo y corresponden a la inversión de dinero o especie que harán los socios. Asimismo, los fondos obtenidos por préstamos, se buscaran en lo posible en el largo plazo y con tasas competitivas del mercado, optando, incluso, por tasas subsidiadas (tasas preferenciales para proyectos de inversión que incentiven los sectores productivos). La propuesta busca que la inversión del proyecto, en un mayor porcentaje provenga de aporte de préstamos, y un menor porcentaje de aporte de socios.

Por otro lado, hay que tener en cuenta que el acceso al crédito en general para países latinoamericanos, es un tema de gran relevancia; varios factores están ligados con su obtención bajo condiciones favorables. Entre los obstáculos de las Pymes para obtener crédito, desde el punto de vista de la demanda, se encuentra el alto costo del crédito, la falta de confianza de los bancos respecto de los proyectos, el exceso de burocracia de los intermediarios financieros y la petición de excesivas garantías.

Pese a ello, en la última década, el BID (Banco Interamericano de Desarrollo), ha implantado una serie importante de programas financieros dirigidos a las Pymes para que accedan a financiamiento.

En Argentina, la cartera de Industria, y la Subsecretaría Pyme (SEPYME) en particular, han implementado diversos planes de asistencia y beneficios impositivos para las Pymes. De manera que hay apoyo para los emprendimientos. Cabe anotar que no están específicamente definidos para proyectos de importación, pero hay características que pueden favorecer este proyecto en particular, asociadas específicamente con acuerdos de colaboración empresaria. 


\subsection{Objetivos del Proyecto}

A través de un análisis detallado del mercado, viabilidad financiera, utilizando los recursos y facilidades para el intercambio comercial de productos florícolas entre Colombia y Argentina; el objetivo general del presente proyecto es desarrollar el establecimiento de los principales puntos de la determinación de un plan de mercadeo para la importación y comercialización de flores frescas cortadas de origen colombiano en el mercado argentino, bajo un enfoque de las herramientas de marketing internacional. Este emprendimiento tendrá su fundamento en una evaluación, medición y análisis del mercado Argentino, así como la viabilidad técnica y la opción logística acorde para ejecutar con éxito el proceso de comercialización de flores colombianas en el mercado anteriormente mencionado.

Para la consecución del objetivo general impuesto, se pretenden alcanzar los siguientes objetivos específicos.

- Determinar las regiones de mayor concentración de operaciones de comercio de flores frescas cortadas en la República Argentina.

- Segmentación del mercado meta.

- Definir el Producto a importar.

- Identificar el tipo de embalaje y empaque más adecuado para la comercialización del producto.

- Seleccionar los canales para comercializar el producto.

- Definir un plan para la promoción del producto de acuerdo a los canales de comercialización

- Determinar los aspectos logísticos que implicará el proyecto.

- Identificar el marco regulatorio, las barreras arancelarias y las no arancelarias del mercado argentino con respecto al producto.

- Determinar posibles costos del proyecto.

- Estimar el precio de venta del producto y sus ganancias

- Determinar la viabilidad financiera del proyecto.

Todos los objetivos anteriormente mencionados tendrán desarrollo en cada uno de los capítulos. 


\subsection{Alcance del Proyecto}

El estudio se basa en un análisis del diagnóstico interno de algunas de las áreas del mercado de flor en Argentina (hábitos de consumo, dinámica del sector, competencia local y extranjera) y los aspectos más importantes a considerar para la importación de flores frescas de origen Colombiano a Argentina (evaluación y selección del mercado meta, aspectos logísticos, marco regulatorio, entre otros), a fin de elaborar una propuesta de comercialización hacia los mercados meta que se hayan seleccionado dentro del estudio.

Es importante mencionar que este proyecto es un emprendimiento novedoso ya que el intercambio comercial de flores entre Colombia y Argentina no ha sido representativo en los últimos años y por lo tanto, antes de evaluar lo anterior, se elaborará un análisis preliminar del mercado que sirva para determinar en primera instancia la viabilidad del proyecto; cabe señalar que al respecto, hay pocos datos, por lo que la información de mercado aquí presentada, estará en función de escasos datos históricos y se basará en datos proporcionados básicamente por revistas especializadas, estudios afines de las entidades de promoción de exportaciones y el no menos importante trabajo de campo realizado In Situ (entrevistas con importadores y comercializadores de flor en Capital Federal).

Como base de estudio, se estableció un cronograma de ejecución (Anexo No.1) con los valores de las inversiones; lo anterior es una guía de las etapas y actividades que han sido y deberán ser ejecutadas para la correcta puesta en marcha del proyecto.

\subsection{Estrategia General de Marketing}

La primera parte de la estrategia general de marketing estará enmarcada en una segmentación acertada del mercado argentino. Clientes potenciales, patrones de compra, estilos de vida, patrones de utilización del producto. Asimismo, se analizará el paquete total de beneficios que obtendrá el cliente respecto de los productos; el punto de partida habrá sido la identificación de la necesidad que no está siendo satisfecha adecuadamente, y así, proponer las estrategias de producto más acordes. 
Por otro lado, el proceso de determinación de precios habrá sido producto de un análisis preliminar que contemplará la mejor estrategia de precio. La estrategia se basa en el establecimiento del costo como factor determinante, donde el precio final a los clientes varía dependiendo de los márgenes de intermediación existentes en la cadena de abastecimiento. En un inicio la estrategia tendrá referencia a los precios encontrados en el mercado, sin embargo a futuro, esta estrategia puede cambiar de acuerdo al comportamiento de las ventas.

En cuanto al sistema de distribución local - se hablará con más detalle en apartados posteriores, sin embargo en un inicio se pretende incorporar una camioneta adaptado con reefer ${ }^{11}$ a través de un leasing financiero, con la cual se transportara la flor desde el aeropuerto de Buenos Aires hasta entregarla a cada uno de los clientes en sus sitios de operación y/o utilización.

\section{Conclusiones del Capítulo}

En relación con la fijación de la idea de marketing y la estrategia para alcanzar los objetivos establecidos, se concluye lo siguiente:

1. En el aspecto organizacional, se conformará un equipo de trabajo de tres (3) personas para la parte administrativa y contable, marketing y distribución; adicionalmente, habrá asesores externos en las primeras etapas que permitan evaluar la calidad de las flores, revisar el tema para el establecimiento de sociedades y la gestión impositiva, y en Colombia se contará con un inspector de calidad.

2. La estructura financiera del proyecto contempla el uso de capital propio y préstamos de terceros a largo plazo.

3. El objetivo general del proyecto está orientado a determinar las actividades y aspectos relevantes de mercadeo para importar y comercializar flores frescas cortadas de origen colombiano en el mercado argentino.

4. El estudio se soporta en el análisis del diagnóstico del mercado de flor en la Argentina y los aspectos más importantes a considerar para la importación de

\footnotetext{
${ }^{11}$ Equipo refrigerado para el traslado en forma segura y a temperaturas controladas toda carga perecedera como frutas, vegetales, pescados, flores, etc.
} 
flores frescas de origen colombiano, para elaborar una propuesta de comercialización hacia el mercado meta que se seleccione.

5. La estrategia de marketing requiere de una segmentación acertada del mercado argentino en lo referente a clientes potenciales, patrones de compra, estilos de vida, patrones de uso del producto, beneficios del cliente respecto a los productos. 


\section{OPORTUNIDAD COMERCIAL}

\subsection{Oportunidad de Comercio Colombia-Argentina}

Es importante en el presente estudio explicar la razón por la cual se determina que la operación de comercio internacional, se realiza entre 2 países como Argentina y Colombia, y por la cual no se instala dicha operación en cualquier otro país.

La flor de exportación que ofrece Colombia, siempre ha sido considerada de buena calidad, y tiene buena imagen en los mercados externos. Su principal cliente es Estados Unidos, el cual se ha llevado el mayor porcentaje del destino de las exportaciones históricamente. El objetivo de la presente propuesta, se basa en la búsqueda de nuevos mercados, los cuales puedan estar desatendidos, y los cuales tengan una proyección de facilidades para el desarrollo de la operación a futuro. La oficina de Proexport Colombia (Entidad de gran importancia que promueve el turismo, la inversión extranjera y las exportaciones en Colombia) insta por la exploración en países que han sean considerados como mercados de crecimiento inmediato y de precios altos en el consumo de la flor, donde se presenten nuevos segmentos de mercado online, oportunidad en la venta de bouquets y productos por estación, todas características que reúne totalmente el mercado argentino.

Analizando si existen restricciones de comercio internacional, Argentina ha sido un país que ha mostrado un uso muy cauto de las salvaguardias $\mathrm{OMC}^{12}$ y esto en parte, está relacionado con el nivel de exigencia de las reglas multilaterales ${ }^{13}$. En este contexto, hay que mencionar que Argentina no tiene salvaguardias en materia de productos de la floricultura. Sin embargo, las importaciones florícolas de Argentina tuvieron un importante descenso entre los años 1999 y 2006 debido a las altas exigencias fitosanitarias.

Tras una reunión bilateral sobre asuntos fito y zoosanitarios entre Colombia y Argentina realizada en el año 2007, el Gobierno de Colombia logró mejorar

\footnotetext{
${ }^{12}$ Organización Mundial del Comercio - Antes GAAT (General Agreement on Tariffs and Trade (Acuerdo General sobre Aranceles y Comercio).

${ }^{13}$ LATN - Latin America Trade Network - Serie LATN Papers N43, Mecanismos de Protección Contingente en el Comercio Intrarregional del Mercosur. Julio J. Nogués, Septiembre de 2005.
} 
considerablemente las condiciones de exportación de flores hacia el mercado Argentino. Este protocolo fitosanitario excluye plagas sobre las cuales Colombia debía demostrar el desarrollo de planes de monitoreo y control ${ }^{14}$. Argentina igualmente, exigía que todos los embarques de flores colombianas estuvieran respaldados por análisis de laboratorio, y gracias al protocolo, se acordó reducir el volumen de muestras por año.

Este último punto es otro factor clave por el cual se consideró avocar el presente estudio a una operación entre estos 2 países, ya que el ambiente actual para la importación y comercialización de productos de la floricultura en Argentina, se encuentran en buenas condiciones actualmente, facilitando los procesos y consolidando una cooperación que sin duda beneficia tanto a oferentes como demandantes.

Tampoco es ajeno que la República Argentina en los últimos años ha tenido un incremento permanente en su comercio exterior, además de su PIB, lo cual implica que existe actualmente en el país una mayor inversión, empleo y consumo interno, lo cual favorece ampliamente, el objetivo del presente proyecto, el cual es traer a la Argentina un producto caracterizado por ser un bien de lujo.

\footnotetext{
${ }^{14}$ Plan de trabajo para la exportación de flores frescas de corte originarias de Colombia con destino a La Argentina. - Andrés Valencia Pinzón (Gerente General ICA - Colombia) / Calos Milisevic (Jefe de Gabinete y Coordinador General SENASA - Argentina). Buenos Aires, 31 de Enero de 2007.
} 


\section{ANÁLISIS DE OPORTUNIDADES Y ANÁLISIS DE MERCADO}

Para el desarrollo de esta actividad, se tuvo en cuenta fuentes de información primarias (datos directamente del mercado, investigaciones de mercado, de sector, publicaciones y entrevistas con personas conocedoras de la comercialización de flor en Argentina), y fuentes secundarias (estadísticas de exportaciones e importaciones por partida y posición). Las mismas se irán citando en la medida que vayan soportando los argumentos de la presente investigación y análisis de factibilidad.

\subsection{Volumen de mercado y desarrollo del mercado}

\subsubsection{Posición Arancelaria}

A continuación se presenta la posición arancelaria bajo la cual se puede importar el producto en análisis.

Tabla No. 1 Posición Arancelaria Productos a Importar

\begin{tabular}{|c|c|}
\hline \multicolumn{2}{|c|}{ CLASIFICACIÓN ARANCELARIA } \\
\hline Descripción & Flores frescas cortadas \\
\hline Capítulo 06 & $\begin{array}{l}\text { Plantas vivas y productos de la floricultura (Se Excluyen } \\
\text { Papas - Patatas - Cebollas Hortenses - Chalotes - Ajos) }\end{array}$ \\
\hline Partida 06.03 & $\begin{array}{l}\text { Flores y capullos, cortados para ramos y adornos, } \\
\text { frescos, secos, blanqueados, teñidos, impregnados o } \\
\text { preparados de otra forma }\end{array}$ \\
\hline Sistema Armonizado 0603.10 & Frescos \\
\hline 0603.11 .00 & Rosas \\
\hline 0603.12 .00 & Claveles \\
\hline 0603.13 .00 & Orquídeas \\
\hline 0603.14 .00 & Crisantemos \\
\hline 0603.19 .00 & Los demás \\
\hline 0603.90 .00 & Los demás \\
\hline
\end{tabular}

Fuente: Comex. Información tomada el 07 de Nov. 2009

Los aranceles establecidos para la partida anteriormente señalada en la Tabla No.1 son los siguientes:

\begin{tabular}{|c|c|}
\hline \multicolumn{2}{|c|}{ Aranceles Partida 060310 } \\
\hline Arancel Externo Común (AEC) & $10 \%$ \\
\hline Derecho de Importación Extrazona (DIE) & $10 \%$ \\
\hline Derecho de Importación Intrazona (DII) & $0 \%$ \\
\hline Tasa Estadística (TE) & $0,50 \%$ \\
\hline IVA & $21 \%$ \\
\hline IVA Adicional & $5 \%$ \\
\hline IVA Reducido & $10,5 \%$ \\
\hline Ganancias & $3 \%$ \\
\hline Ingresos Brutos (IIBB) & $1,5 \%$ \\
\hline
\end{tabular}

Fuente: Comex. Información tomada 07 Nov. 2009 


\subsubsection{Evaluación del mercado meta}

Tras la gran crisis que sufrió Argentina desde mediados de 1998 (con una caída total del PIB del 21\%), culminada en 2002 con una caída del PIB del 14\%, default y devaluación, Argentina ha obtenido cinco años seguidos de elevado crecimiento ( $8,8 \%$ en 2003 , $9 \%$ en $2004,9,2 \%$ en $2005,8,5 \%$ en $2006,8,7 \%$ en 2007 y $7 \%$ en 2008), aumentos en el consumo, la inversión, el empleo, la masa salarial, la recaudación impositiva y las reservas del Banco Central. Estos resultados se lograron gracias a las medidas adoptadas (regulaciones, control de exportaciones, control de precios, subsidios al sector privado, entre otros $)^{15}$.

A continuación se presenta la información relevante del país destino.

Tabla No. 2 Argentina: Generalidades

\begin{tabular}{|c|c|}
\hline INFORMACIÓN GENERAL DEL PAíS \\
\hline Nombre & Información \\
\hline Capital & Buenos aires \\
\hline Idioma & Español \\
\hline Tipo de Gobierno & República \\
\hline Religión & Católica 92\%, otras 8\% \\
\hline Moneda & $\begin{array}{c}\text { Peso argentino (argentina) } \\
\text { La Plata , Mendoza } \\
\text { Rosario , Santa fe , Tucumán }\end{array}$ \\
\hline Principales Ciudades & $\mathbf{2 0 0 8}$ \\
\hline INFORMACIÓN SOCIOECONÓMICA \\
\hline Nombre & $39,746,383$ \\
\hline Población & 396,685 \\
\hline PIB (US\$ millones) & 14.413 \\
\hline PIB per cápita (US\$) & 7 \\
\hline \% Crecimiento PIB & 2.60 \\
\hline Tasa de devaluación (\%) & 3.84 \\
\hline Tipo de cambio (moneda del país / USD\$) & 519.79 \\
\hline Tipo de cambio bilateral (moneda del país / col \$) & 7.90 \\
\hline Tasa de desempleo (\%) & 7.20 \\
\hline Inflación (\%) & \\
\hline Fing & \\
\hline
\end{tabular}

Fuente: Aladi. Información tomada el 07 Nov. 2009

\footnotetext{
${ }^{15}$ Informe Económico y Comercial de la República Argentina-Elaborado por la Oficina Económica y Comercial de España en Buenos Aires / Actualización: Julio/2009
} 
Se presenta a continuación el valor de las exportaciones e importaciones totales realizadas en Argentina entre los años 2006 y el 2008. (Adicionalmente se tomaron valores de los 5 primeros meses del 2009)

Tabla No. 3 Exportaciones e Importaciones Argentinas Totales 2006-2009*

\begin{tabular}{|c|c|c|c|c|}
\hline \multicolumn{5}{|c|}{$\begin{array}{c}\text { Importaciones de Argentina } 2006-2009 \\
\text { (Datos expresados en miles de US\$ - Valor CIF) }\end{array}$} \\
\hline Copartícipe & 2006 & 2007 & 2008 & $2009 / 5 M$ \\
\hline Alemania & $\$ 1.544 .873$ & $\$ 2.131 .317$ & $\$ 2.533 .584$ & $\$ 764.748$ \\
\hline Brasil & $\$ 11.749 .368$ & $\$ 14.522 .981$ & $\$ 17.687 .225$ & $\$ 3.969 .980$ \\
\hline China & $\$ 3.121 .706$ & $\$ 5.092 .952$ & $\$ 7.103 .889$ & $\$ 1.735 .440$ \\
\hline $\begin{array}{l}\text { Estados } \\
\text { Unidos }\end{array}$ & $\$ 4.246 .887$ & $\$ 5.263 .975$ & \$ 6.894.299 & $\$ 1.766 .505$ \\
\hline Paraguay & $\$ 505.183$ & $\$ 1.056 .420$ & $\$ 1.782 .956$ & $\$ 500.074$ \\
\hline Otros & $\$ 12.717 .718$ & $\$ 16.371 .983$ & $\$ 21.116 .279$ & $\$ 4.942 .869$ \\
\hline Total & \$ 33.885.735 & $\$ 44.439 .628$ & $\$ 57.118 .232$ & $\$ 13.679 .616$ \\
\hline \multicolumn{5}{|c|}{$\begin{array}{c}\text { Exportaciones Argentinas } 2006 \text { - } 2009 \\
\text { (Datos expresados en miles de US\$ - Valor FOB) }\end{array}$} \\
\hline Copartícipe & 2006 & 2007 & 2008 & $2009 / 5 M$ \\
\hline Alemania & $\$ 1.124 .427$ & $\$ 1.264 .815$ & $\$ 1.475 .195$ & $\$ 550$ \\
\hline Brasil & $\$ 8.140 .942$ & $\$ 10.497 .885$ & $\$ 13.258 .684$ & $\$ 3.848 .077$ \\
\hline Chile & $\$ 4.403 .818$ & $\$ 4.180 .184$ & $\$ 4.715 .679$ & $\$ 1.934 .875$ \\
\hline China & $\$ 3.465 .853$ & $\$ 5.169 .817$ & $\$ 6.390 .213$ & $\$ 1.892 .813$ \\
\hline España & $\$ 1.825 .812$ & $\$ 2.064 .843$ & $\$ 2.743 .645$ & $\$ 645$ \\
\hline $\begin{array}{l}\text { Estados } \\
\text { Unidos }\end{array}$ & $\$ 4.025 .331$ & $\$ 4.153 .420$ & $\$ 5.209 .776$ & $\$ 1.466 .859$ \\
\hline Italia & $\$ 1.095 .554$ & $\$ 1.387 .222$ & $\$ 1.687 .918$ & $\$ 677$ \\
\hline Uruguay & $\$ 1.174 .823$ & $\$ 1.173 .375$ & $\$ 1.762 .267$ & $\$ 574$ \\
\hline Otros & $\$ 20.499 .949$ & $\$ 25.134 .153$ & $\$ 31.394 .340$ & $\$ 12.279 .797$ \\
\hline Total & $\$ 45.756 .509$ & $\$ 55.025 .714$ & $\$ 68.637 .717$ & $\$ 21.424 .867$ \\
\hline $\begin{array}{l}\text { Balanza } \\
\text { Comercial }\end{array}$ & $\$ 11.870 .774$ & $\$ 10.586 .086$ & $\$ 11.519 .485$ & $\$ 7.745 .251$ \\
\hline
\end{tabular}

La Tabla No. 3 muestra las Exportaciones e Importaciones totales de la República Argentina para los años 2006 - 2009, componiendo este último año datos preliminares. Se puede ver una tendencia creciente en el comercio global pero siempre manteniendo una balanza positiva. Como es de esperarse, los principales socios comerciales son países del Mercosur (Brasil, Paraguay y Uruguay), pero también encuentra un volumen importante de transacciones con Estados Unidos, Alemania y China, sumándose Chile y México como destino importante de las exportaciones. 
En virtud de lo anteriormente expuesto, y con base en estudios macroeconómicos del ICEX ${ }^{16}$, se puede decir que Argentina en materia de comercio exterior era una de las economías menos abiertas del mundo, al suponer su comercio exterior tan sólo un $18 \%$ del PIB. Posteriormente, las exportaciones y las importaciones han ido aumentando notablemente su participación en el PIB, y el grado de apertura comercial de Argentina, medido por el ratio (exportaciones + importaciones) / PIB, se ha elevado considerablemente, hasta alcanzar en 2007 el 38,2\% y el 38,9\% durante 2008.

De igual modo, el volumen de importaciones sobre el total del Producto Interno Bruto se ha elevado en los últimos años, y así, el coeficiente de importación (importaciones/PIB) ascendió, desde el 13,3\% de 2006, hasta el 16,5\% en 2007 y el $17,4 \%$ en 2008.

\section{Detalle General de Exportaciones de Argentina $\left({ }^{17}\right)$.}

Las exportaciones argentinas muestran una fuerte concentración en torno a los productos agropecuarios, en bruto (23\% de las exportaciones) o procesados (35\%) y otros productos primarios como los derivados del petróleo y otros productos energéticos (11\%). Los productos de origen animal supusieron el $6 \%$ de las exportaciones, los productos de origen vegetal el $21 \%$ (especialmente granos como la soja, el maíz y el trigo), aceites y grasas el 10\%, alimentos, bebidas y tabaco el $16 \%$ y los productos minerales un $11 \%$.

A pesar de que las exportaciones de productos primarios y sus derivados se concentran en torno a los granos, en los últimos años se han desarrollado con fuerza otros sectores. Así la pesca se ha desarrollado con fuerza, con una significativa presencia de empresas españolas. También la exportación de vinos y de frutas y hortalizas ha crecido con fuerza. Argentina es también un importante exportador de manufacturas industriales (que representan el $31 \%$ de las exportaciones). Destacan los automóviles y camiones, así como algunos de sus componentes (que en

\footnotetext{
16 ICEX Instituto Español de Comercio Exterior

17 Informe Económico y Comercial - Elaborado por la Oficina Económica y Comercial de España en Buenos Aires, Julio de 2009.
} 
conjunto suponen el $10 \%$ de las exportaciones), y otras manufacturas de metalmecánica. La industria química, especialmente los plásticos, representa el 3\% de las exportaciones totales. Otros sectores con exportaciones significativas son el textil, papel y manufacturas de piel.

\section{Detalle General de Importaciones de Argentina $\left({ }^{17}\right)$.}

Al igual que en el caso de las exportaciones, las importaciones crecieron de forma muy significativa en 2008 , un $28,4 \%$. Sin embargo, en este caso fue el aumento en las cantidades importadas (16\%), más que el aumento en los precios (11\%) lo que impulsó las importaciones.

Atendiendo a su uso económico, los bienes intermedios suponen el 35\% de las importaciones argentinas. Los bienes de capital suponen el 22\% de las importaciones y las piezas y accesorios para bienes de capital el 17\%. Los bienes de consumo suponen sólo un $11 \%$ de las importaciones, los combustibles y lubricantes el $8 \%$ y los vehículos de pasajeros un $7 \%$.

Durante 2008 el mayor incremento en las importaciones se dio en los productos intermedios, impulsada por las mayores compras de soja (fundamentalmente a Paraguay, para su posterior reexportación), minerales de hierro, glifosato, ácido fosfonometilimino diacético, fosfato diamónico y alúmina calcinada. Los bienes de capital fueron el segundo grupo con un mayor crecimiento de las importaciones, destacando las mayores compras de aviones -ingresados temporalmente por más de 365 días-, chasis con motor y cabina para transporte de mercancías, aparatos de telefonía celular y computadoras portátiles. Entre las importaciones de piezas y accesorios para bienes de capital, destacaron los aumentos de partes y accesorios de carrocerías de vehículos automóviles y de partes de calderas de vapor y de agua sobrecalentada. Las importaciones de combustibles y lubricantes aumentaron impulsadas por las compras de gasoil, gas natural licuado, coques de hulla, lignito o turba, hulla bituminosa sin aglomerar y fuel oil. Las importaciones de vehículos de pasajeros se debieron fundamentalmente al aumento del turismo. Entre las importaciones de bienes de consumo destacaron las motocicletas y los televisores. 


\subsubsection{Análisis de Intercambio Comercial entre Argentina y Colombia}

A continuación se presentan datos del intercambio comercial que ha existido entre Argentina y Colombia en los últimos años.

Tabla No. 4 Intercambio Bilateral Argentina - Colombia

\begin{tabular}{|c|c|c|c|}
\hline \multicolumn{4}{|c|}{$\begin{array}{c}\text { Balanza comercial entre Argentina y Colombia años 2006-2009* } \\
\text { (Montos expresados en miles de dólares) }\end{array}$} \\
\hline Año & $\begin{array}{c}\text { Exportaciones FOB } \\
\text { Argentinas con destino } \\
\text { a Colombia }\end{array}$ & $\begin{array}{c}\text { Importaciones CIF } \\
\text { Argentinas de origen } \\
\text { Colombiano }\end{array}$ & Balanza comercial \\
\hline 2006 & USD 550.873,00 & USD 55.954,00 & USD 494.919,00 \\
\hline 2007 & USD 576.451,00 & USD 91.018,00 & USD 485.433,00 \\
\hline 2008 & USD 808.179,00 & USD 154.046,00 & USD 654.133,00 \\
\hline $2009^{*}$ & USD 379.851,00 & USD 33.710,00 & USD 346.141,00 \\
\hline \multicolumn{4}{|c}{${ }^{*}$ Datos Preliminares } \\
\hline
\end{tabular}

Fuente: Aladi. Información tomada 07 Nov. 2009.

Como se puede observar, existe incremento tanto de exportaciones como de importaciones entre Colombia y Argentina. Quizá en mayor proporción de crecimiento están las exportaciones realizadas desde Argentina hacia Colombia. Esto concluye aun más, la apertura de comercio internacional que está teniendo Argentina, no solo a nivel general, sino también específicamente con Colombia, lo cual es un factor de importancia para tener en cuenta en el momento de proponer una operación de comercialización como la que se presenta en este estudio. La balanza comercial entre estos 2 países ha aumentado positivamente basándose en el mayor aumento en mayor medida de las exportaciones que realiza Argentina a Colombia.

Para un mayor enfoque del comercio del producto en el ámbito internacional, se presenta a continuación los valores del producto exportado desde Colombia a todos los destinos del mundo. Se toma como valor referencia los de la Rosa, el cual es el producto que tiene mayor movimiento.

Tabla No. 5 Exportaciones Colombianas de la Subpartida Arancelaria 060311 (Rosas), por destino durante los años 2008 y 2009.

\begin{tabular}{|c|c|c|}
\hline País & $\begin{array}{c}\text { 2008 } \\
\text { USD - Valor FOB }\end{array}$ & $\begin{array}{c}\text { USD 2009 } \\
\text { USD - Valor FOB }\end{array}$ \\
\hline ESTADOS UNIDOS & 267.117 .776 & 276.898 .486 \\
\hline RUSIA & 36.200 .497 & 28.529 .329 \\
\hline
\end{tabular}




\begin{tabular}{|c|c|c|}
\hline ESPANA & 9.306 .067 & $\$ 8.605 .120$ \\
\hline REINO UNIDO & 5.206 .491 & $\$ 6.067 .541$ \\
\hline CANADA & 6.706 .983 & $\$ 5.951 .569$ \\
\hline PAISES BAJOS & 2.366 .423 & $\$ 3.114 .838$ \\
\hline UCRANIA & 3.209 .703 & $\$ 2.283 .650$ \\
\hline BRASIL & 1.726 .352 & $\$ 2.019 .017$ \\
\hline JAPON & 1.079 .560 & $\$ 1.654 .607$ \\
\hline SUIZA & 1.110 .404 & $\$ 541.341$ \\
\hline PUERTO RICO & 1.870 .130 & $\$ 1.637 .240$ \\
\hline ALEMANIA & 2.349 .767 & $\$ 1.545 .158$ \\
\hline FRANCIA & 1.256 .346 & $\$ 810.998$ \\
\hline ARGENTINA & 412.645 & $\$ 236.003$ \\
\hline OTROS & 6.749 .461 & $\$ 7.328 .937$ \\
\hline TOTAL & $\mathbf{3 4 6 . 6 6 8 . 6 1 1}$ & $\$ 347.223 .841$ \\
\hline
\end{tabular}

Fuente: Aladi. Información tomada 07 Nov. 2009.

La Tabla No 5 muestra las exportaciones de rosas colombianas en los años 2008 y 2009 por destino, en ella se puede observar el tamaño del sector floricultor colombiano al exportar en último año más de 347 millones de dólares. Esta magnitud convierte a Colombia en el segundo exportador mundial de flores frescas cortadas después de Holanda.

Ahora bien, si se analiza a mas detalle el valor exportado desde Colombia a Argentina, este no supera los US 500.000 al año, valor el cual nos hace entender que tiene muy baja participación dentro de la operación completa, razón por la cual se concluye que actualmente lo que se importa a la Argentina no sufriría algún aspecto de desabastecimiento por proveedores colombianos. También es importante resaltar y la ventaja de producciones en contra - estación respecto del hemisferio norte de manera tal que la necesidad de flores por colores y variedades en Argentina, se presenta justamente cuando no se requieren para Estados Unidos.

\subsubsection{Análisis del Comercio del Sector de Flores}

Si se analiza el comportamiento del sector de la floricultura en Argentina se encuentra lo siguiente: 
Tabla No.6 Importaciones del sector floricultor (Plantas Vivas y productos de la floricultura) en la Argentina (2006-2008)

\begin{tabular}{|c|c|c|c|}
\hline Pais Procedencia & 2006 USD & 2007 USD & 2008 USD \\
\hline Ecuador & 759.049 & 1.077 .900 & 991910 \\
\hline Italia & 873.441 & 1.319 .632 & 1.101 .158 \\
\hline Países Bajos & 253.188 & 247.241 & 541.518 \\
\hline Francia & 1.003 .914 & 559.276 & 277.978 \\
\hline Estados Unidos & 256.583 & 229.245 & 349.623 \\
\hline Chile & 18.606 & 160.993 & 154.997 \\
\hline Colombia & 119.091 & 388.225 & 293.210 \\
\hline España & 62.938 & 104.503 & 286.196 \\
\hline Brasil & 180.258 & 229.903 & 102.090 \\
\hline Bélgica & 229.342 & 254.666 & 130.344 \\
\hline Otros & 133.949 & 238.071 & 222.322 \\
\hline Total & 3.890 .359 & 4.809 .654 & 4.451 .348 \\
\hline \multicolumn{4}{|c}{ Fuente: Nosis } \\
\hline
\end{tabular}

Tabla No. 7 Exportaciones del sector floricultor (Plantas Vivas y productos de la floricultura) de la Argentina (2006-2008)

\begin{tabular}{|c|r|r|r|}
\hline Pais Destino & \multicolumn{1}{|c|}{ 2006 USD } & \multicolumn{1}{c|}{ 2007 USD } & \multicolumn{1}{|c|}{ 2008 USD } \\
\hline Brasil & 328.091 & 444.995 & 596.066 \\
\hline Uruguay & 1.156 .742 & 384.524 & 617.973 \\
\hline España & 578.576 & 525.384 & 646.473 \\
\hline Sudáfrica & 37.550 & 80.737 & 521.528 \\
\hline Chile & 352.283 & 199.696 & 133.294 \\
\hline Italia & 241.341 & 160.051 & 250.730 \\
\hline Colombia & 166.032 & 133.498 & 169.438 \\
\hline Países Bajos & 20.072 & 48.414 & 57.622 \\
\hline Francia & 17.828 & 55.600 & 126.107 \\
\hline Ecuador & 73.089 & 82.090 & 105.954 \\
\hline Otros & 406.571 & 844.910 & 519.361 \\
\hline Total & 3.378 .174 & 2.959 .898 & 3.744 .547 \\
\hline \multicolumn{4}{|r}{ Fuente: Nosis }
\end{tabular}

Como se puede percibir entre los años 2006 y 2008 hubo en un aumento en el valor tanto en las exportaciones como en las importaciones en el sector floricultor.

Teniendo en cuenta el total de importaciones y exportaciones del sector floricultor en argentina entre los años 2006 y 2008 se establece lo siguiente:

\begin{tabular}{|l|c|c|c|c|c|}
\cline { 2 - 5 } \multicolumn{1}{c|}{} & AÑO 2006 & AÑO 2008 & $\begin{array}{c}\% \\
\text { Crecimiento }\end{array}$ & $\begin{array}{c}\% \\
\text { Crecimiento } \\
\text { Anual }\end{array}$ & $\begin{array}{c}\% \\
\text { Crecimiento } \\
\text { Promedio del } \\
\text { Sector }\end{array}$ \\
\hline Importaciones Sector Flores & USD 3.890.359 & USD 4.451.348 & $14,4 \%$ & $7,2 \%$ & \multirow{2}{*}{$\mathbf{6 , 3} \%$} \\
\hline Exportaciones Sector Flores & USD 3.378.174 & USD 3.744.547 & $10,8 \%$ & $5,4 \%$ & \\
\hline
\end{tabular}

\footnotetext{
Fuente: Cálculos Propios.
} 
Existe un crecimiento promedio anual del sector del $6.3 \%$ entre los años mencionados, lo cual nos indica que es un sector que crece a una medida muy similar que el PIB del país (Año 2008 en un 7\%). Esto ratifica y apertura que está teniendo la república Argentina, en su comercio exterior, y en especial en este sector, lo cual es una razón para determinarlo como una oportunidad para ingresar al mercado al cual apunta el presente trabajo.

A continuación se presentan los valores importados de flor fresca desde Argentina con sus respectivos países de procedencia.

Tabla No. 8 Importaciones de flor fresca en la Argentina (2007-2008)

\begin{tabular}{|c|c|c|}
\hline PAIS PROCEDENCIA & $\mathbf{2 0 0 7}$ (USD) & $\mathbf{2 0 0 8}$ (USD) \\
\hline BOLIVIA & 3.041 & \\
\hline BRASIL & 111.287 & \\
\hline CHILE & 28.408 & 17.329 \\
\hline COLOMBIA & 661.123 & 466.967 \\
\hline ECUADOR & 1.961 .035 & 1.880 .117 \\
\hline HONG KONG - CHINA & 60 & \\
\hline INDIA & 556 & 3.797 \\
\hline INDONESIA & 13.006 & \\
\hline PARAGUAY & 3.702 & \\
\hline PERU & 2.360 & \\
\hline THAILANDIA & 65.146 & \\
\hline Total general & $\mathbf{2 . 8 4 9 . 7 2 8}$ & $\mathbf{2 . 3 6 8 . 2 1 1}$ \\
\hline
\end{tabular}

Fuente: Nosis y Comex: Datos tomados 15 Nov. 2009

El principal análisis que nos deja esta información obtenida, es que claramente en la actividad de importación de flores frescas a Argentina los principales proveedores son Ecuador y Colombia.

De acá sale una conclusión importante y es que se identifica claramente el principal competidor, que son las flores ecuatorianas, con un volumen mayor aproximadamente 3 veces más que el volumen exportado desde Colombia.

Se observa una buena oportunidad para incrementar los volúmenes colombianos fundamentados en la calidad de flor que es igual o incluso mejor en algunos tipos de flor, y en una cadena logística similar a la ecuatoriana. La oportunidad de restar participación a Ecuador por un lado, e incentivar el consumo diversificado de 
diferentes variedades de flores de alta calidad, son los objetivos - que como ya se mencionó - persigue el presente proyecto.

Si bien se ha analizado en líneas generales el comercio internacional de flores entre Argentina y Colombia, es importante detallar cual serian el tipo de flores que más se importan en Argentina, de manera tal que se vaya focalizando el producto a comercializar. Para esto se presenta la siguiente información donde se detallan los volúmenes por tipo de flor importados a Argentina entre 2007 y 2008.

Tabla No. 9 Importaciones de flor en la Argentina (2007-2008)

\begin{tabular}{|c|c|c|}
\hline TIPO DE FLOR & $\begin{array}{c}\mathbf{2 0 0 7} \\
\text { (No. de Tallos) }\end{array}$ & $\begin{array}{c}\mathbf{2 0 0 8} \\
\text { (No. de Tallos) }\end{array}$ \\
\hline CLAVEL & 4.360 .272 & 3.182 .520 \\
\hline CRISANTEMO & 1.922 .600 & 56.850 \\
\hline OTROS & 3.338 .386 & 934.334 \\
\hline ROSA & 15.121 .754 & 16.974 .076 \\
\hline Total General & $\mathbf{2 4 . 7 4 3 . 0 1 2}$ & $\mathbf{2 1 . 1 4 7 . 7 8 0}$ \\
\hline
\end{tabular}

El tipo de flor que más importa el mercado argentino es rosa, seguido por clavel y crisantemos. Asimismo, dentro de otro tipo de flor se encuentran alstroemerias, lirios, entre otros. La oferta exportable colombiana abarca ampliamente las cantidades y tipos de flor que ha manejado el mercado en los últimos años como se ha mencionado anteriormente.

Se puede concluir entonces que los principales productos con los cuales se podría iniciar la operación, serian las rosas, los claveles y los crisantemos. Las otras variedades pueden ser un segundo paquete de productos que pueden ser explorados poco a poco de acuerdo al conocimiento y madurez que se vaya dando en el mercado argentino.

\subsubsection{Mercado de las Flores en Argentina}

Un estudio reciente de la cámara de importadores y exportadores de flor en Argentina ${ }^{18}$, señala las bondades y crecimiento que ha tenido el sector en los últimos años, puntualiza los avances que en materia de cosecha, pos-cosecha, embalajes,

\footnotetext{
${ }^{18}$ Publicación mensual de la Confederación Argentina de la Mediana Empresa CAME. Revista Comerciar, N 55 - Diciembre 2009.
} 
comercialización y exportación tienen los productos originarios de Argentina, pero también, indica el largo camino que le espera al sector floricultor argentino para entrar a ser jugador importante en el comercio internacional de este tipo de bienes.

En Argentina existen 2 grandes grupos de floricultores:

> $70 \%$ se dedica al manejo rápido de la flor para consumo interno.

> 30\% está especializándose y logrando mejoras para que la flor pueda ser exportada.

Mensualmente se exportan 25.000 docenas de rosas y, aproximadamente 18.000 docenas de claveles. Los destinos son: $85 \%$ del total a Europa y un $15 \%$ a EEUU y otros países, especialmente de Latinoamérica $\left({ }^{18}\right)$.

De acuerdo con el trabajo realizado por el INTA ${ }^{19}$, las principales provincias productoras de plantas y flores son: Buenos Aires, Santa Fe, Corrientes, Formosa, Tucumán, Córdoba, Mendoza, Jujuy y Entre Ríos. También hay producción en menor escala en las provincias de San Luis, Catamarca, Chubut, Salta, Chaco, Santa Cruz y Tierra del Fuego.

\subsubsection{Proceso de producción de flor local $\left({ }^{19}\right)$.}

El proceso va desde el mejoramiento de la calidad del suelo, hasta el mejoramiento de la calidad de la flor o de las plantas por manipulación genética ${ }^{20}$. Para el proceso de exportación se ha desarrollado un empaque especial que le asegura a la flor una vida útil de aproximadamente entre 10 y 15 días después de cortada. Este desarrollo es de vital importancia ya que la resguarda de los golpes durante el traslado y le garantiza mayor resistencia al paso del tiempo.

\footnotetext{
${ }^{19}$ INTA - Agencia de Cooperación Internacional del Japón (JICA), “Estudio sobre la caracterización de la producción florícola en la República Argentina", 2003.

${ }^{20}$ Es una aplicación de la biotecnología que involucra la manipulación de genes entre especies para incentivar rasgos deseados. El enfoque actual de la ingeniería genética en Agricultura está en el desarrollo de cultivos tolerantes a herbicidas, así como cultivos resistentes a plagas y enfermedades.
} 
La flor sale refrigerada a 4 grados bajo cero, y se traslada vía aérea en el término de 24 - 26 hs. desde que se corta hasta que llega a destino. Todo el trayecto se hace como carga aérea refrigerada.

En relación a la estructura productiva según datos del año 2002, existen en el país unas ochocientas mil empresas dedicadas a la actividad florícola y de acuerdo al relevamiento de productores realizado por el INTA - JICA en el año, 2003, el 75\% de las mismas son de tipo unipersonal.

Con respecto a las especies bajo cultivo, en Argentina se producen más de 50 especies diferentes de flores. Las tres mas cultivadas son crisantemo, clavel y rosa, que representan entre el 60 y $70 \%$ de la oferta del mercado nacional. Otras especies comunes son Ghypsophila, Fresia y lisiantus $\left({ }^{19}\right)$.

El principal destino de la producción nacional es el área metropolitana de Buenos Aires, concentrándose las actividades comerciales en la Capital Federal y La Plata. Según datos del INTA, la producción de plantas y flores, se comercializa en un 98\% en el mercado interno.

\subsubsection{Comercialización de flor en el Mercado Interno $\left({ }^{19}\right)$.}

La comercialización de flores en Argentina se hace de dos maneras:

$>$ El mercado mayorista situado en las inmediaciones de Corrientes 4062, en la Capital Federal, vende las producciones que son traídas de lugares tales como Escobar, Berisso, La Plata o Los Hornos.

> Se venden directamente en viveros o por intermedio de distribuidores que llevan la flor a las florerías en Capital o Gran Buenos Aires.

La principal forma de comercialización de las flores argentinas en el mercado local es por medio de los mercados concentradores de flores ${ }^{21}$ (donde se vende el $80 \%$ del total producido). El resto se comercializa ya sea por venta directa a las florerías, kioskos o por contratos.

\footnotetext{
${ }^{21}$ Son tres principales: Capital Federal (Corrientes 4000), y dos en la plata.
} 
Los cambios tecnológicos han incorporado una tercera variante de comercialización en crecimiento:

En los últimos años ha proliferado la venta de flores a través de Internet, sobre todo como regalo para ocasiones especiales (cumpleaños, aniversarios, etc.). Esta forma de comercialización se vislumbra como la que generará mayor competencia con el comercio minorista, especialmente en las grandes ciudades donde la gente cuenta con menos tiempo para ir a realizar las compras, mientras que diariamente un número significativo de personas se sientan frente a una PC y se conectan a Internet.

En relación a la importancia económica, el sector florícola en el contexto nacional registró un valor bruto de ventas mayoristas de 284,46 millones de dólares ${ }^{22}$. Después de la devaluación de enero del año 2002, la cifra alcanzó los 444 millones de pesos (158 millones de dólares).

Teniendo en cuenta lo anterior se identifica entonces una gran zona de comercialización en la zona de Capital Federal donde se encuentran los principales mayoristas a los cuales se les puede ofrecer el producto. La estrategia de comercialización puede tener como principal cliente el canal mayorista, sin embargo existe la posibilidad a acceder al canal detallista, ya sea llegando a floristerías o viveros de la ciudad.

\subsection{Barreras de Acceso}

\subsubsection{Acuerdo de Complementación Económica ACE No 59 CAN - Mercosur ${ }^{23}$} Los países miembros de la Comunidad Andina (Con excepción de Bolivia) y MERCOSUR (Argentina, Brasil, Paraguay y Uruguay), suscribieron el 18 de octubre

\footnotetext{
${ }^{22}$ Cifra Bruta de Ventas: 284,46 millones de pesos o dólares considerando la paridad peso-dólar vigente en ese momento: Fuente INTA-JICA 2003.

${ }^{23}$ Guía para Exportar a la República Argentina - Ministerio de Industria y Comercio /Proexport Colombia Diciembre de 2008.
} 
de 2004 el Acuerdo de Alcance Parcial de Complementación Económica No. 59, el cual entró en vigencia a partir del 1 de febrero de 2005.

El Ministerio de Comercio, Industria y Turismo destacó la importancia que tiene el Tratado de Libre Comercio para Colombia, Mercosur ofrece a la Comunidad Andina un mercado potencial de 222 millones de habitantes, con un producto interno bruto cercano al billón de dólares, lo cual le permite una demanda por productos importados cercana a los US\$ $\$ 3.000$ millones y exportaciones de US\$80.000 millones.

Las negociaciones de la ACE 59, se extendieron más allá del tiempo previsto al inicio. Esto se debió, en gran parte, a la complejidad de las materias tratadas, a las asimetrías existentes entre las economías de los países signatarios y a la dificultad para articular los objetivos comunes con algunos intereses económicos y comerciales contrapuestos entre los países de ambos bloques.

En esta medida, se puntualizaron temas de trato nacional, licencias de importación, medidas antidumping y compensatorias y valoración aduanera. Todo dentro del marco la normativa vigente de la organización mundial del comercio. Si bien no se puntualizó en el sector floricultor (tema que nos compete), se discutieron temas generales que pueden afectar directamente el comercio de este tipo de bienes.

\subsubsection{Programa de Liberación $\left({ }^{23}\right)$.}

Uno de los objetivos centrales del Acuerdo es la conformación de una Zona de Libre Comercio que se alcanzará mediante un Programa de Liberación Comercial (PLC) aplicado sobre el universo de los productos originarios de los territorios de las Partes Contratantes.

Las desgravaciones son anuales y progresivas y se aplican sobre el arancel vigente para terceros países. En virtud de ello los márgenes de preferencia van creciendo en forma progresiva hasta alcanzar el 100\%. El PLC refleja el reconocimiento de las asimetrías entre los países signatarios, y establece cronogramas diferenciados nivel de inicio, ritmo de la desgravación y plazo, según se trate de las concesiones 
dadas y recibidas entre la Argentina, Brasil, Paraguay o Uruguay, con Colombia y Venezuela, y entre cada uno de los cuatro Estados Partes del MERCOSUR con Ecuador.

Para propósitos de la desgravación arancelaria del acuerdo establece que la misma se aplicará "sobre aranceles vigentes para la importación de terceros países al momento de la aplicación de preferencias de conformidad con lo dispuesto en sus legislaciones".

No obstante, para ciertos productos agrícolas ${ }^{24}$ sujetos a un Mecanismo de Estabilización de Precios (MEP) - Franja de Precios - según lo establecido en la legislación andina vigente, la desgravación se aplicará únicamente sobre los aranceles y que corresponden al componente fijo del arancel del Sistema Andino de Franjas de Precios, con lo cual se preserva la permanencia de este mecanismo.

Si bien tanto el acuerdo como este programa de liberación no afectan directamente a los productos del sector florícola, es importante resaltarlo como el avance que se quiere dar para el incremento del comercio entre países de la zona.

\subsubsection{Aranceles y otros impuestos a las importaciones $\left({ }^{23}\right)$.}

Anteriormente se habían enunciado los aranceles e impuestos aplicables a la partida correspondiente a las flores frescas. Sin embargo a continuación se analizan todos estos aranceles, el cual es un factor importante para la determinación del desarrollo de una actividad de comercio internacional.

En materia arancelaria, Argentina adopta la clasificación del Sistema Armonizado Internacional para la imposición de los impuestos con el desglose del MERCOSUR que es de ocho (8) dígitos. Argentina adiciona 3 dígitos más a las posiciones arancelarias del MERCOSUR, con el fin de entre otros, realizar diferenciaciones para la aplicación de impuestos internos.

\footnotetext{
${ }^{24}$ No incluye productos de la floricultura
} 
Los aranceles en Argentina para países extra - zona como Colombia, aplican según lo acordado en el MERCOSUR. Estos oscilan entre $0 \%$ y $24 \%$, los vehículos importados de países no miembros del MERCOSUR deben pagar un arancel del 35\%.La Administración Federal de Ingresos Públicos (AFIP) del Ministerio de Economía y Obras y Servicios Públicos es la entidad facultada para regular las normas y aranceles aduaneros.

Los impuestos son ad valorem y aplican sobre el valor CIF (Cost, Isurance and Freight) de las importaciones. Para productos textiles, prendas de vestir y calzado se pueden imponer derechos específicos mínimos.

Adicionalmente al arancel, existen otros impuestos a las importaciones. La Tasa Estadística es del $0.5 \%$ del valor CIF, cubre a la mayoría de los productos importados; excepto combustibles, armas, libros, periódicos y bienes de capital no usados entre otros. Esta tasa no aplica para los productos provenientes de los países miembros del MERCOSUR.

El IVA general en Argentina es del $21 \%$. Algunos productos agrícolas, mineros, educacionales y medicinas pagan una tasa diferencial de IVA.

Se impone un 3\% de Impuesto Anticipado a la Utilidad para bienes de consumo o de venta al por menor, excepto para aquellos que son importados por el usuario final en donde el impuesto es del $11 \%$.

\subsubsection{Regulaciones y Normas $\left({ }^{23}\right)$.}

El proceso de apertura e internacionalización de la Argentina, ha llevado a ésta a convertirse en una de las economías más abiertas de Latinoamérica, gracias a la reducción y eliminación de barreras no arancelarias, licencias e impuestos específicos a la importación, así como requerimientos de tipo documental.

Algunos productos están sujetos a licencias no restrictivas, con el fin de velar por que se cumpla la legislación interna. En el caso de productos agroindustriales y 
animales, se requiere una autorización previa por parte del Instituto Argentino de Sanidad y Calidad Vegetal (IASCAV) así como del Instituto Nacional de Alimentos (INAL) y del Servicio Nacional de Sanidad Animal (SENASA), dependiendo del tipo de producto.

En cuanto a productos del sector químico y farmacéutico como cosméticos, herbicidas, fungicidas y medicamentos, se requieren autorizaciones previas de la Secretaria de Salud del Ministerio de Salud y Acción Social, del Servicio Nacional de Sanidad Animal (SENASA), del Instituto Argentino de Sanidad y Calidad Vegetal (IASCAV), y del Instituto Nacional de Alimentos (INAL).

Algunos equipos de tecnología como telecomunicaciones y electrodomésticos, deben cumplir con rangos de valor importado (Valoración en Aduana).

Adicionalmente, Las autoridades fiscales y aduaneras de la Argentina han divulgado, una serie de medidas para aumentar los ingresos de recaudación, evitar la subfacturación y establecer controles eficientes a las importaciones.

Las medidas tomadas se resumen así:

1.) Aumento de posiciones arancelarias para inspección pre-embarque, conllevando un sobre costo de las importaciones, por el servicio que prestan las entidades internacionales certificadoras para emitir un concepto de conformidad en precios y en calidades del bien objeto de la transacción. Este sobre costo puede llegar a sobrepasar el $1 \%$ del valor FOB de la mercancía.

2.) A los importadores argentinos se les exige un pago de US $\$ 10$ por cada operación de importación, con el fin de mantener el Sistema Aduanero María.

3.) Establecimiento de un Sistema de Control Morado, para controlar precios de referencia, el cual en caso de existir duda en los precios de referencia, se le exige al importador la constitución de una garantía por posibles dudas del funcionario aduanero de turno. Implica posteriormente comprobar con documentos que el valor declarado de la mercancía importada es el correcto. En Argentina, las garantías tienen un costo, dependiendo de sí son bancarias o de compañías de seguros. 
4.) Obligación de inscripción ante la Administración Federal de Ingresos Públicos, con el objetivo de obtener el Certificado de Validación, el que consiste en un empadronamiento a todos los importadores en la Argentina y aquellos que no obtengan el Certificado de Validación de Datos de Importadores, se les sancionará con el aumento del $100 \%$ en los impuestos de ganancias y el anticipo del I.V.A.

\subsubsection{Requerimientos de Etiquetado $\left({ }^{23}\right)$.}

Las etiquetas de todos los productos comercializados en la Argentina deben estar en español a excepción de palabras que no tengan equivalencia en el idioma castellano. Los productos importados podrán conservar la etiqueta original del país en su idioma, pero deberán tener una etiqueta pegada en español con la información indicada en párrafos anteriores.

Algunos productos que deben cumplir requisitos especiales de etiquetado, incluyen frutas; textiles y confecciones, sombreros, guantes, calzado, muebles, artículos de limpieza, juguetes, productos de papel y fertilizantes.

Con el fin de evitar el pago de posibles multas o padecer trabas para el ingreso del producto al mercado por problemas de etiquetado, siempre es aconsejable que los exportadores colombianos soliciten instrucciones al importador argentino sobre las características específicas para etiquetar el producto en cuestión.

\subsubsection{Prohibiciones $\left({ }^{23}\right)$.}

Entre los productos prohibidos para la importación en el territorio argentino se incluyen: vegetales, bulbos o tubérculos que no hayan sido lavados y tengan tierra nativa en sus raíces, polen de rosáceas, flora y fauna natural del país de origen, materiales y desechos radiactivos, instrumentos de medida que no empleen el sistema métrico legal argentino; especies porcinas, excepto aquellas que cuenten con pedigree; Algodón en bruto o sin mezcla; placenta humana; nitrato de sodio; productos agrícolas que contengan arsénico; productos químicos tales como 
endrina, sulfato de estricnina, di bromuro de etileno y pentaclorofenol; ropa de segunda, excepto si está destinada como donación para una entidad del gobierno.

También se prohíbe el ingreso de bicicletas y motos usadas; vehículos usados, excepto aquellos que tengan un uso mayor a 22 años y sean avaluados en US\$ 4.000 o más, que hagan parte de una colección o que representen interés histórico a su vez, los vehículos de diplomáticos extranjeros o de argentinos en el exterior.

\subsection{Análisis de la Competencia}

En el mercado internacional de flores se encuentran los siguientes competidores los cuales tienen unas características generales que los hacen representativos:

\section{Holanda:}

- Primer exportador de flores del mundo. (Total exportaciones 2006: US\$3,021 millones)

- Gran productor y centro de re exportación hacia Europa y Asia.

- Líder en la producción bajo invernadero y en el mejoramiento genético de las variedades producidas.

- Amplia oferta de servicios logísticos.

\section{Ecuador:}

- Asume el 9\% de las exportaciones mundiales.

- Sus principales mercados en 2006: USA 59\%, Rusia 14\% Holanda $11 \%$.

- Su competitividad se basa en la implementación de nuevas variedades de flor y la innovación en procesos de producción tanto en poscosecha como en campo.

\section{Kenya:}

- Principal proveedor de flores de la Unión Europea, representando el $40 \%$ del total importado por este bloque, equivalente a US\$392.5 millones.

- Principales productos de exportación son: rosas $74 \%$, bouquets $10 \%$, astromelia $5 \%$ y Clavel $3 \%$. 
- En los últimos 4 años las exportaciones en volumen han crecido a una tasa anual compuesta de $25 \%$, pasando a 127 mil Ton. (48\% rosas).

- Las grandes empresas son propiedad de holandeses y británicos: Homegrown, Sulmac y Oserian.

\section{República Popular China:}

- Principales mercados: Japón 58\%, Hong Kong 14.7\%, Singapur 7\%, Tailandia $5 \%$ y Australia $3 \%$

- Holanda invierte en la producción de flores en China para abastecer la demanda de Japón, los países del Sudeste Asiático y la propia demanda China que está en expansión.

- El gobierno subsidia al sector en aspectos como la adquisición de semillas, inversiones en I\&D y además ofrece incentivos tributarios a la exportación.

\section{Colombia:}

- Mayor exportador a Estados Unidos, quien es el primer exportador de claveles en el mundo y el segundo exportador mundial de flores.

- El crecimiento de las exportaciones colombianas en términos de volumen ha sido de $124 \%$ equivalentes a una tasa compuesta de $17.5 \%$ anual.

- Las nuevas y mejores prácticas han fortalecido la imagen internacional del sector. Es el caso de Florverde, que es la única certificación para asegurar que todas las flores cultivadas y cosechadas en Colombia cumplen con determinadas normas sociales y medioambientales.

- La diversificación de mercados y la elaboración de productos con valor agregado (bouquets) han generado nuevas oportunidades para el país. 
Si bien anteriormente, se había identificado que el principal producto competidor en el volumen de importaciones a Argentina, era la flor ecuatoriana, debe también tenerse en cuenta el análisis de la oferta de flor local, y también los importadores ya radicados que están ejecutando la importación de flores frescas.

\subsubsection{Oferta Local de Flores Frescas Cortadas $\left({ }^{25}\right)$.}

La producción de flor en Argentina se concentra principalmente en la provincia de Buenos Aires, en la zona denominada cinturón verde bonaerense, comprendida por un área de 390 hectáreas aproximadamente bajo cubierta, desde la Capital Federal, destacándose el polo sur (La Plata y alrededores) y el norte (Escobar), respondiendo esta localización más a factores económicos que a factores ecológicos, ya que el flete es un ítem que encarece significativamente el valor de la producción florícola.

Le siguen en importancia Corrientes, Santa Fe, Mendoza, Río Negro, Chubut, Misiones, Tucumán, Salta y Jujuy. Según la misma fuente la provincia de Corrientes cuenta con 450 hectáreas de flores de corte que se comercializan a principios de invierno, siendo los gladiolos, crisantemos, jazmines y las rosas las especies más importantes.

La provincia de Santa Fe, en particular el corredor Rosario-Casilda, se destaca por la producción de claveles, crisantemos, rosas y gladiolos. La superficie cultivada en Santa Fe es de alrededor de 58 hectáreas bajo cubierta, opiniones actuales de informantes calificados dan cuenta de que la situación del sector es crítica y que, de los 90 socios que originalmente conformaban la Cooperativa de Floricultores de Rosario, el último balance solo registra 27 productores.

En dicha provincia Coronda Cooperativa de Agricultores Ltda., principalmente exportadores de frutillas a EE.UU, aprovechando el canal de comercialización con dicho país, han realizado una experiencia piloto con muestras de gladiolos que lograron buena aceptación en dicho mercado. La posibilidad de exportación es

\footnotetext{
${ }^{25}$ C.F.I - Concejo Federal de Inversiones - Informe de la Situación del Sector Floricultura en Argentina, García Filgueira, Silvia - Di Stéfano, Domingo, 2002.
} 
factible pero los productores deben agruparse para lograr volumen y adecuar las técnicas de producción a las exigencias del ente de control sanitario de EE.UU.

En cuanto a la provincia de Mendoza se dispone de información que surge del censo realizado por el Instituto de Desarrollo Rural en el año 2000, el cual identificó 111 productores de cultivo de flor de corte y una superficie de 88 hectáreas, de las cuales el $59 \%$ se encuentra al aire libre y el resto bajo cubierta. Las principales especies cultivadas en dicha zona son crisantemos y rosas, le siguen en importancia el lisianthus y fresias. La mayor producción se concentra en el cinturón verde de Mendoza, (Guaymallén, Maipú y las Heras). Por su parte la zona sur el departamento de San Rafael concentra el 10\% de la producción.

En la provincia de Tucumán existen alrededor de 107 hectáreas dedicadas a la floricultura, de las cuales sólo 5 hectáreas son producciones bajo cubierta. En cuanto a flor de corte específicamente existen 10 productores que cultivan 40 hectáreas a cielo abierto y 1 hectáreas bajo cubierta, localizados en la zona oeste del Gran San Miguel de Tucumán y en los falderos de la Sierra de San Javier que principalmente producen jazmín del cabo, rosas y crisantemos.

Chubut por su parte se ha orientado a la producción de bulbos de tulipán aprovechando el nicho comercial que ofrece el desfase de estación con el hemisferio norte. La actividad recibe el apoyo y el asesoramiento de CORFO Chubut. La producción se localiza en los valles cordilleranos cercanos a las localidades de Esquel, Trevelin y Corcovado y alcanza a las 10 hectáreas cultivadas, estimándose un rendimiento de 150.000 bulbos vendibles por hectárea y en condiciones de calidad que se ajustan a las exigencias del mercado externo. Cabe mencionar que la provincia de Santa Cruz, la empresa Flores de la Patagonia S.A. con el apoyo de la Secretaría de Estado de la Producción y la EEA de INTA Santa Cruz, inició en 1998 la experiencia de cultivo de tulipanes. En la actualidad existen 1,5 hectáreas plantadas en Los Antiguos y 1,8 hectáreas en Gob. Gregores con 8 variedades de tulipán cuyos bulbos se importaron de Holanda. 
Analizando toda la producción y oferta local, el principal centro de comercialización se encuentra en Capital Federal, donde se encuentra el mayor número de hectáreas de producción de flor. Si bien ya se identifico que la zona donde se encuentran los principales mayoristas está dentro de Capital Federal, existe oferta local ubicada en las cercanías de la ciudad que puede llegar a este canal, sin embargo como se ha podido percibir, mucha producción de la oferta local argentina se realiza con cultivos al aire libre lo cual incide directamente en la calidad de la flor ofrecida. La otra zona a la cual podría llegarse directamente es en la provincia de Santafé, por la cercanía que se tiene a Buenos Aires, y aprovechando la baja oferta de flores de calidad que se cultivan en esa zona del país.

\subsubsection{Oferta Extranjera de Flores Frescas de Corte $\left({ }^{25}\right)$.}

Las importaciones de flor en la Argentina representan el $63 \%$ en Rosa y $31 \%$ en clavel del mercado, encontrando como principales importadores:

Tabla No.10 Importadores de flor en la Argentina (2007-2008)

\begin{tabular}{|c|c|c|}
\hline \multicolumn{3}{|c|}{ Cantidad Declarada (Tallos) } \\
\hline Importador & $\mathbf{2 0 0 7}$ & $\mathbf{2 0 0 8}$ \\
\hline Argenflor SA. & 12.904 .864 & 11.086 .684 \\
\hline Center Flowers SA & 2.330 .016 & 1.984 .471 \\
\hline De Almeida Julio Nestor & 477.690 & 1.935 .947 \\
\hline Ikebana S.A. & 423.511 & 328.698 \\
\hline Leiva Kienast Pablo Martin & 650.768 & 865.511 \\
\hline Libertini Claudio Alberto & 1.000 .446 & 741.973 \\
\hline Muchellini Raul Alberto & 169.800 & \\
\hline Nor Flor S.R.L. & 564.000 & \\
\hline Rocoflor SRL. & 2.464 .166 & 1.419 .516 \\
\hline Roma Romina Soledad & 701.008 & 457.478 \\
\hline Selene SRL. & 1.762 .256 & 1.256 .859 \\
\hline
\end{tabular}

Fuente: Nosis S.A. (Información Comercial y Crediticia de Empresas y Personas) - Datos tomados en Nov. 2009.

La Tabla No. 10 muestra los principales importadores de flor en la Argentina para los años 2007 y 2008 en número de tallos. Encontrando como actores relevantes: Argenflor S.A, Center Flowers S.A., Libertini Claudio Alberto, Rocoflor S.R.L., y Selene S.R.L. 
Respecto a la calidad de los productos nacionales, como se menciono anteriormente y como se ha encontrado en alguna bibliografía, las flores argentinas en algunas variedades especialmente como la rosa no alcanzan estándares internacionales de calidad. En el extremo opuesto, se encuentran países actualmente exportadores de flores como Colombia y Ecuador donde existe una industria desarrollada y las cuales se han convertido en los primeros exportadores mundiales de variedad tales como la rosa, con parámetros de calidad que cumplen los estándares internacionales ${ }^{26}$.

Las flores importadas a pesar de tener un precio entre un 50 a un $60 \%{ }^{27}$ mayor a las producidas localmente, son aceptadas por el mercado argentino. Por ejemplo, las flores ecuatorianas, se han posicionado en el mercado local por su belleza, calidad, durabilidad en florero y variedad.

Razón por la cual se estima que la principal competencia se radica en la oferta extranjera de flor ya que tiene estándares de calidad similares a los cuales se quiere desarrollar la actividad en el presente estudio.

\section{Valoración de Calidad en Flores Tipo Exportación}

Teniendo en cuenta la opinión valorada por su experiencia en el sector floricultor del proveedor colombiano de flor de exportación (Sunchine Bouquets), a continuación se detallan los factores claves que son diferenciadores y que determinan la calidad del producto en estudio.

1. Aspecto físico: La flor colombiana se caracteriza por tener unas características físicas especiales, ya que desde su proceso de cultivo en invernaderos, se trabaja para que la flor cumpla con los requisitos y estándares internacionales. Las principales características ofrecidas son el grosor y longitudes de tallo, tamaño de la cabeza de la flor, y número y tamaño de hojas o pétalos de la flor según la variedad.

2. Durabilidad en florero: La flor colombiana también tiene su factor diferenciador marcado por esta característica, ya que desde su proceso de cultivo, y

\footnotetext{
${ }^{26}$ En referencia con los parámetros propuestos por la Sociedad Americana de Floricultores (Society of American Florists).

${ }^{27}$ Estudio de campo realizado durante el 2009. Comparación: AR\$30-40 docena de rosas nacionales vs AR\$ 50 - 90 docenas de rosas importadas.
} 
postcosecha, se manipulan las flores con un tratamiento especial basado en el mantenimiento de las flores con temperaturas y nivel de hidratación ideales, además de suministro de ciertos nutrientes, que hacen que la durabilidad de la flor según su variedad sea mayor en el número de días que las demás flores que no fueron sometidas a este tratamiento. Este es un factor bastante importante, porque para nuestro caso de estudio, puede ser un factor de decisión para la compra dentro de nuestro mercado meta.

\subsection{Análisis FODA y evaluación de oportunidad}

La presente investigación contempla las limitaciones y bondades de todos los agentes intervinientes en la cadena productiva y de abastecimiento, así como su participación y proyección. Temas en los que se basa la generación de estrategias que permitan afrontar y aprovechar cada uno de esos aspectos.

Asimismo, conocer en profundidad las variables que inciden directamente al interior del presente estudio, puntualmente las fortalezas y debilidades, será de gran aporte para potencializar aquellas características competitivas y reducir progresivamente el impacto de las desventajas asociadas.

\section{FORTALEZAS}

$\checkmark$ Reconocimiento y buena imagen de los productos de la floricultura colombiana.

$\checkmark$ Variedad de tipo, variedades, tamaños y colores de flor.

$\checkmark$ Logística de distribución adecuada y especializada en flores.

$\checkmark$ Oferta exportable acorde a las demandas del mercado Argentino.

$\checkmark \quad$ Frecuencia diaria de vuelos de carga Bogotá - Buenos Aires ${ }^{28}$. Ver Anexo No 4.

\section{OPORTUNIDADES}

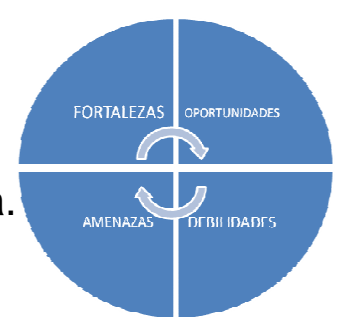

$\checkmark$ Recuperación y crecimiento sostenido de la economía Argentina.

$\checkmark$ Crecimiento favorable del consumo.

$\checkmark$ Actualmente tiene baja presencia de flor colombiana en el mercado.

\footnotetext{
${ }^{28}$ Seis (6) vuelos semanales: Fuente: Proexport - Colombia (Anexo 4)
} 
$\checkmark$ Clima de tipo estacional (variedades de flor y colores dependiendo de la estación).

$\checkmark \quad$ Infraestructura favorable para la distribución (aeropuerto, vías), en Buenos Aires y Santafé).

$\checkmark$ No hay derechos de exportación en Colombia.

$\checkmark$ Producción en contra-estación respecto al Hemisferio Norte.

\section{DEBILIDADES}

$\checkmark \quad$ Financiación y garantías iníciales ${ }^{29}$.

$\checkmark$ Aranceles para la importación de productos de la floricultura originaria de Colombia.

$\checkmark$ Procesos de documentación excesivamente demorados (Ej. registros en cámaras de importadores, registros en Aduana).

$\checkmark$ Poco desarrollo de canales alternativos de comercialización.

\section{AMENAZAS}

$\checkmark$ Competencia de flor Ecuatoriana.

$\checkmark$ Crecimiento local del sector floricultor.

$\checkmark$ Crecimiento del sector floricultor en Brasil.

$\checkmark$ Aumento de las barreras de entrada no arancelarias (incremento nuevamente de exigencias fitosanitarias).

$\checkmark$ Medidas del gobierno que desincentiven las importaciones.

De la identificación de las variables tanto internas como externas se concluye que las fortalezas y oportunidades estratégicas del sector se relacionan principalmente en el aprovechamiento de la buena imagen en la calidad de las flores colombianas y el crecimiento general en Argentina, ofreciendo producto con diversidad en tipos de flores y colores.

Se debe aprovechar específicamente la industria del sector de flores desarrollada en Colombia, teniendo el acceso a un gran número de proveedores del producto,

\footnotetext{
${ }^{29}$ Se limita el acceso al crédito debido a que no se tendría información histórica financiera de los ejecutores del emprendimiento
} 
grandes variedades de flor, modelo de distribución especializado, y la gran oferta de vuelos diarios que existen entre Colombia y Argentina para la distribución.

\section{Conclusiones del Capítulo}

Se puede decir que la economía Argentina ha mostrado un fuerte dinamismo a través de los últimos años producto de la recuperación y reactivación de los factores de producción. El sector Floricultor no ha sido ajeno a ese crecimiento y ha generado grandes oportunidades no solo para el producto local sino también para los importados. En el ámbito local, aún hay mucho trabajo para posicionar fuertemente los productos de la floricultura en el contexto internacional, y requerirá de grandes inversiones en tiempo, dinero, tecnología y capacitación.

En virtud de lo anteriormente expuesto, y atento a las tendencias del mercado hacia productos suntuosos diferenciados, la colocación de flor colombiana en el mercado argentino es una oportunidad viable para los intereses económicos y de incremento comercial bilateral que persigue el presente proyecto.

La flor colombiana compite favorablemente en su calidad y variedad, y de tal forma, se buscara aumentar la participación de las importaciones de flor desde Colombia hacia Argentina y a la vez incentivar el consumo.

El producto a importar desde Argentina serán flores frescas, donde las variedades principales serán las rosas, los claveles, y los crisantemos. Inicialmente las regiones de Buenos Aires y Santafé, son las seleccionadas para desarrollar procesos de comercialización de este producto.

Para este producto el principal competidor es la flor ecuatoriana, que actualmente tiene el mayor porcentaje de las importaciones de flores a la Argentina con más del $60 \%$. Si bien la flor ecuatoriana tiene casi las mismas características de la flor colombiana, mas adelante en el plan de marketing se determinaran los factores diferenciadores con lo cual se podrá contrarrestar esta competencia. 
El proceso de apertura e internacionalización de la Argentina, ha llevado a ésta a convertirse en una de las economías más abiertas de Latinoamérica, gracias a la reducción y eliminación de barreras no arancelarias, licencias e impuestos específicos a la importación, así como requerimientos de tipo documental. Esto está representado en las estadísticas de incremento tanto de exportaciones e importaciones de Argentina en los últimos años, soportado sobre el apoyo del gobierno para el fomento del comercio, lo cual incide directamente en un crecimiento económico y en el consumo local, lo cual es un factor importante para la determinación de encontrar la viabilidad para desarrollar el presente proyecto. 


\section{DETERMINACIÓN DE GRUPO OBJETIVO Y OBJETIVOS DE MERCADEO}

\subsection{Segmentación de Mercado y Cuantificación de la demanda}

La observación de las características relacionadas con el negocio de las flores en Argentina, se inició con una investigación interna y externa, donde no sólo se consultaron fuentes públicas y variables blandas ${ }^{30}$, sino que también se mantuvieron entrevistas con personas que desde hace mucho tiempo se dedican a la importación y comercialización de flores en Capital Federal.

Al iniciar proceso de segmentación se tuvo en cuenta -como es lógico-, el tipo de producto y los beneficios que traerá a los compradores. No es necesario profundas investigaciones para determinar que las flores en Argentina son un típico bien suntuoso y su comercialización deberá estar dirigida a un grupo de mercado con características determinadas. De igual forma, al estar más limitado el grupo objetivo, será necesario ofrecer productos que cumplan no solo con sus necesidades de primera mano, sino que también les proporcione beneficios intangibles que, en definitiva, será el verdadero factor que marcará el éxito del negocio.

Para determinar las variables de segmentación, se inició desde un marco global hasta el nivel de detalle más preciso que la investigación podía proporcionar. De tal forma, se partió desde una segmentación geográfica que proporcionó información de la población en las regiones de Gran Buenos Aires y Santa Fe (regiones de Argentina en dónde se iniciará la comercialización de flores, argumento anteriormente determinado); sobre este grupo, se analizaron las variables demográficas para determinar edad, sexo e ingresos. Por último, se realizó la segmentación socioeconómica que agrupó la división de población de acuerdo con las clases sociales.

Si bien, las variables duras ${ }^{31}$ proporcionan un buen acercamiento al mercado meta, no son suficientes para describir acertadamente nuestro nicho. De manera que el

\footnotetext{
${ }^{30}$ Es aquella variable cuya medición puede ser fácilmente modificable por circunstancias externas o internas: "perfil psicográfico": Actitudinal, personalidad, intereses, estilo de vida, etc.

${ }^{31}$ También llamadas "perfil demográfico" Edad, sexo, nivel socioeconómico, lugar de residencia, nivel de educación, etc.
} 
estudio de variables blandas es el nivel de detalle que queremos para dirigir correctamente las estrategias. En este sentido, las variables psicográficas, las cuales nos muestran las características de clase social, estilo de vida y personalidad; y las variables conductuales, que dividen a los compradores con base en su conocimiento del producto, su uso y su actitud ante el mismo, serán la aproximación que requerimos para un buen resultado de la segmentación.

El consumo per cápita anual de plantas ornamentales, flores cortadas y follaje en Argentina se estima entre los 4 a 5 U\$S. Estos valores son muy bajos, si se le compara con países europeos como Holanda con 67 U\$S, Inglaterra con 42 U\$S, o con los Estados Unidos con un consumo de 27 U\$S per cápita. ${ }^{32}$

De acuerdo con esta segmentación, el grupo objetivo para nuestros productos, se encuentran caracterizados por mujeres mayores de 25 años de las provincias de Buenos Aires y Santa Fe, pertenecientes a las clases sociales media, media alta y alta.

El canal de distribución para llegar al grupo objetivo estará conformado inicialmente por mayoristas, o detallistas que serían floristerías exclusivas o viveros que ofrecen diversidad de flores, tamaños y colores, así como productos de calidad.

El consumidor tradicional, se inclina marcadamente por especies de flores grandes de colores fuertes, principalmente rojo. En especies como claveles, gladiolos y rosas lo anterior es marcadamente relevante, luego las preferencias van por el color blanco (notorio en crisantemo, lilium, tulipán). En general el mercado masivo accede poco a las especies no tradicionales, esto puede tener dos explicaciones: Por un lado está el costo y por otro que el consumo que ellos tienen está orientado al uso en cementerio, por lo que no se justifica la compra de una flor más delicada, que puede eventualmente ser sustraída.

Existen fechas puntuales en donde se logran precios atractivos, independiente de la estación, como son: día de la secretaria (septiembre), navidad (diciembre), año

\footnotetext{
${ }^{32}$ Asociación Colombiana de Exportadores de Flores, 2005 en http://www.asocolflores.org/site/ppal.php y FIA. Prochile (Promotora de Comercio Exterior de Chile).
} 
nuevo (diciembre), día de San Valentín (febrero), pascua de resurrección (abril), día de la madre (octubre), fiestas patrias (mayo), día del profesor (septiembre), graduaciones (diciembre) y día de la primavera (septiembre).

En relación a las ventas se observa una tendencia a mejorar la percepción visual de las flores y la presentación de las mismas. Estos factores actúan como disparadores que incentivan la compra. Es notable ver en las florerías y otros comercios destinados a tal fin, la evolución del packaging. Se utilizan diferentes arreglos en el packaging de rosas, claveles y otras especies que se colocan en materiales novedosos de distintos colores, acompañados también por accesorios.

Según datos del $\mathrm{CF}^{33}$, los consumidores de flores y plantas ornamentales son principalmente mujeres de entre 26 y 45 años, pertenecientes a los nichos socioeconómicos medio, medio alto y alto. Este segmento responde principalmente a compras por impulso, realizadas en kioskos o puestos callejeros. Por su parte, los hombres compran en ocasiones puntuales, prefiriendo adquirir los productos en floristerías, en lugar de puestos o kioskos.

Con relación a las características evaluadas por los compradores a la hora de adquirir productos florícolas, se indica en el trabajo citado que las personas más jóvenes (de 20 a 30 años), se guían principalmente por el precio, mientras que las personas adultas (de 30 a 55 años), analizan factores como color, precio, fragancia y belleza. Por otra parte, las personas mayores (de 55 años en adelante), tienen una idea más acabada de los elementos determinantes de calidad, tales como firmeza y longitud del tallo, coloración de las hojas, pétalos, botones de flores, color y aspecto general. Estas entonces serian las características requeridas por el segmento de mercado para satisfacer las necesidades de belleza y elegancia que desean obtener para sus espacios donde viven o trabajan diariamente

Al mencionar la segmentación del mercado sobre los productos florícolas, es importante tener en cuenta la frecuencia de compra, ya que ésta impacta directamente sobre el volumen de las ventas. La frecuencia de compra, se relaciona

${ }^{33}$ CFI - Fundación Fortalecer, 2006. 
directamente con el nivel socioeconómico del adquiriente. Esto se relaciona a los cambios de pautas de consumo de la población con altos niveles de ingresos, que integran este producto a sus hábitos de compra. A mayor poder adquisitivo, mayor frecuencia de compra, y alta calidad en las flores adquiridas. Un dato aproximado del número de florerías que se ajustarían al tipo de productos que se ofrecerán, se encuentran alrededor de 120 en Capital Federal y 65 en Rosario ${ }^{34}$.

\section{Calculo de la demanda.}

A continuación se determina el número de mujeres estimado para el año 2010 y 2015 las cuales están clasificadas por edades, con el objetivo de cuantificar la demanda.

Tabla No. 11 Cantidad de mujeres en el grupo de edad objetivo 2010 - 2015

\begin{tabular}{|c|c|c|c|}
\hline \multirow{2}{*}{ Provincia } & \multirow{2}{*}{$\begin{array}{l}\text { Grupos de } \\
\text { Edad }\end{array}$} & 2010 & 2015 \\
\hline & & Mujeres & Mujeres \\
\hline \multirow{5}{*}{$\begin{array}{c}\text { Ciudad de } \\
\text { Buenos Aires }\end{array}$} & $25-29$ & 121.471 & 111.804 \\
\hline & $30-34$ & 133.227 & 123.462 \\
\hline & $35-39$ & 117.430 & 129.932 \\
\hline & $40-44$ & 99.915 & 113.357 \\
\hline & $45-49$ & 94.637 & 96.289 \\
\hline \multicolumn{2}{|r|}{ Subtotal } & 566.680 & 574.844 \\
\hline \multirow{5}{*}{ Buenos Aires } & $25-29$ & 590.286 & 606.642 \\
\hline & $30-34$ & 627.961 & 592.904 \\
\hline & $35-39$ & 537.455 & 628.435 \\
\hline & $40-44$ & 472.155 & 535.679 \\
\hline & $45-49$ & 438.879 & 468.339 \\
\hline \multicolumn{2}{|r|}{ Subtotal } & 2.666 .736 & 2.831 .999 \\
\hline \multirow{5}{*}{ Santa Fe } & $25-29$ & 133.605 & 134.088 \\
\hline & $30-34$ & 133.018 & 132.156 \\
\hline & $35-39$ & 104.630 & 131.455 \\
\hline & $40-44$ & 93.542 & 103.466 \\
\hline & $45-49$ & 93.313 & 92.754 \\
\hline \multirow{2}{*}{\multicolumn{2}{|c|}{$\begin{array}{r}\text { Subtotal } \\
\text { Total }\end{array}$}} & 558.108 & 593.919 \\
\hline & & 3.791 .524 & 4.000 .762 \\
\hline
\end{tabular}

Fuente: Tomado de las proyecciones provinciales de población por sexo y grupos de edad 2001 2015. Análisis Demográfico - Informe Técnico INDEC

Por otro lado, según el índice socioeconómico analizado en Argentina en el año 2002 (Analizado en el marco de un estudio de la CEPAL, por el consultor Manuel Mora y Araujo), que estima variables tales como el nivel educacional, ocupacional y posesiones de materiales a continuación se presenta una clasificación general de los

\footnotetext{
${ }^{34}$ Consulta a través de las páginas amarillas y publicaciones en internet
} 
niveles socioeconómicos en la República Argentina la cual nos ayudará a estimar con un mayor detalle un tamaño de mercado objetivo y su proyección a futuro.

DISTRIBUCIÓN DEL INDICE NES-IMAR

\begin{tabular}{|c|c|c|c|}
\hline Posición & Segmento & $\%$ & \\
\hline Alto-alto & $A-B-C 1$ & 7 & afluentes \\
\hline Alto & $\mathrm{C} 2$ & 11 & \\
\hline Medio alto & $\mathrm{C} 3$ & 26 & clase media \\
\hline Medio bajo & D1 & 22 & \\
\hline Bajo & D2 & 29 & clases bajas \\
\hline Bajo-bajo & $E$ & 5 & \\
\hline & \multicolumn{3}{|c|}{100} \\
\hline
\end{tabular}

Fuente: Ipsos-Mora y Araujo/Analogías-RIOP 2001

La distribución del índice desarrollado presentado en el anterior cuadro muestra que la posición más baja es el índice (E) (nivel bajo-bajo). Luego se clasifica como de clase "baja inferior" (D2) (nivel bajo), como "baja superior" (D1) (medio-bajo). Los hogares C3 son los hogares de clase "media baja" (en nuestra terminología media), mientras que la "media típica" (C2) (en nuestra terminología alto). Por último los estratos más altos- $C 1$ y AB. Comprendiendo esta clasificación, se estima que el producto de flores frescas de importación apunta a los segmentos de A hasta C3 es decir media, media alta, alta, y alta-alta, lo cual corresponde a un $44 \%$ de la Población Total.

Con la información anteriormente expuesta se realiza una estimación del cálculo de la demanda y su crecimiento, representado en la siguiente tabla:

Tabla No. 12 Cálculo de la Demanda y su proyección de crecimiento.

\begin{tabular}{|r|c|c|}
\cline { 2 - 3 } \multicolumn{1}{c|}{} & AÑO 2010 & AÑO 2015 \\
\hline No. De Mujeres de Ciudad de Buenos Aires entre los 25 y 49 años & USD 566.680 & USD 574.844 \\
\hline No. De Mujeres de Provincia de Buenos Aires entre los 25 y 49 años & USD 2.666.736 & USD 2.831.999 \\
\hline No. De Mujeres de Provincia de Santafé entre los 25 y 49 años & USD 558.108 & USD 593.919 \\
\hline $\begin{array}{r}\text { Total No. De Mujeres Entre } 25 \text { y } 49 \text { años de Provincias de Buenos } \\
\text { Aires y Santafé }\end{array}$ & USD 3.791.524 & USD 4.000.762 \\
\hline Consumo Estimado Percápita en Argentina (Asocolflores) & USD 4,5 & USD 4,5 \\
\hline $\begin{array}{r}\text { Tamaño Mercado en USD Clasificando Mujeres de de 25 a 49 años } \\
\text { de las provincias de Buenos Aires y Santafé } \\
\text { de las provincias de Buenos Aires y Santajé y estimando que el 44\% } \\
\text { es del segmento de nivel socioeconómico medio, medio alto, alto y } \\
\text { alto-alto. }\end{array}$ & USD 7.507.218 & USD 7.921.509 \\
\hline $\begin{array}{r}\text { Crecimiento Porcentual en } 5 \text { años } \\
\text { Crecimiento Porcentual Anual }\end{array}$ & USD 18.003.429 \\
\hline
\end{tabular}

Fuente: Cálculos Propios 
En virtud de lo anteriormente expuesto se puede estimar que la demanda de flores frescas cortadas en el segmento de mercado, para el año 2010 es de US $\$ 7.507 .218$ y por un valor de US $\$ 7.921 .509$ para el año 2015 y con una tasa de crecimiento anual del $1 \%$.

Se puede concluir entonces, que el mercado argentino actualmente se encuentra desabastecido en flores frescas cortadas de alta gama ya que las importaciones anuales suman cerca de tres millones de dólares (Ver Tabla No. 6). De manera que el mercado presenta amplias oportunidades actuales y futuras para la inserción de productos de gran calidad y variedad.

De acuerdo con los anteriores argumentos, la realización del proyecto ayudará a satisfacer parcialmente las necesidades de demanda en las provincias estudiadas, ítems que se refieren a flor de gran calidad, variedad y durabilidad. Una flor tipo exportación que cumpla con los estándares de calidad impuestos por consumidores en mercados especializados en la comercialización de flores frescas cortadas.

\section{Comportamiento de compra y análisis del consumidor}

Se realizó un análisis y clasificación del consumidor y su comportamiento de compra, basado en la clasificación realizada por la Universidad Tecnológica Nacional de Argentina, la cual se detalla a continuación:

\section{a) ANÁLISIS DEL ¿QUÉ COMPRA?}

\section{Mercado Masivo}

Artículos no duraderos: Es todo aquello que puede usarse una sola vez, un solo consumo. En Nuestro caso las flores se compran para ser usadas una sola vez mientras duran en florero.

Producto de Elección: Son aquellos productos donde no nos queda más remedio que elegir: En nuestro caso las flores son un producto de elección porque siempre se debe elegir la variedad de flor, o el color, según sea el evento a celebrar o incluso la fecha del año. Difícilmente puede pasarse a ser un producto de conveniencia o de especialidad. 


\section{b) ANÁLISIS DEL ¿POR QUE COMPRA?}

En nuestro caso se busca satisfacer necesidades secundarias o aprendidas que son todas aquellas necesidades que se crean por estar en contacto con la sociedad. La compra de flores no cubre necesidades primarias tales como comida, seguridad, abrigo o protección.

\section{La conducta del consumidor}

La conducta del consumidor se basa en tres aspectos:

El Deseo de la compra: Comprar un ramo de flores.

\section{El Motivo de la compra:}

- Brindar emoción a una persona que queremos, haciendo le ver a la otra persona lo importante que es.

- Generar un ambiente de elegancia a una ceremonia o momentos del cual hacemos parte. Hacer notar a la o las personas que hacen parte de un encuentro que están en lugar elegante o status.

- Darle estilo a espacios donde vivimos o trabajamos.

La Necesidad de la compra: Se satisfacen necesidades de demostración de afecto, amor, elegancia, estilo, prestigio o status.

\section{Modelo de escala de necesidades de Maslow}

Entendiendo que las personas tienen una serie de motivaciones que satisfacer y que éstas siguen una escala progresiva, es decir, hasta que no está cubierto un nivel de satisfacción no se demanda el siguiente, y siguiendo los niveles de la pirámide de Maslow, un producto como las flores apunta a cubrir necesidades del tercer nivel llamado el de pertenencia (Integración en grupos, clubes, amistad, familia, amor, etc.) y también el cuarto nivel, que son las necesidades de estima (Status, prestigio, autorrespeto, superioridad, etc.)

\section{c) ANALIZAMOS ¿QUIEN COMPRA?}

Se estima que existen cinco personajes que siempre están en toda decisión de compra:

El iniciador que dice: Hay que ir a comprar un ramo de flores. 
El influenciador que dice: no lo compres allá, cómpralo en tal floristería, cómpralo de rosas que esas le gustan, etc. Puede ser un amigo o alguien conocido a la persona a la cual se le va a regalar el ramo de flores quien aconseja la variedad y el color.

El decididor que dice: está bien voy a comprarlo yo.

El comprador propiamente dicho: el que va y lo compra

El usuario: es el propio comprador o a la persona a la cual se le regala el ramo de flores.

En la mayoría de casos para un ramo de flores, los cinco personajes están en uno solo. El influenciador en algunos casos puede ser alguna persona diferente la cual puede ser un familiar o un amigo que recomienda alguna floristería que ya conoce donde puede encontrar lindas flores. En general a todos se les vende la variedad de la flor, su fragancia, su belleza, su tamaño y sus colores, el precio.

\section{Conductas de elección del consumidor}

Para el caso de la flores fresca aplicaría una conducta de selección siguiendo un "Modelo Conjuntivo" que se define como el modelo de compra en el cual el consumidor antes de comprar pone un conjunto de características sobre el producto que desea adquirir. En nuestro producto aplica, pues las flores deben cumplir un cierto número de características que exige el consumidor.

En flores se busca que tengan colores exóticos y vivos, que tengan un tamaño grande y una apertura según sea la variedad, o que por ejemplo cuando las tengan en florero duren el mayor tiempo posible.

No aplican modelos como el Modelo Dominante, donde se compra sin razonar y se actúa impulsivamente, o por ejemplo el Modelo Disyuntivo, que exige fundamentalmente que alguna característica que si o si se debe cumplir, o finalmente el Modelo de Punto Ideal donde se define en forma más detallada o precisa lo que se requiere, lo cual no se considera a este nivel en el mercado de las flores. 


\subsection{Unidad de Negocio}

De acuerdo con las investigaciones preliminares que se han referenciado a lo largo del presente proyecto, se puede decir, nuevamente, que los productos que marcarán mayor volumen en ventas serán la rosa, el clavel, y los crisantemos como eje principal de las estrategias de producto que marcará el comportamiento general del negocio, por lo cual sería la unidad de negocio de productos maduros. Estos pueden manejar estrategias de venta por volumen pero un margen menor de ganancia, y pueden estar orientados especialmente para los mayoristas del mercado.

Sin embargo, durante la comercialización de las variedades de flor que están posicionadas, se puede pretender diversificar ofreciendo variedades las cuales pueden ser exóticas y no comunes en el mercado argentino; esto es, productos catalogados como exóticos debido a sus niveles de producción, los cuales se caracterizan por sus exigentes métodos. De manera tal, tipos de la floricultura colombiana como el girasol, heliconias y algunos follajes ornamentales, podrían ser productos catalogados con baja participación en el mercado pero con altas y atractivas posibilidades de crecimiento.

La estrategia con estas variedades que son novedosas, no están orientadas al volumen de ventas, sino por el contrario al margen de ganancia, que influye en precios altos en la etapa de introducción del producto. Este tipo de variedades pueden ser introducidas por medio de las floristerías de manera tal que cuando se logre una aceptación y reconocimiento de estas variedades, se puedan incrementar gradualmente los volúmenes ya sea por necesidad de estos detallistas, o por solicitud de mayoristas que perciben nuevos requerimientos de sus clientes.

\subsection{Objetivos del Plan de Mercadeo}

La realización del plan de mercadeo, implicaría no solo una mejora de las condiciones actuales de intercambio comercial en este tipo de productos, sino que también se generaría un aporte importante de diversificación para los consumidores de este tipo de bienes. 
El impacto económico del mismo, se enfoca principalmente en un ahorro de los costos directos de logística, principalmente los asociados al transporte por medio de la optimización de las rutas. También existirá un sensible ahorro en la distribución local al poderse realizar el transporte de los productos de manera propia ${ }^{35}$, evitando así, excesivo pagos de fletes y riesgos asociados.

Asimismo, los objetivos del plan de marketing se reúnen en las siguientes premisas:

$\checkmark$ Propender por el crecimiento de productos como rosas, claveles y crisantemos.

$\checkmark \quad$ Incrementar el nivel de notoriedad de la marca que se utilice para comercializar los productos.

$\checkmark \quad$ Introducir lentamente al mercado argentino, productos diferentes tales como girasoles, heliconias o minirosas.

$\checkmark \quad$ Puesta en marcha de un servicio de atención al via web.

$\checkmark$ Propender por incrementar las ventas continuamente a lo largo del tiempo.

$\checkmark$ Lograr un margen de ganancia aproximado al 35\% posterior a la nacionalización del producto en Argentina.

\subsection{Posicionamiento}

El posicionamiento de un producto es la manera en la que los consumidores definen un producto a partir de sus atributos importantes, es decir, el lugar que ocupa el producto en la mente de los clientes en relación de los productos de la competencia.

Para el proceso de posicionamiento del producto en primera medida se enfoca a la segmentación realizada del mercado, donde se definió que el mercado final que recibirá el producto son mujeres mayores a 25 años de clases media, media-alta, y alta, las cuales obtienen de la flores un concepto de elegancia y belleza que adornan sus espacios, traducidos en el color, fragancia, firmeza y longitud de tallo, coloración de las hojas o pétalos, durabilidad y aspecto general de la flor, cualidades que como hemos mencionado anteriormente, la flor colombiana tiene un reconocimiento aceptado en el mercado internacional.

\footnotetext{
${ }^{35}$ Vehículo de carga adaptado para transporte de flores, se proyecta la consecución del mismo a través de un leasing financiero.
} 
Es muy importante ligar la marca de la empresa en la mente no solo del consumidor final, sino de los clientes, llámese mayoristas, o floristerías, con el país del cual proviene el producto, precisamente por el reconocimiento adquirido de las flores colombianas las cuales garantizan todas las cualidades y beneficios esperados por el mercado seleccionado.

La estrategia de posicionamiento debe enfocarse entonces en proporcionar el concepto de recordar el lugar de donde proviene el producto, y también que existan marcas que avalen la calidad esperada del producto.

En este contexto se pretende desarrollar en primera medida material publicitario que acompañen los productos con información útil y en diseños llamativos para posicionar positivamente las flores de origen colombiano con la marca o logo de la empresa importadora acompañados de marcas que logren esa recordación. También estas marcas pueden ir en el embalaje o empaque en el cual serán transportados y distribuidas las flores.

En Colombia existe la marca país ${ }^{36}$ que como objetivo principal busca mejorar la percepción de Colombia en el exterior, y que liga el país del cual proviene.

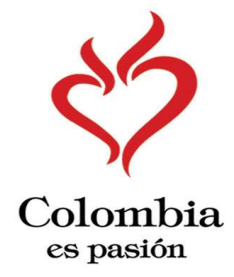

Fuente: Programa Nacional para la Promoción del País. Portal Colombia es Pasión.

Por otro lado se pueden incluir logos de certificaciones tales como:

- Flor Verde es el sello que certifica que el producto se realizó en empresas que se preocupan por el bienestar de los trabajadores, por la protección del medio ambiente, tienen especial cuidado y manejo del producto y existe una responsabilidad gerencial. Este sello garantiza los requerimientos de tipo

\footnotetext{
${ }^{36}$ Ministerio de Comercio/Marca País. Colombia es Pasión: Imagen País http://www.colombiaespasion.com/
} 
fitosanitario en Argentina, y prácticamente es el sello de calidad de este tipo de productos.

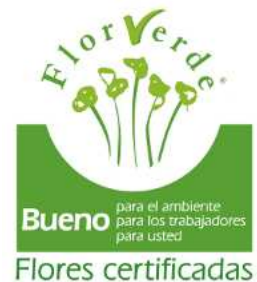

- RainForest que asegura que los productos son producidos de manera social, económicamente y ambientalmente sostenible.

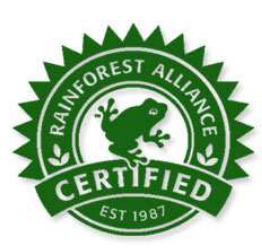

- Global Gap es una norma que garantiza y que brinda confianza al consumidor la manera en que se lleva a cabo la producción agropecuaria, minimizando el impacto perjudicial de la explotación en el medio ambiente, reduciendo el uso de insumos químicos y asegurando un proceder responsable en la salud y seguridad de los trabajadores, como también en el bienestar de los animales,

- Basc enfocada a la certificación de estándares en la Gestión en Control y Seguridad en el comercio internacional orientado a la administración de organizaciones

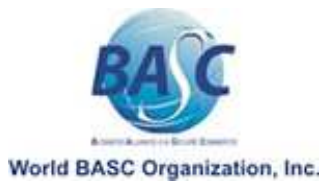

- Aprobación fitosanitaria de ICA (Instituto Colombiano Agropecuario), certificado establecido por el gobierno colombiano que asegura que se están cumpliendo los requisitos fitosanitarios exigidos por el país importador.

Como se puede ver son sellos que pueden acompañar la marca de la empresa, que garantizan no solo, la calidad del producto, sino que también el producto proviene de empresas colombianas las cuales tienen programas de Responsabilidad Social Empresarial, lo cual es muy importante en la actualidad en el comercio internacional. 


\section{Conclusiones del Capítulo}

1. Se realizó una segmentación inicial del mercado meta, el cual quedo definido a mujeres de las provincias de Buenos Aires y Santafé probablemente mayores de 25 años, pertenecientes a los nichos socioeconómicos medio y medio alto y las cuales analizan factores como color, tamaño, durabilidad, fragancia y belleza. También el mercado meta puede estar orientado a Restaurantes y Hoteles que manejen una decoración de este tipo. Nuestros canales de distribución serán entonces aquellos mayoristas radicados en las principales zonas de comercialización de Buenos Aires o detallistas que pueden ser floristerías exclusivas o viveros que ofrezcan este producto al cliente final descrito anteriormente.

2. Las principales fechas donde se demanda el producto durante un año son el día de la secretaria (septiembre), navidad (diciembre), año nuevo (diciembre), día de San Valentín (febrero), pascua de resurrección (abril), día de la madre (octubre), fiestas patrias (mayo), día del profesor (septiembre), graduaciones (diciembre) y día de la primavera (septiembre).

3. Se definen 2 tipos de unidades de negocio las cuales son los productos maduros, que serian los tipos de flor más comercializadas como lo son las rosas, claveles y crisantemos. Además estaría la unidad de negocio de los productos nuevos, que sería el tipo de flor exóticas que no son comunes en el mercado argentino como lo pueden los girasoles, que se pueden ir incorporando lentamente al mercado argentino de acuerdo a la aceptación que vayan teniendo.

4. Los objetivos del plan de marketing están enfocados siempre al crecimiento futuro de las ventas, brindando un producto de alta calidad y con muchas variedades, además de posicionar la marca de la empresa para la comercialización de los productos. Se espera mantener un margen de ganancia aproximado al $35 \%$ del importador.

5. Para el posicionamiento de marca se establecerá una estrategia donde se resalten los atributos ofrecidos por el producto, siempre acompañado de sellos que certifiquen los estándares internacionales de calidad del producto, y políticas de responsabilidad social empresarial de los proveedores del mismo. 


\section{ESTRATEGIA DE MARKETING Y PLAN DE ACTIVIDADES}

\subsection{Estrategia: Liderazgo, Diferenciación y Enfoque}

El objetivo general del negocio está dirigido a realizar directamente el proceso de importación de flores frescas cortadas de origen colombiano. Hay que destacar que se planea tener clientes directos dedicados al manejo de flor de tipo exclusivo (para un mercado de poder adquisitivo media alto y alto), y también mayoristas que hacen su propia distribución y tienen sus propios clientes.

Por otro lado, la estrategia básica de liderazgo que se adoptará para afrontar el mercado argentino estará concentrada en la diferenciación de los productos y nivel de precios. Diversificación de colores y variedades, mayor vida útil en floreros y mejor apariencia, serán los ítems de calidad que la importadora brindará de los productos que comercializa. Asimismo, los precios si bien no enmarcarán el carácter del líder en el mercado, serán competitivos y ampliamente asequibles. De igual forma, el diseño de la cadena de abastecimiento tendrá la trazabilidad y flexibilidad adecuada para adaptarse a los tiempos de respuesta que requiere el negocio. Se estima un lead time ${ }^{37}$ logístico de cinco (5) días para reabastecimiento el cual se irá ajustando con el tiempo y conocimiento de los requerimientos de los clientes, pero esto será también el enfoque de diferenciación que la importadora promoverá como factores competitivos.

En el Anexo No. 2 se muestra todo el proceso de importación destacando los responsables de cada actividad.

\subsection{Factores Claves de Éxito}

El encuadre general del plan de marketing y la forma como se abordará la comercialización de flor colombiana en los mercados argentinos de Buenos Aires y Santafé, proponen los siguientes factores como fundamentales para incursionar con éxito y permanencia en el tiempo en el mencionado mercado.

\footnotetext{
${ }^{37}$ Tiempo que se necesita desde que se solicita un producto hasta que es entregado.
} 
a. Durabilidad: La vida útil de la oferta de flores en Argentina (extranjera y nacional), muestra en promedio unos 12-15 días en florero ${ }^{38}$ dependiendo el tipo de flor. La flor colombiana, según estudios de vida útil en florero realizados por Asocolflores ${ }^{39}$, muestran un duración de 16-20 días dependiendo del tipo de flor, y, si sumamos un preservante, se estaría en un rango de hasta 23 de días en florero.

Esto sin duda, es un factor de éxito que marca la decisión en los consumidores a la hora de hacer una elección.

b. Diversificación: No sólo en tipo de flor sino en colores, variedades y largo de tallo. En esta medida los consumidores tendrán una amplia gama de productos, dirigidos a consumidores exigentes y de diferentes gustos y necesidades.

c. Armado de Ramos de acuerdo a la necesidad del cliente, será un factor evidentemente importante ya que se complementa con el punto de diversificación donde se ofrecen diferentes variedades de flor.

d. Los proveedores certificados son tema crucial para el éxito del emprendimiento, gracias a la oferta diversificada y a gran escala que se tiene en Colombia para este tipo de bienes.

\subsection{Plan de Marketing (4P's): Definición del Marketing Mix}

\section{a. PRODUCTO}

\section{¿Cuál es el Producto a comercializar y qué beneficios generará el producto a los clientes?}

\section{Descripción}

El producto seleccionado para el desarrollo del plan de mercadeo son los ramos de de flores frescas por docena, de las variedades de rosas, claveles, o crisantemos, los cuales pueden ser armados ya sea en "Bulk" que son ramos de un solo tipo de flor y color, "Assortment" ramos de un solo tipo de flor y diferentes colores, o "Bouquets" ramos de diferentes flores y colores.

\footnotetext{
${ }^{38}$ Consulta realizada a comerciantes de flores en Buenos Aires (Capital Federal), en el mes de noviembre de 2009

${ }^{39}$ Asociación Colombiana de Floricultores
} 

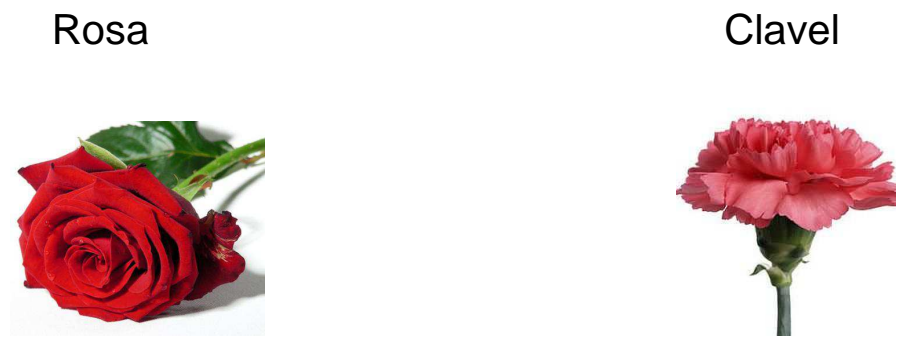

Crisantemo

Ramo de Rosas

Ramo de Claveles

Ramo de Crisantemo
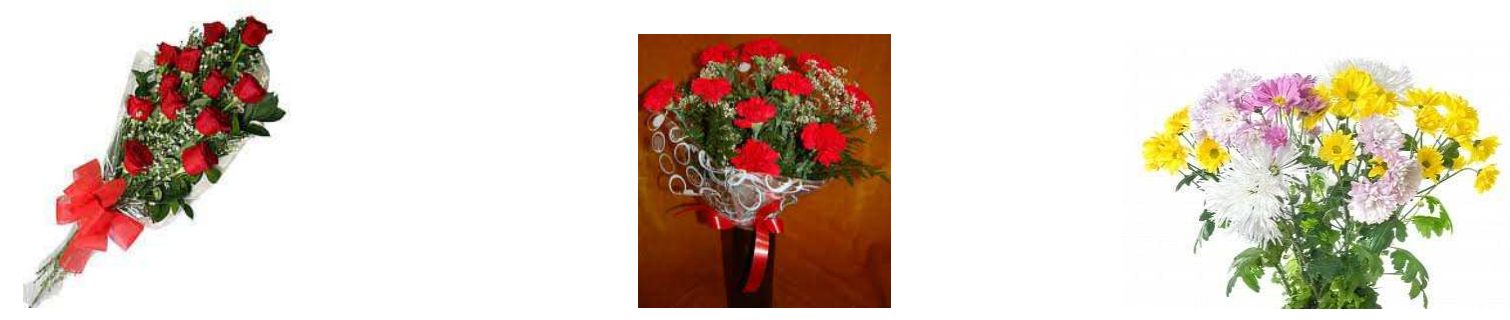

Inicialmente se podría ofrecer en esas tres variedades de tipo de flor, sin embargo si un cliente requiere algún otro tipo de flor se arma según la necesidad del mismo.

Los beneficios y bondades que el producto traerá a los clientes se han venido comentando a lo largo del estudio. Sin embargo, vale la pena recordar que los beneficios están ligados directamente hacia la solución de necesidades afectivas, elegancia, buen gusto, diseño y demás características que poseen este tipo de bienes suntuosos.

Por otro lado, el beneficio que trae la calidad y diversidad de la flor no solo está relacionado con los costos sino que además permite obtener confianza y credibilidad en un elemento que en la mayoría de los casos será la representación propia de los clientes.

Los principales atributos del producto son las características físicas propias de las flores como los son su tamaño, sus colores, su durabilidad, y su fragancia. 


\section{Conformación de Producto}

La importadora trabajará con la filosofía de servicio y calidad, tratando de satisfacer las exigentes demandas de nuestros clientes, es por eso que se ofrecerá una amplia selección de las mejores variedades de flores.

Se ofrecerán ramos que estarán compuestos por 12 tallos de rosas, clavel o crisantemo en colores sólidos o arco iris. Ellos serán personalizados embalados para su conveniencia de manera especial y recibirá un paquete de alimento para flores frescas con cada uno de nuestros ramos de flores. Como se menciono anteriormente los ramos pueden ser Bulk, Assortment o Bouquets.

A continuación y como ejemplo se muestran variedades y tipo de colores, en este caso de Rosa, con los cuales se puede conformar un Ramo según las necesidades del cliente.

\begin{tabular}{|c|c|c|c|c|c|}
\hline Color & Variedad & IMAGEN & Color & Variedad & IMAGEN \\
\hline \multirow{3}{*}{ Bicolor } & Blush & & \multirow{3}{*}{ Orange } & Cherry Brandy & \\
\hline & Circus & & & Iguana & \\
\hline & Latin Lady & & & Movie Star & \\
\hline \multirow{3}{*}{ Blanco } & Akito & & \multirow{3}{*}{ Pink } & Attache & \\
\hline & Vendela & & & Livia & \\
\hline & Virginia & & & Sophie & \\
\hline \multirow{3}{*}{ Hot Pink } & Hot Princess & & \multirow{3}{*}{ Yellow } & Gold Strike & \\
\hline & Topaz & & & Skyline & \\
\hline & High and magic & & & Latina & \\
\hline \multirow{6}{*}{ Rojo } & \multicolumn{2}{|c|}{ Charlotte } & & & \\
\hline & \multicolumn{2}{|c|}{ Classy } & & & \\
\hline & \multicolumn{2}{|c|}{ Forever } & & & \\
\hline & \multicolumn{2}{|c|}{ Freedom } & & & \\
\hline & \multicolumn{2}{|c|}{ MDB } & & & \\
\hline & \multicolumn{2}{|c|}{ Rouge Baiser } & & & \\
\hline
\end{tabular}




\section{Embalaje:}

El embalaje consiste en cajas de cartón corrugado de diferentes medidas ideales para soportar las bajas temperaturas, prácticas para el proceso de paletizado y económicas. Las cajas más usadas en el mercado tienen la siguiente denominación, según sus medidas:

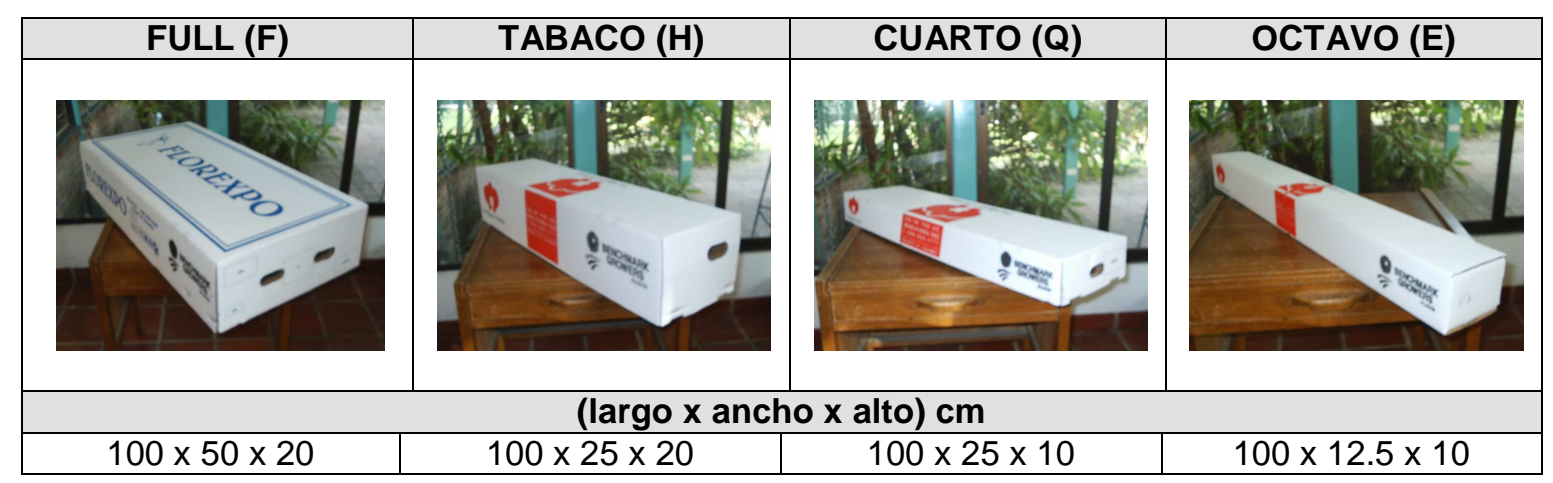

Para la modelación del transporte físico internacional del presente trabajo se toma como estándar la caja denominada Tabaco (o también llamada Half) en la cual se estima que pueden acomodarse 15 ramos, cada uno con una docena de flores.

\section{Empaque}

Dentro del proceso de producción, en la postcosecha, la operación de empaque consiste en embalar el ramo de tal forma que se garantice la calidad del mismo hasta su destino final. Para esto puede ser usado lo siguiente:

Láminas: Fabricadas con cartón corrugado blanco, marcadas con el logo de la empresa. Su función principal es envolver el ramo de flor, protegiéndola, evitando que se maltrate en el viaje.

Capuchones o protector de follaje: Fabricados con polipropileno macroperforado y contramarcados con el logo de la empresa 

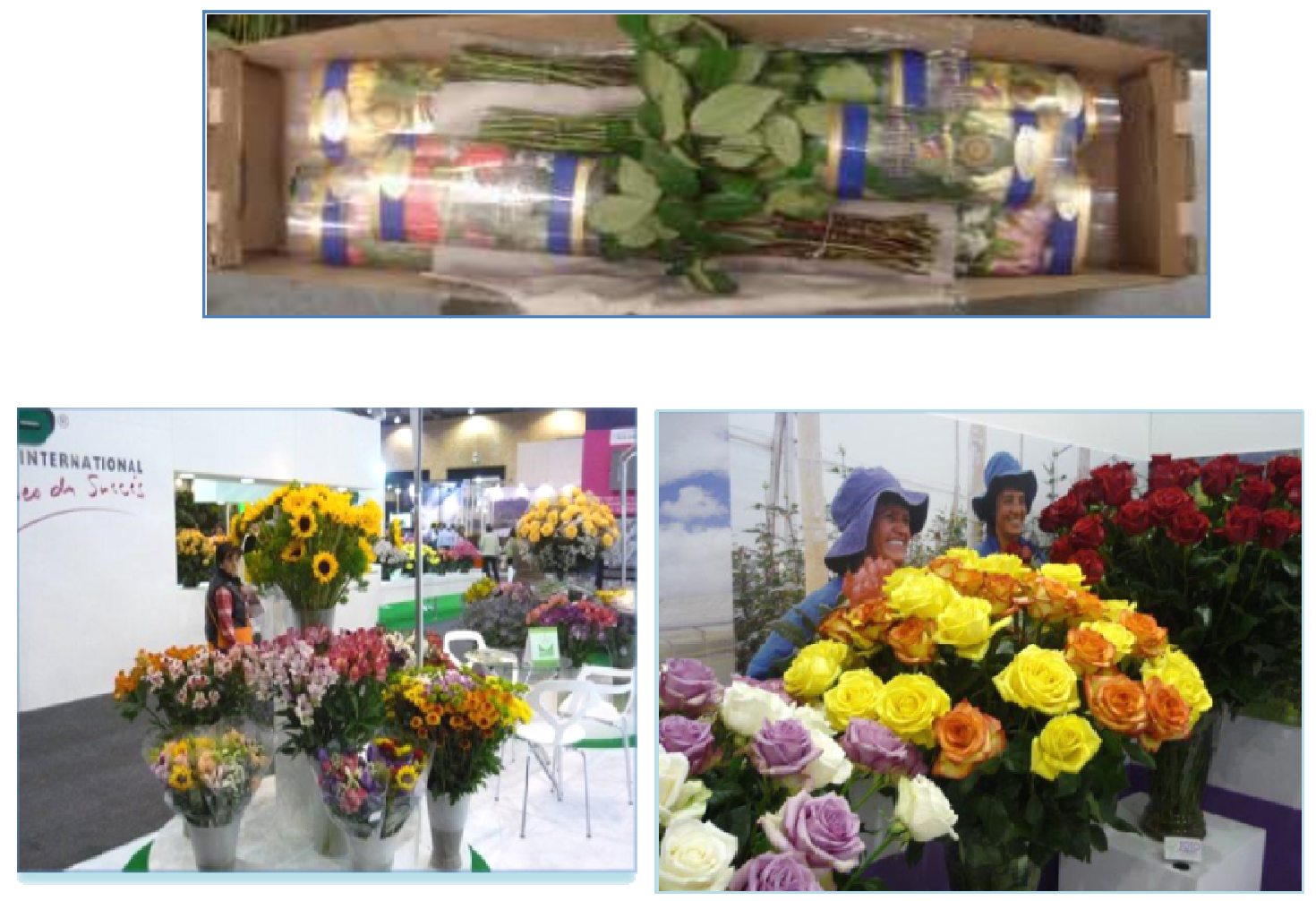

Fuente: Asocoflores

Finalmente en el Anexo No. 3 se muestra una simulación obtenida del software free "Quick Pallet Maker 4.4" el cual nos provee información acerca de la optimización del pallet según las dimensiones de las cajas. Como resultado, nos muestra que por cada pallet aéreo se pueden ubicar 12 cajas Tabaco con un porcentaje de utilización de $84.48 \%$ en área y $75.23 \%$ en volumen.

\section{b. PRECIO}

\section{¿A qué precio se ofrecerá el producto?}

Para este punto es importante anotar, que para la determinación del precio se tomo un estándar determinado de un precio promedio ofrecido por un proveedor de flor colombiana (Sunchine Bouquets) a Valor FCA (Semejante al Valor FOB pero por transporte aéreo). Es importante resaltarlo porque el objetivo de este punto es la modelación de un precio promedio para llegar a su determinación final en toda la cadena de distribución, ya que el precio en una situación real puede variar de acuerdo a la variedad de la flor, color, o temporada del año en la cual se realiza una compra. 
Teniendo en cuenta lo anterior a continuación en la Tabla No. 13 se realiza la modelación para la determinación del precio de nuestro producto en cada uno de los puntos de la cadena de abastecimiento.

Para determinar el valor del número de unidades a modelar, se utilizó el programa Quick Pallet Maker (Demo versión Free), para simular la manera más óptima de estibar la carga en un pallet aéreo de acuerdo con las medidas de las cajas a utilizar y el peso promedio de cada una ${ }^{40}$. El resultado se muestra en el Anexo 3, y fue básicamente la composición de 12 cajas de flores acomodadas en un pallet aéreo.

La mencionada estructura de la Tabla No.13 se estimo bajo la importación de un Pallet compuesto por 12 cajas Tabaco, cada una de estas cajas conteniendo 15 ramos de flores (lo cual corresponde a 2.160 tallos), desde Bogotá a Buenos Aires vía aérea, con el precio ofrecido por el mencionado por el proveedor colombiano.

Finalmente la estructura modelada contiene los márgenes estimados de ganancia de los diferentes canales con el producto puesto en Argentina.

Tabla No. 13. Estructura de Costos y Gastos Proceso de Importación

\begin{tabular}{|c|c|}
\hline \multicolumn{2}{|c|}{ SIMULACIÓN COSTOS DE EXPORTACIÓN } \\
\hline \multicolumn{2}{|c|}{ INFORMACIÓN BÁSICA DEL PRODUCTO } \\
\hline Nombre técnico o comercial del producto: & Flores Frescas Cortadas \\
\hline Posición arancelaria del país exportador: & \multicolumn{1}{|c|}{060310} \\
\hline Posición arancelaria del país importador: & 060310 \\
\hline Unidad comercial de venta: & Tallo \\
\hline Valor FCA de la unidad comercial (Tallo): & U\$S 0.324 \\
\hline Moneda: & Dólar de Estados Unidos \\
\hline INFORMACIÓN BÁSICA DEL EMBARQUE \\
\hline País (Origen): & Colombia \\
\hline Ciudad Punto de Embarque (Origen): & Bogotá \\
\hline País (Destino): & Argentina \\
\hline Ciudad Punto de Desembarque (Destino): & Buenos Aires \\
\hline No. Unidades Comerciales Venta por Embarque: & 2160 Tallos (180 ramos) \\
\hline Tipo Empaque / Embalaje & Cajas de Cartón Corrugado \\
\hline Tipo Unidad de Carga & Europallet \\
\hline Dimensiones & Empaque / Embalaje \\
\hline No. Unidades por Pallet & 12 \\
\hline
\end{tabular}

\footnotetext{
${ }^{40}$ Información obtenida de los potenciales proveedores
} 


\begin{tabular}{|c|c|}
\hline Largo Caja: (mts) & 1.05 \\
\hline Ancho Caja: (mts) & 0.25 \\
\hline Alto Caja: (mts) & 0.25 \\
\hline Volumen Total Embarque (En M3): & 0.79 \\
\hline Peso por Caja (Ton): & 0.015 \\
\hline Peso Total Pallet Cargado (Ton): & 0.18 \\
\hline Base para Liquidar el Flete (Carga Suelta): & 0.18 Ton \\
\hline Aéreo & FCA \\
\hline Término de venta-Incoterm: & Carta de Crédito \\
\hline Forma de Pago: & A la vista \\
\hline Plazo: & 3.82 \\
\hline Tipo de cambio utilizado: & 1 \\
\hline Porcentaje tasa de seguro (\%): & 14 \\
\hline
\end{tabular}

\begin{tabular}{|c|c|}
\hline $\begin{array}{c}\text { Valor FCA } \\
\begin{array}{c}\text { Pallet de } 12 \text { Cajas (180 Ramos }-2.160 \text { tallos) } \\
\text { Valor Proporcionado por Sunchine Bouquets }\end{array}\end{array}$ & US\$700 \\
\hline \multicolumn{2}{|l|}{ Tránsito Internacional } \\
\hline \multicolumn{2}{|l|}{ Costos Directos >> } \\
\hline Transporte Internacional (U\$S)/Pallet de 12 cajas & US\$152,86 \\
\hline Valor CFR & US\$ 852,86 \\
\hline Seguro Internacional & US\$ 8,53 \\
\hline Valor CIP & US\$ 861,39 \\
\hline Manipuleo desembarque & US\$ 51,64 \\
\hline \multicolumn{2}{|l|}{ Costos Indirectos >> } \\
\hline Capital e inventario & US\$ 0,00 \\
\hline Costo DFI Tránsito Internacional & US\$ 0,00 \\
\hline Valor DEQ & US\$ 913,03 \\
\hline \multicolumn{2}{|l|}{ País Importador } \\
\hline \multicolumn{2}{|l|}{ Costos Directos >> } \\
\hline Transporte Local & US $\$ 40,41$ \\
\hline Almacenamiento & US $\$ 0,00$ \\
\hline Seguro & US\$ 6,74 \\
\hline Valor DDU & US\$ 960,18 \\
\hline Documentación (SIM) & US\$20,21 \\
\hline Aduaneros (Impuestos-Se describen a continuación)* & US\$380,76 \\
\hline Agentes (Despachante de Aduana) & US\$ 8,61 \\
\hline Bancario & US\$7,86 \\
\hline \multicolumn{2}{|l|}{ Costos Indirectos >> } \\
\hline Capital e inventario & US\$ 0,00 \\
\hline Costo DF país importador & US $\$ 24,58$ \\
\hline Valor DDP total & US\$ $1.402,2$ \\
\hline
\end{tabular}


Detalle del rubro de impuestos aduaneros.

\begin{tabular}{|c|c|}
\hline \multicolumn{2}{|c|}{ CÁLCULO IMPUESTOS * } \\
\hline Valor CIP & US\$ 861,39 \\
\hline Derecho de Importación AEC/DIE (10\%) & US\$ 86,14 \\
\hline Tasa Estadística TE $(0,5 \%)$ & US\$4,31 \\
\hline Base Imponible IVA & US\$ 951,83 \\
\hline IVA $(21 \%)$ & US\$199,89 \\
\hline IVA $\operatorname{ad}(5 \%)$ & US\$ 47,59 \\
\hline Impuesto a las Ganancias (3\%) & US\$28,56 \\
\hline Impuesto Ingresos Brutos(1.5\%) & US\$14,28 \\
\hline Total Impuestos & US\$ 380,76 \\
\hline
\end{tabular}

Fuente: Cálculos Propios

Teniendo en cuenta esta estructura de costos el Valor DDP de 12 cajas, es decir 180 ramos de flor, nacionalizados en la Argentina cuesta US1.400 aproximadamente.

A continuación se muestra una Matriz de Precios y Márgenes de Ganancia por Canal calculada (Tabla No.14), donde se estiman márgenes por canales de distribución hasta el cliente final, con la determinación de precios, ya sean de 180 ramos de flores (Cantidad bajo la cual se estimo la estructura), así como del precio de un solo ramo de flores.

Tabla No. 14. Matriz de Precios y Márgenes de Ganancia por Canal

\begin{tabular}{|c|c|c|c|c|c|c|}
\cline { 2 - 7 } \multicolumn{1}{c|}{} & $\begin{array}{c}\text { Margen } \\
\text { de } \\
\text { Ganancia } \\
\text { por } \\
\text { Canal }\end{array}$ & $\begin{array}{c}\text { Valor } \\
\text { Ganado por } \\
\text { cada 180 } \\
\text { Ramos de } \\
\text { Flores }\end{array}$ & $\begin{array}{c}\text { Precio } \\
\mathbf{1 8 0} \text { Ramos de } \\
\text { Flores } \\
\text { (1 Pallet de 12 } \\
\text { Cajas) }\end{array}$ & $\begin{array}{c}\text { Precio } \\
\text { Unitario } \\
\text { 1 Ramo de } \\
\text { Flor } \\
\text { (USD) }\end{array}$ & $\begin{array}{c}\text { Precio } \\
\text { Unitario } \\
\text { 1 Ramo de } \\
\text { Flor } \\
\text { (\$ Arg) }\end{array}$ & $\begin{array}{c}\text { Precio } \\
\text { Unitario } \\
\mathbf{1} \text { Tallo de } \\
\text { Flor } \\
\text { (USD) }\end{array}$ \\
\hline $\begin{array}{c}\text { Valor FCR Aeropuerto de } \\
\text { Colombia }\end{array}$ & & 700 USD & 4 USD & $\$ 15,56$ & 0,32 USD \\
\hline $\begin{array}{c}\text { Valor DDP Argentina } \\
\text { (Nacionalizado) }\end{array}$ & & 1.400 USD & 8 USD & $\$ 31,11$ & 0,65 USD \\
\hline $\begin{array}{c}\text { Precio a Canal Mayorista } \\
\text { Precio a Canal Minoristas }\end{array}$ & $35 \%$ & 490 USD & 1.890 USD & 11 USD & $\$ 42,00$ & 0,88 USD \\
\hline Precio a Clientes Finales & $30 \%$ & 737 USD & 3.194 USD & 18 USD & $\$ 70,98$ & 1,48 USD \\
\hline
\end{tabular}

Fuente: Cálculos Propios

Teniendo en cuenta la información presentada se puede establecer que el precio de un ramo de flores frescas colombianas para los clientes finales (Consumidores) según las estimaciones realizadas, es cercano a los US\$18, que corresponde aproximadamente a 70 pesos argentinos lo cual es un precio competitivo si se tiene en cuenta que en florerías especializadas y exclusivas, la docena de rosas importadas son vendidas alrededor en un rango de precios entre 50 a 90 pesos y la 
venta a través de internet a precios aun superiores ${ }^{41}$.

La ganancia esta estimada de acuerdo al margen del 35\% del importador, 30\% del mayorista y $30 \%$ del detallista. Sin embargo esto puede variar dependiendo de la negociación con el cliente pero son los rangos estimados inicialmente.

\section{c. PLAZA}

\section{¿Cómo y dónde se venderá el producto?}

\section{Donde}

En principio, se quiere establecer una base de clientes conformados por mayoristas concentrados en las provincias de Buenos Aires y Santa Fe, así como algunos detallistas potenciales representados en florerías exclusivas o viveros que manejan flor con altos estándares de calidad. Además, se quiere establecer también relaciones comerciales con hoteles y restaurantes que demandan este tipo de bien.

También se puede planear tener vínculos comerciales importadores que tengan un campo de acción más amplio en el mercado y que requieran una fuente alterna de abastecimiento de flor de buena calidad.

\section{Como}

La manera como se comercializará la flor se estima de la siguiente forma:

1. Toma de órdenes de compra (florerías, hoteles y restaurantes, importadores/mayoristas), por Teléfono, personal o medios electrónicos (fax, email, o página web).

2. Relevamiento orden de compra al productor (productores colombianos).

3. Gestión de pago (carta de crédito).

4. Envío de la mercadería.

5. Recepción y puesta a plaza de la mercadería.

6. Distribución propia a los clientes ${ }^{42}$.

\footnotetext{
${ }^{41}$ Estudio de campo realizado en florerías de Recoleta, Palermo y San Telmo en 2009.

${ }^{42}$ Se hará por intermedio de un vehículo acondicionado para la distribución de este tipo de productos. El bien se obtendrá a través de un leasing financiero.
} 
Como se menciono anteriormente la distribución física local se propone realizar por medio de una camioneta con compartimiento refrigerado, la cual será adquirida por medio de un leasing financiero, el cual es un arrendamiento del activo fijo. Esto se toma como una estrategia financiera ya que será establecido como un gasto fijo de arrendamiento, y no se incurrirá en gastos como:

1. Pago de Transporte Local el cual depende de los precios del servicio y el precio de la gasolina.

2. Pagos por mantenimiento

3. Pagos por impuestos

4. Depreciación del activo fijo.

Esta estrategia está siendo actualmente muy utilizada por las PYMES la cual tiene como beneficio al final del tiempo del contrato, un valor de opción de compra del activo.

A continuación se presenta un esquema de arrendamiento de activo de transporte de carga proporcionado por la entidad financiera Bancolombia, la cual se encuentra representada más adelante en el análisis financiero.

\begin{tabular}{|c|c|}
\hline \multicolumn{2}{|c|}{ PROPUESTA SEGÚN CONDICIONES BANCOLOMBIA.COM } \\
\hline Valor Estimado Camioneta Dist. Refrigerado & USD 30.000 \\
\hline Valor de Opción de Compra (10\%) & USD 3.000 \\
\hline Valor Sobre Leasing (90\%) & USD 27.000 \\
\hline Valor Tasa (E.A - 10\%) & $10 \%$ \\
\hline
\end{tabular}

\begin{tabular}{|c|c|c|c|c|c|}
\hline \multirow{3}{*}{$\begin{array}{l}\text { Valor a Pagar por Activo = } \\
\text { Valor a Pagar por Interés = }\end{array}$} & Año 1 & Año 2 & Año 3 & Año 4 & Año 5 \\
\hline & USD 6.000 & USD 6.000 & USD 6.000 & USD 6.000 & USD 6.000 \\
\hline & USD 600 & USD 600 & USD 600 & USD 600 & USD 600 \\
\hline ión de & USD 0 & USD 0 & USD 0 & USD 0 & USD 3.000 \\
\hline Total a desembolsar por año $=$ & USD 6.600 & USD 6.600 & USD 6.600 & USD 6.600 & USD 9.600 \\
\hline
\end{tabular}

Con esta estructura se asegura (en principio), que las cantidades compradas a las productores ya tienen clientes en Argentina, no hay stocks o inventarios y por ende no hay almacenamiento. 


\section{d. PROMOCIÓN}

\section{¿Cómo promover el producto?}

En este punto se hace relación a lo mencionado anteriormente en el punto de posicionamiento, donde se desea realizar material publicitario que pueda acompañar los productos, donde se establezcan la información relevante como puede ser:

- Variedades de flor que se ofrece con fotos de muestra

- Colores por variedad

- Tipo de armado de flores (Bulk, Assortment y Bouquet)

- Características de las flores colombianas.

- Beneficios adquiridos con el producto.

- Marca de la empresa y sellos que certifican la calidad de los productos.

Esto puede estar distribuido de diferente forma en los siguientes tipos de materiales o instrumentos de apoyo para el impulso y venta del producto:

1. Diseño de brochures ya sean físicos o electrónicos.

2. Diseño de tarjetas de presentación de los integrantes de la importadora.

3. Diseño de Página Web. (Propuesta ver Anexo No.8)

4. Muestras de las variedades

También otro aspecto importante puede ser la participación de actividades culturales y comerciales con la embajada de Colombia, así como la asistencia a ferias del sector serán eventos que la importadora tendrá dentro de sus actividades promocionales. La feria de Escobar (Buenos Aires) denominada "Fiesta Nacional de La Flor" es un espacio importante donde debe hacerse presencia para la promoción de los productos a ofrecer.

Este tipo de publicidad se enfoca para llegar a los clientes directos, como lo son mayoristas, floristerías, viveros, hoteles o restaurantes. No se estiman medios publicitarios tales como prensa, radio o televisión pues son medios bastante costosos de acceso masivo, a lo cual no apunta el objetivo de este proyecto. 
Para tener un acercamiento al valor de la propuesta de promoción y publicidad que se ha propuesto, a continuación se presenta un estudio de precios investigados de forma personal y por internet, de materiales publicitarios tales como brochures, tarjetas de presentación, pendones, diseño de marca de la empresa, pagina web, y stand en feria de flores, de acuerdo a cantidades estimadas para el proyecto.

\begin{tabular}{|c|c|c|c|c|}
\hline \multicolumn{6}{|c|}{ Cotización de precios Ofrecido por ULA.com } \\
\begin{tabular}{|c|c|c|c|c|}
\hline Tarjetas de Presentación & Unidades & $\begin{array}{c}\text { Precio Por } \\
\text { Unidad }\end{array}$ & Valor Total & $\begin{array}{c}\text { Valor Total } \\
\text { (USD) }\end{array}$ \\
\hline Producción e Impresión & 1.000 & $\$ 90$ & $\$ 90.000$ & USD 47 \\
\hline Diseño y Arte Total Tarjetas = & 1.000 & $\$ 60$ & $\$ 60.000$ & USD 32 \\
\hline
\end{tabular} \\
\hline
\end{tabular}

\begin{tabular}{|c|c|c|c|c|}
\hline Brochures & Unidades & $\begin{array}{c}\text { Precio Por } \\
\text { Unidad }\end{array}$ & Valor Total & $\begin{array}{c}\text { Valor Total } \\
\text { (USD) }\end{array}$ \\
\hline Producción e Impresión & 1.000 & $\$ 500$ & $\$ 500.000$ & USD 263 \\
\hline Diseño y Arte & 1.000 & $\$ 100$ & $\$ 100.000$ & USD 53 \\
\hline \multicolumn{2}{|c}{ Total Brochures = } & USD 316 \\
\hline
\end{tabular}

\begin{tabular}{|c|c|c|c|c|}
\hline Diseño de Logo Empresarial & Unidades & $\begin{array}{c}\text { Precio Por } \\
\text { Unidad }\end{array}$ & Valor Total & $\begin{array}{c}\text { Valor Total } \\
\text { (USD) }\end{array}$ \\
\hline Diseño y Arte & 1 & $\$ 100.000$ & $\$ 100.000$ & USD 53 \\
\\
Total Logo $=$ & USD 53 \\
\hline
\end{tabular}

\begin{tabular}{|c|c|}
\hline \multicolumn{2}{|c|}{ Resumen Propuesta } \\
\hline Tarjetas de Presentación (1.000 Unds) & USD 79 \\
\hline Brochure (1.000 Unds) & USD 316 \\
\hline Logo Empresarial & USD 53 \\
\hline Total = & USD 447 \\
\hline
\end{tabular}

Fuente: Ula.com

\begin{tabular}{|r|c|c|c|c|c|}
\hline Costos Asociados a Página Web & ULA.com & Paginasweb.com.co & Winkhosting & Hosting.com.co & $\begin{array}{c}\text { Valor } \\
\text { Promedio }\end{array}$ \\
\hline Estructuración y Diseño de Página WEB $=$ & USD 474 & USD 316 & - & - & USD 395 \\
\hline Valor de Hosting / Año $=$ & USD 237 & USD 95 & USD 275 & USD 600 & USD 302 \\
\hline
\end{tabular}

Fuente: Ula.com, Páginasweb.com.co 
Mapa de Costos Estimados para la Promoción de Flores Frescas en Argentina

\begin{tabular}{|c|c|c|c|c|c|}
\hline & Año 1 & Año 2 & Año 3 & Año 4 & Año 5 \\
\hline \multicolumn{6}{|c|}{ Costos de Página Web } \\
\hline Estructuración y Diseño de Página WEB = & USD 395 & USD 0 & USD 0 & USD 0 & USD 0 \\
\hline Valor de Hosting / Año = & USD 302 & USD 317 & USD 333 & USD 350 & USD 367 \\
\hline Subtotal Pagina Web = & USD 697 & USD 317 & USD 333 & USD 350 & USD 367 \\
\hline \multicolumn{6}{|c|}{ Costos Material de Impulso } \\
\hline Tarjetas de Presentación (1.000 unidades) & USD 79 & USD 79 & USD 59 & USD 59 & USD 59 \\
\hline Brochures (1.000 Unidades) & USD 316 & USD 316 & USD 237 & USD 237 & USD 237 \\
\hline Logo Empresarial & USD 53 & USD 0 & USD 0 & USD 0 & USD 0 \\
\hline Subtotal Material de Impulso = & USD 448 & USD 395 & USD 296 & USD 296 & USD 296 \\
\hline \multicolumn{6}{|c|}{ Participación Feria Nacional de La Flor en Escobar } \\
\hline Valor Stand & USD 2.000 & USD 2.100 & USD 2.205 & USD 2.315 & USD 2.431 \\
\hline Pendones Publicitarios & USD 500 & USD 525 & USD 551 & USD 579 & USD 608 \\
\hline Subtotal Participación Feria = & USD 2.500 & USD 2.625 & USD 2.756 & USD 2.894 & USD 3.039 \\
\hline Total Costos Estimados de Promoción = & USD 3.645 & USD 3.337 & USD 3.385 & USD 3.540 & USD 3.702 \\
\hline
\end{tabular}

Estas valoraciones estimadas para los gastos de comercialización y promoción del producto, también son involucrados dentro del análisis financiero que se realizara en el próximo capítulo.

\subsection{Cadena de Comercialización - Manejo de Producto}

La cadena de comercialización comienza desde proceso de cultivo de la flor.

Brevemente se dará explicación de dicho proceso:

Las fincas productoras están localizadas en la sabana de Bogotá, Colombia, aproximadamente a 60 minutos del aeropuerto internacional, donde se puede combinar personal altamente calificado, clima y altitud perfectas, y tecnología de punta, para poder ofrecer la mejor calidad.

Las flores que se importarían, son flores cultivadas con las más altas normas de producción. Si bien anteriormente se menciono que la calidad de la flor dependía del tratamiento especial que se daba en los procesos de cultivo y postcosecha a continuación se describe de forma abreviada el proceso: 
En cada una de las fincas productoras se crea un microambiente garantizando condiciones de suelo, clima y capacitación adecuados para el manejo de la flor.

La planta se siembra en suelo preparado con nutrientes, fertilizantes y agua, esto bajo invernadero (construcción de vidrio o plástico en la que se cultivan plantas, a mayor temperatura que en el exterior). Estos deben cumplir con condiciones en cuanto a sus dimensiones, transmisión de luz, ventilación, calefacción, entre otras.

Según el tipo de flor (Rosa, Clavel, etc.) el tiempo de siembra varía. Durante el período de crecimiento se aplican productos químicos que combatan los problemas fitosanitarios generados por las condiciones climáticas e insectos, esto acompañado con riego continuo de agua. Al terminar el proceso de crecimiento de la flor (punto de corte, tamaño del tallo), ésta es cortada, empacada y transportada a la postcosecha. Todo este proceso se realiza en las primeras horas de la mañana.

La Postcosecha es el área en donde a través de cierto procesos y tecnología se garantiza la conservación de los productos en su estado natural. Al llegar la flor esta tiene un proceso de hidratación en frío de mínimo 12 horas. Al terminar esta etapa, la flor es llevada a las mesas de Clasificación y Armado de ramos según las especificaciones de los clientes (tamaño, armado, apertura).

Luego los ramos armados son llevados a un cuarto frio para terminar el proceso de hidratación, que debe ser mínimo de 6 horas y la temperatura aproximada es entre los 2 y 4 grados centígrados. Finalmente la flor es empacada en cajas de cartón que debe ser cerrada, sellada y marcada para su posterior despacho en un camión en el que se mantiene la cadena de frío. Al llegar la flor al aeropuerto es distribuida en las agencias de carga y respectivas aerolíneas. En este caso puntual de operación se tiene un esquema general de oferta de vuelos de carga internacional especificado en el Anexo No.4.

Para garantizar a los clientes - a nivel mundial- que van a recibir flor de excelente calidad, los cultivos de flores deben estar certificados por: Norma Flor Verde, RainForest, Global Gap, Basc, Aprobación fitosanitaria de ICA (Instituto Colombiano 
Agropecuario) ya anteriormente mencionados. Estos son programas basados en mantener una estrategia orientada a optimizar el uso de los recursos, buscando así la forma de mejorar la rentabilidad en el sector de cultivadores dentro de un concepto de desarrollo sostenible.

Al llegar la flor a la República Argentina, debe ser revisada por las autoridades de SENASA ex IASCAV para protección vegetal, quienes determinan si la flor cumple con las especificaciones fitosanitarias necesarias para ingresar al país.

Posteriormente la flor debe ser distribuida directamente a nuestros clientes quienes ya se encargan de ponerla a disposición de los clientes finales (Consumidores del producto). Por medio de un camión con un reefer se realiza la distribución local, el cual mantendrá la misma cadena de frio hasta la entrega al cliente.

\section{Conclusiones del Capítulo}

Para el Plan de Mercadeo del producto se definieron entonces los siguientes puntos:

\section{Aspectos Diferentes del Producto:}

a. Durabilidad: La flor colombiana, según estudios de vida útil en florero realizados por Asocolflores, muestran un duración de 16-20 días dependiendo del tipo de flor, y, si sumamos un preservante, se estaría en un rango de hasta 23 de días en florero.

b. Diversificación: No sólo en tipo de flor sino en colores, variedades y largo de tallo. En esta medida los consumidores tendrán una amplia gama de productos, dirigidos a consumidores exigentes y de diferentes gustos y necesidades

Producto: Ramos de Flores frescas colombianas, las cuales serán empacadas en cajas de cartón corrugado para su transporte y bajo refrigeración. Los ramos pueden ser conformados por diferentes tipos de flores como lo son Rosas, Claveles o Crisantemos. 
Precio: El precio estimado final para clientes finales es aproximadamente de US\$ 18 que corresponde a $70 \$ \mathrm{Arg}$, con un margen de ganancia del importador del $35 \%$

Plaza: Se venderá a través de mayoristas, floristerías especializadas, viveros o directamente a hoteles y restaurantes de las ciudades de Buenos Aires y Rosario.

Promoción: Se dará a través materiales publicitarios tales como brochures, tarjetas, muestras, y también con la puesta en marcha de una página web para la comercialización e impulso del producto. Se dará asistencia a distintos eventos de flores, o alianzas estratégicas con otros importadores. 


\section{PRESUPUESTO Y CONTROL}

\subsection{Recursos e Inversiones}

Teniendo en cuenta todo lo expresado a lo largo del estudio a continuación se desglosan los ítems que hacen parte de la inversión inicial del proyecto.

\begin{tabular}{|c|c|c|c|}
\hline $\begin{array}{l}\text { Recursos e } \\
\text { Inversiones }\end{array}$ & Qué & Dónde & $\begin{array}{c}\text { Cuánto } \\
\text { (\$AR) }\end{array}$ \\
\hline $\begin{array}{c}\text { Selección y } \\
\text { Contratación de } \\
\text { Personal }\end{array}$ & $\begin{array}{l}\text { Avisos en redes de } \\
\text { búsqueda de empleo } \\
\text { (Zonajobs, Bumerang) }\end{array}$ & $\begin{array}{c}\text { Buenos Aires - Capital } \\
\text { Federal }\end{array}$ & $\$ 7.300 .00$ \\
\hline \multirow{6}{*}{$\begin{array}{c}\text { Inscripciones Registros } \\
\text { y Licencias }\end{array}$} & $\begin{array}{l}\text { Inscripción como } \\
\text { Comerciante }\end{array}$ & $\begin{array}{l}\text { Registro Público de } \\
\text { Comercio }\end{array}$ & $\$ 0.00$ \\
\hline & $\begin{array}{c}\text { Inscripción en la Aduana } \\
\text { DGA }\end{array}$ & $\begin{array}{c}\text { Dirección General de } \\
\text { Aduanas }\end{array}$ & $\$ 0.00$ \\
\hline & $\begin{array}{l}\text { Inscripción en la Dirección } \\
\text { General Impositiva }\end{array}$ & $\begin{array}{c}\text { Administración Federal } \\
\text { de Ingresos }\end{array}$ & $\$ 0.00$ \\
\hline & $\begin{array}{c}\text { Inscripción en el Registro de } \\
\text { Importadores y } \\
\text { Exportadores }\end{array}$ & $\begin{array}{c}\text { Dirección General de } \\
\text { Aduanas - Azopardo } \\
350 \text { PB }\end{array}$ & $\$ 0.00$ \\
\hline & $\begin{array}{l}\text { Inscripción en el Registro de } \\
\text { Importadores del SENASA }\end{array}$ & SENASA & $\$ 0.00$ \\
\hline & $\begin{array}{c}\text { Autorización Fitosanitaria de } \\
\text { Importación - AFIDI }\end{array}$ & $\begin{array}{c}\text { Dirección de } \\
\text { Cuarentena Vegetal } \\
\text { SENASA } \\
\end{array}$ & $\$ 0.00$ \\
\hline Infraestructura & $\begin{array}{c}\text { Alquiler y Gastos - Oficina } \\
\text { Comercial Sede de la } \\
\text { Importadora }\end{array}$ & $\begin{array}{c}\text { Buenos Aires - Capital } \\
\text { Federal }\end{array}$ & $\$ 6.643 .20$ \\
\hline Infraestructura & $\begin{array}{c}\text { Muebles y Equipos de } \\
\text { Oficina - dos Computadoras }\end{array}$ & $\begin{array}{c}\text { Buenos Aires - Capital } \\
\text { Federal }\end{array}$ & $\$ 9.327 .00$ \\
\hline $\begin{array}{l}\text { Capacitación y } \\
\text { Entrenamiento }\end{array}$ & $\begin{array}{c}\text { Asesorías de Contador y } \\
\text { Abogado para } \\
\text { establecimiento de la } \\
\text { importadora }\end{array}$ & $\begin{array}{c}\text { Buenos Aires - Capital } \\
\text { Federal }\end{array}$ & $\$ 5.400 .00$ \\
\hline Mercaderías & $\begin{array}{l}\text { Primer mes de } \\
\text { Importaciones }\end{array}$ & $\begin{array}{c}\text { Buenos Aires - Capital } \\
\text { Federal }\end{array}$ & $\$ 28.779,95$ \\
\hline Publicidad y Promoción & $\begin{array}{c}\text { Página de Internet, } \\
\text { anuncios y material } \\
\text { publicitario }\end{array}$ & $\begin{array}{c}\text { Buenos Aires - Capital } \\
\text { Federal }\end{array}$ & $\$ 4.300 .00$ \\
\hline \multicolumn{3}{|c|}{ INVERSIÓN INCIAL } & $\$ 61.750 .15$ \\
\hline
\end{tabular}

* Póliza de Caución o Garantía Bancaria por AR \$ 30.000

Fuente: Autor 
Es importante resaltar que ítem como la adquisición del camión, requerido para la distribución local del producto, se propone por medio de un leasing financiero el cual se proyecto como gasto fijo en las proyecciones de ventas y costos y análisis de flujo de caja que se presentan dentro de los Anexos No. 5 y 6.

\section{- Total Inversión Inicial: 61.750 (\$Arg)}

Este valor de inversión se ve reflejado en la segunda fase del plan de actividades del plan de mercadeo en el Anexo No.1 (Actividades por ejecutar), además de ser parte integral del análisis financiero de la proyección de flujo de caja a proponer, detallado en el Anexo No.6.

\subsection{Factibilidad Técnica}

\subsubsection{Ensayo e Investigación}

Esta etapa tendrá lugar luego de las primeras importaciones, se medirá el estado de calidad (apertura, frío e hidratación), de la flor luego de todo el proceso de transporte y distribución. Además, se evaluará, a través de encuestas realizadas a los clientes, las opiniones acerca de las características físicas, de calidad y durabilidad observadas durante las primeras compras.

\subsubsection{Ubicación (Cercanía al cliente)}

El centro de operaciones de la importadora será en la Ciudad de Buenos Aires, allí se concentra la mayor parte de los clientes potenciales y competidores. Asimismo, el otro mercado potencial (Santa Fe), se encuentra relativamente cerca del centro de operaciones, esto permitirá atender a los clientes de la mencionada provincia en período corto de tiempo, aproximadamente 4 horas.

\subsubsection{Escalas de Producción}

Como se ha venido mencionando a lo largo del trabajo, la oferta exportable en Colombia puede atender en tiempo y forma los requerimientos del mercado argentino en los picos de demanda, éstos se han establecido a través de análisis provenientes de datos históricos de importación, producción local y beneficios de producción contra-estación.

En términos generales, la importadora centrará sus actividades en ofrecer productos de primera calidad y en establecer relaciones comerciales con participantes claves 
del sector. La idea es incrementar los negocios y la demanda basada en diversificación, durabilidad y buena calidad de las flores comercializadas.

\subsection{Proyecciones (Ventas y Costos)}

Las proyecciones de ventas y costos del negocio se reflejan en Anexo No.5.

Para las proyecciones tanto de ventas como de costos es importante mencionar que se tuvo en cuenta lo siguiente:

Para los costos se tuvo en cuenta como referencia el Valor DDP determinado en la Matriz de Precios (Tabla No. 14) donde el valor de un ramo nacionalizado en Argentina, es de US $\$ 8$ aproximadamente. A futuro con un aumento de cantidades puede estimarse un descuento por volumen por parte del proveedor colombiano.

Para las ventas se tuvo en cuenta como referencia el Precio del cliente Final (Consumidor) determinado en la Matriz de precios (Tabla No.14) donde el valor de un ramo está entre de US\$11 y US\$14 aproximadamente, dependiendo si el cliente es un mayorista o un detallista respectivamente. En el paso del tiempo puede estimarse un aumento de los precios de acuerdo a la inflación general del país.

Para las cantidades se tuvo en cuenta los volúmenes manejado por los actuales importadores de flor a la República Argentina (Tabla No. 10) donde el importador que menos cantidades importo fue IKEBANA S.A: con un total 328.698 tallos de flor. Teniendo en cuenta esto, la proyección de la importadora apunta a importar en volumen aproximadamente el $50 \%$ en tallos con respecto a este último, lo cual en un inicio es una proyección conservadora mientras se conoce a totalidad el mercado. Este presupuesto entonces corresponde a un presupuesto estimado en número de tallos a importar de aproximadamente 155.000 tallos de flor (Corresponde a 12.960 ramos). En inicio se proyecta un aumento anual en volúmenes importados de acuerdo al crecimiento del sector antes mencionado del $6 \%$.

Los gastos fijos están representados en lo expuesto durante lo que se ha mencionado en el trabajo, lo cual es gastos de Recurso Humano (Composición de la importadora), Gastos Administrativos (Arriendo oficina y servicios), Gastos de 
comercialización (Material Publicitario), Gastos Financieros (Leasing financiero de activo de transporte de carga), y Otros Gastos (Imprevistos y papelería).

\subsection{Análisis Financiero}

El presente análisis financiero (Ver Anexo No.6) se basa en el análisis de flujos de caja, y se estableció como principal objetivo para evidenciar la viabilidad financiera del proyecto y medir su rentabilidad, en cuanto a las proyecciones establecidas de inversión, ingresos y egresos de la operación.

Para esto se determinan los flujos de caja con una proyección a 5 años involucrando los ingresos y egresos del Anexo No.5 así como el valor de la inversión inicial propuesto en el presente capítulo y el aporte por parte de los socios.

Posteriormente se determinan indicadores financieros tales como lo son la VAN, y TIR, los cuales nos permiten realizar un análisis que apuntan siempre como lo mencionamos a determinar si efectivamente las proyecciones estimadas a través de todo el trabajo son viables financieramente.

\section{Indicadores Financieros (VAN y TIR)}

a) VAN - Valor Actual Neto: Es un procedimiento que permite calcular el valor presente de un determinado número de flujos de caja futuros. La metodología consiste en descontar al momento actual (es decir, actualizar mediante una tasa, que puede ser una tasa de renta fija o en otros casos el coste de oportunidad), todos los flujos de caja futuros del proyecto. A este valor se le resta la inversión inicial, de tal modo que el valor obtenido es el valor actual neto del proyecto.

La fórmula establecida para el cálculo de la VAN es la siguiente:

$$
\mathrm{VAN}=\sum_{t=1}^{n} \frac{V_{t}}{(1+k)^{t}}-I_{0}
$$

Donde,

$V_{t}$ representa los flujos de caja en cada periodo $t$.

$I_{0}$ es el valor del desembolso inicial de la inversión.

$n$ es el número de periodos considerado.

$\mathrm{k}$ es el tipo de interés el cual puede ser la tasa de renta fija o coste de oportunidad. 
La finalidad de este indicador es determinar la equivalencia en el tiempo cero (0) de los flujos de efectivo futuros con el desembolso inicial (Inversión), y si dicha equivalencia es mayor a este desembolso inicial, se considera que es recomendable aceptar el proyecto.

Teniendo en cuenta el concepto ilustrado, la VAN del proyecto según los flujos de caja y la cantidad de inversión, proyectados en el Anexo No.6, da como resultado un valor positivo de US\$ 34.581. Usando una tasa de renta fija del $5 \%$ a la cual se descuentan los flujos futuros, el indicador nos hace ver que el proyecto bajo las condiciones presupuestadas genera beneficios, lo cual nos hará recuperar la inversión, además de ganar la cantidad mencionada.

El Valor Actual Neto es muy importante para la valoración en proyectos de inversión, en este caso, el proyecto visto desde esta perspectiva, es viable y su aplicación dejará beneficios al inicio del proyecto

b) TIR - Tasa Interna de Rentabilidad: se conceptualiza como la tasa de rentabilidad o interés, o tasa de descuento por medio de la cual se recupera la inversión.

A mayor sea la TIR mayor será la rentabilidad del negocio, y esta se compara y debería ser mayor que una tasa mínima o tasa de corte denominada así cuando existen inversión sin riesgo, ya que sería la tasa de rentabilidad mínima a la cual los inversores de un proyecto destinaria capital para su ejecución.

Es la tasa de interés para la cual el Valor Actualizado Neto (VAN) es igual a cero, por lo que usando la anterior fórmula, y según los flujos de caja y la cantidad de inversión, proyectados en el Anexo No.6, da como resultado un valor positivo de $\mathbf{4 1} \%$, y es un valor de rendimiento bueno lo cual en complemento al indicador VAN soportan la viabilidad financiera del proyecto bajo las condiciones estimadas. 


\section{c) Punto de Equilibrio}

Entendiendo que como todo presupuesto puede variar por $\mathrm{n}$ factores, se hace necesario calcular el punto de equilibrio que es usado comúnmente en las empresas u organizaciones para determinar el volumen mínimo (En nuestro caso las cantidades serian ramos de flores) del negocio para que sea sustentable con la estructura que se plantea,

Tomando los datos del Flujo de Fondos Anexo No.6 donde se determinan Costos Fijos (CF) tales como Recursos Humanos, Gastos Administrativos, de Comercialización y Financieros, Precio de Venta por Unidad Estimado (p) y Costo Variable por Unidad (Cv) (la diferencia de estos dos últimos es llamado contribución marginal por unidad vendida) representado en la siguiente fórmula:

$$
Q *=\frac{C f}{(p-C v)}
$$

Se obtuvo el siguiente resultado:

\begin{tabular}{|r|c|}
\hline PUNTO DE EQUILIBRIO (CANTIDADES - RAMOS) $=$ & 58.506 \\
\hline CANTIDADES ESTIMADAS A IMPORTAR $=$ & 74.530 \\
\hline PORCENTAJE (\%) FRENTE A CANTIDADES TOTALES A IMPORTAR $=$ & $79 \%$ \\
\hline
\end{tabular}

El punto de equilibrio en unidades dio como resultado 58.506 ramos de flores que se deben vender como mínimo para empezar a obtener beneficios, esto en los 5 años proyectados. Eso siempre y cuando el precio de venta se realice entre US\$11 y US\$ 14 dólares por ramo aproximadamente.

Este punto de equilibrio en Cantidad representa el $79 \%$ del presupuesto total de las cantidades estimada para los 5 años de la proyección financiera, lo cual es un margen adecuado para las cantidades que se estiman comercializar bajo los supuestos mencionados.

\section{d) Periodo de Recuperación de Capital}

Finalmente de acuerdo a los flujos proporcionados en el Anexo No.6 se puede estimar el periodo de recuperación de la inversión propuesta, esto de carácter 
importante para cualquier inversor de capital de riesgo que se encuentre interesado en el presente proyecto.

Teniendo en cuenta lo anterior se obtiene el siguiente resultado:

\begin{tabular}{|r|c|}
\hline Periodo de Recuperación de Inversión (días) $=$ & 1.149 \\
\hline Periodo de Recuperación de Inversión $=$ & 3 Años, 1 Mes, 24 Días \\
\hline
\end{tabular}

Este indicador nos muestra que para la inversión inicial de este proyecto, se estima un tiempo de recuperación cercano a los 3 años posterior al inicio del proyecto. Es un tiempo que es extenso pero si se tiene en cuenta los flujos de caja acumulados para los periodos del año 4 y 5 , es una posibilidad bastante atractiva, pues son beneficios en el largo plazo, y con las perspectivas de la importadora, se espera que en ese tiempo las cantidades importadas y el posicionamiento de los productos se hayan aumentado considerablemente. 


\section{CONCLUSIONES GENERALES}

Esta investigación estuvo dirigida a visualizar la viabilidad de una oportunidad de negocio basado en la importación de productos de la floricultura colombiana y su posterior comercialización en los mercados argentinos de las provincias de Buenos Aires y Santa Fe inicialmente. Para analizar esta posibilidad, a lo largo del estudio se analizaron las características, situación actual y mercado de la industria a nivel nacional y mundial. Con todos estos elementos se evaluó el potencial de la oportunidad detectada y se llegó a las conclusiones que se detallan a continuación:

$\checkmark$ Con respecto al aspecto organizacional, se conformará un equipo de trabajo de tres (3) personas para la parte administrativa y contable, marketing y distribución; adicionalmente, habrá asesores externos en las primeras etapas que permitan evaluar la calidad de las flores, revisar el tema para el establecimiento de sociedades y la gestión impositiva, y en Colombia se contará con un inspector de calidad.

$\checkmark$ La estructura financiera del proyecto contempla el uso de capital propio y préstamos a de terceros.

$\checkmark$ El ambiente actual para la importación y comercialización de productos de la floricultura en Argentina, se encuentran en las mejores condiciones de los últimos años, facilitando los procesos y consolidando una cooperación que sin duda beneficia tanto a oferentes como demandantes

$\checkmark$ Se puede decir que la economía Argentina ha mostrado un fuerte dinamismo a través de los últimos años producto de la recuperación y reactivación de los factores de producción. El sector Floricultor no ha sido ajeno a ese crecimiento y ha generado grandes oportunidades no solo para el producto local sino también para los importados. En el ámbito local, aún hay mucho trabajo y posicionar fuertemente los productos de la floricultura en el contexto internacional requerirá grandes inversiones en tiempo, dinero, tecnología y capacitación. 
$\checkmark \quad$ La colocación de flor colombiana en el mercado argentino es una oportunidad viable para los intereses económicos y de incremento comercial bilateral que persigue el presente proyecto.

$\checkmark$ La flor colombiana compite favorablemente en su calidad y variedad, de tal forma, se buscara aumentar la participación de las importaciones de flor desde Colombia hacia Argentina y a la vez incentivar el consumo gracias a la diversificación.

$\checkmark$ El producto a importar desde Argentina serán flores cortadas, donde las variedades principales serán las rosas, los claveles, y los crisantemos, en las regiones de Buenos Aires y Santafé, que contienen zonas con alto grado de comercialización de este producto.

$\checkmark$ Para este producto el principal competidor es la flor ecuatoriana, que actualmente tiene el mayor porcentaje de las importaciones de flores a la Argentina con más del $60 \%$.

$\checkmark$ El proceso de apertura e internacionalización de la Argentina, ha llevado a ésta a convertirse en una de las economías más abiertas de Latinoamérica, gracias a la reducción y eliminación de barreras no arancelarias, licencias e impuestos específicos a la importación, así como requerimientos de tipo documental.

$\checkmark$ Se definen 2 tipos de unidades de negocio las cuales son los productos maduros, que serian los tipos de flor más comercializadas como lo son las rosas, claveles y crisantemos. Además estaría la unidad de negocio de los productos nuevos, que sería el tipo de flor exóticas que no son comunes en el mercado argentino como lo pueden los girasoles, que se pueden ir incrementando su importación gradualmente de acuerdo a la aceptación que vayan teniendo.

$\checkmark$ Los objetivos del plan de marketing están enfocados siempre al crecimiento futuro de las ventas, brindando un producto de alta calidad y con muchas variedades, además de posicionar la marca de la empresa con la marca-país y los sellos de calidad para la comercialización de los productos. Se espera mantener un margen del importador del 35\%. 
$\checkmark$ Se realizó una segmentación inicial del mercado meta, el cual quedo definido a mujeres de las provincias de Buenos Aires y Santafé probablemente mayores de 25 años, pertenecientes a los nichos socioeconómicos medio y medio alto y las cuales analizan factores como color, precio, fragancia y belleza. También el mercado meta puede estar orientado a Restaurantes y Hoteles que manejen una decoración de este tipo.

$\checkmark$ Nuestros clientes directos serán el canal de mayoristas que le ofrezcan el producto a las floristerías. También pueden ser floristerías exclusivas que ofrezcan este producto al consumidor final.

$\checkmark$ Las principales fechas donde se demanda el producto durante un año son el día de la secretaria (septiembre), navidad (diciembre), año nuevo (diciembre), día de San Valentín (febrero), pascua de resurrección (abril), día de la madre (octubre), fiestas patrias (mayo), día del profesor (septiembre), graduaciones (diciembre) y día de la primavera (septiembre).

$\checkmark$ La cuantificación actual de la demanda está cercana a los 7 millones de dólares, cifra que está muy por encima del valor de las importaciones de este tipo de flor a la República Argentina, lo cual supone una oportunidad para satisfacer esa demanda insatisfecha.

$\checkmark$ Los factores diferenciadores del producto serán su calidad, su variedad, un servicio eficiente, tiempos de respuesta competitivos, precios cómodos y respaldo asociado con garantías de los productos, así como alineación y diseño de estrategias conjuntas importador-cliente, serán los valores intangibles que los clientes y consumidores obtendrán tras los negocios realizados con la operación.

Con respecto al plan de Marketing del producto se definieron entonces los siguientes puntos:

$\checkmark$ Producto: Ramos de Flores frescas colombianas, las cuales serán empacadas en cajas de cartón corrugado para su transporte y bajo refrigeración. Los ramos pueden ser conformados por diferentes tipos de flores como lo son Rosas, Claveles o Crisantemos. 
$\checkmark$ Precio: El precio estimado final para consumidor final es aproximadamente de US\$18 que corresponde a $70 \$ \mathrm{Arg}$, con un margen de ganancia del importador del $35 \%$

$\checkmark$ Plaza: Se venderá a través de mayoristas, floristerías especializadas, o directamente a hoteles y restaurantes de las ciudades de Buenos Aires y Rosario.

$\checkmark$ Promoción: Se dará a través de asistencia a distintos eventos de flores, alianzas estratégicas con otros importadores, y también con la puesta en marcha de una página web para la comercialización e impulso del producto.

$\checkmark$ Con un VPN de US\$34.581 y una TIR de $41 \%$, el proyecto es viable financieramente si se cumplen las condiciones dadas.

$\checkmark$ La cantidad mínima de ramos a vender durante el proyecto se estima en 58.506 ramos, lo cual es un volumen de $20 \%$ al presupuestado.

$\checkmark$ El Capital correspondiente a la inversión inicial, tendrá un periodo de recuperación de 3 años, donde los flujos acumulados empiezan a ser positivos. Esto también teniendo en cuenta la propuesta de que existirá un aporte de los socios, o emprendedores del proyecto por un valor de US\$ 6.500 correspondiendo al 30\% aproximado de la inversión total.

Considerando todos los puntos estudiados, se concluye que el negocio de importación y comercialización de especies de la floricultura colombiana en el mercado argentino, es una oportunidad de negocio con grandes posibilidades de éxito. 


\section{BIBLIOGRAFÍA}

- C.F.I. - Fundación Fortalecer. "Estudio del mercado interno e internacional de flores de corte, plantas ornamentales y follajes". 2006

- López Damrauf, G. "Cálculo Financiero Aplicado" - Un enfoque profesional. Editorial Facultad de Ciencias Económicas - Universidad de Buenos Aires. 2006.

- COMité de SANidAd VEgetal DEL CONO SUR. Marzo 1995. Estándar Regional en Protección Fitosanitaria. 2.6. Glosario de términos fitosanitarios.2.7. Glosario de términos afines al Registro de Productos Fitosanitarios.

- CAME - CONFEDERACIÓN ARGENTINA DE LA MEDIANA EMPRESA. "Flores, una oportunidad en colores" - Revista Comerciar N ${ }^{\circ} 55$, Diciembre de 2009.

- C.F.I. - CONCEJO FEDERAL DE INVERSIONES. "Informe de Situación del Sector Floricultura en Argentina". García Filgueira, Silvia - Di Stéfano, Domingo, 2002.

- IASCAV-INSTITUTO ARGENTINO DE SANIDAD Y CALIDAD VEGETAL. 1993. Recopilación de Recomendaciones para el correcto uso y manipuleo de productos fitosanitarios y sus envases. Página 11.

- ICA-SENASA. "Plan de Trabajo para la Exportación de Flores Frescas de Corte Originarias de Colombia con Destino a La Argentina", Enero de 2007.

- ICEX - INSTITUTO ESPAÑOL DE COMERCIO EXTERIOR. Oficina Económica y Comercial de España en Buenos Aires. "Informe Económico y Comercial de la República Argentina", Julio de 2009.

- INTA- AGENCIA DE COOPERACIÓN INTERNACIONAL DEL JAPÓN (JICA), "Estudio sobre la caracterización de la producción florícola en la República Argentina", 2003

- $\quad$ LATN - LATIN AMERICA TRADE NETWORK, Serie LATN Papers No 43. "Mecanismos de Protección Contingente en el Comercio Intrarregional del Mercosur", Julio J. Nogués, Septiembre de 2005.

- Tenjo G, Fernando. "Comportamiento Reciente (2000-2005), del Sector Floricultor Colombiano", Enero de 2006. 
- Pacheco, María P - Fiszman, Eduardo. “¿Existe una oportunidad de negocio en la biotecnología aplicada a plantas ornamentales?" - Tesina. Universidad del CEMA.

- PROEXPORT COLOMBIA, "Análisis del Mercado de Flores Cortadas en Latinoamérica" - Inteligencia de Mercados. Julio de 2006

- PROEXPORT COLOMBIA. "Guía para Exportar a Argentina" - Ministerio de Comercio, Industria y Turismo. Diciembre de 2008.

\section{DOCUMENTOS DE INTERNET}

- ALADI, Asociación Latinoamericana de Integración, "Acuerdos, Aranceles, normas de origen, regulaciones y normas", 2009 en http://www.aladi.org

- ASOCOLFLORES, "Consumo, Tamaño, Segmentación y Tendencias de Consumo de Flores Frescas en el Mercado de la Unión Europea “, 2005 en http://www.asocolflores.org/site/ppal.php

- CIRA, Cámara de Importadores de la República Argentina, "Informes Estratégicos por Sector", 2009 en http://cira.org.ar//index.php?page=informacion-de-interes

- CAME, Confederación Argentina de la Mediana Empresa, "FLORES, una Oportunidad en Colores", 2006 en http://redcame.org.ar/index.php

- FIA, Fundación para la Innovación Agraria, Boletín Trimestral No.5, 2000. Ministerio de Agricultura de Chile en http://www.fia.gob.cl/difus/boletin/bflor/bfoctu2000.pdf

- INDEC, "Indicadores de coyuntura, Indicadores macroeconómicos, Información Estadística Nacional y Provincial", 2009 en www.indec.mecon.gov.ar

- INTA, "Programa Hortalizas y Flores", 2002 en http://www.inta.gov.ar/ins/docum/05 hortalizas flores.pdf

- INTA - Agencia de Cooperación Internacional del Japón (JICA), "Estudio sobre la caracterización de la producción florícola en la República Argentina", 2003 en http://www.inta.gov.ar/floricultura/index.asp

- INVERTIR, Fundación INVERTIR Argentina, "Información sobre oportunidades de negocios, legislación comercial y de Inversión, Políticas y 
Procedimientos generales de Exportación e Importación",2009 en www.invertir.com

- MERCOSUR, "Información Macroeconómica de los Países Miembros”, 2009 en www.mercosur.org.uy

- MINCOMEX, "Perfil: Cadena de la Floricultura Ministerio de Comercio Exterior de Colombia. 2002."

http://www.colombiacompite.gov.co/archivos/perfil\%20flores.pdf

- PROCHILE, "Estudios de Mercado Sectoriales", 2009 en http://www.prochile.cl/documentos/2009/2009 estudios.php

- PROEXPORT, Promotora de Exportaciones de Colombia "Información Comercial y Logística de Exportación Países”, 2009 en www.proexport.com.co

- Mora y Araujo, Manuel. "La estructura social de la Argentina: Evidencias y conjeturas acerca de la estratificación actual", Proyecto CEPAL/GTZ sobre "Desarrollo social y equidad en América Latina y el Caribe"2002 en http://www.eclac.org/publicaciones/xml/7/11307/L1772e-P.pdf 
ANEXOS

\section{Anexo $N^{\circ}$ 1. Cronograma de Ejecución Plan de Marketing}

ANEXO CRONOGRAMA DE EJECUCIÓN PLAN

\begin{tabular}{|c|c|c|c|c|c|c|c|c|c|c|c|c|c|c|c|c|c|c|c|}
\hline \multicolumn{7}{|c|}{$\begin{array}{c}\text { PLAN DE TRABAJO PARA LA EJECUCIÓN DEL PLAN DE NEGOCIOS IMPORTADOR REFERENTE A LA IMPORTACIÓN } \\
\text { Y COMERCIALIZACIÓN DE FLORES FRESCAS COLOMBIANAS EN ARGENTINA }\end{array}$} & \multicolumn{9}{|c|}{$\begin{array}{l}\text { Seguimiento de las actividades a través } \\
\text { de los meses de ejecución del Proyecto }\end{array}$} & \multicolumn{3}{|c|}{$\begin{array}{l}\text { Costos Proyectados sin IVA (En } \\
\quad \text { Pesos Argentinos \$AR) }\end{array}$} & \multirow[b]{2}{*}{ 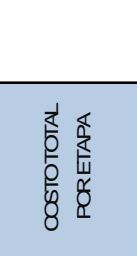 } \\
\hline 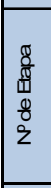 & Nombre de la Etapa & & Tareas / Actividades & 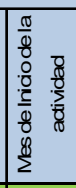 & 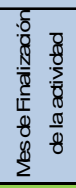 & 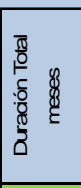 & $\bar{s}$ & $\tilde{\tilde{\omega}}$ & 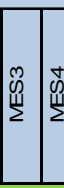 & 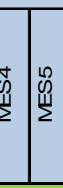 & 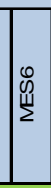 & 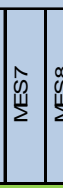 & 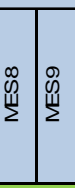 & 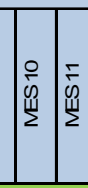 & $\frac{\frac{N}{c}}{\stackrel{n}{L}}$ & 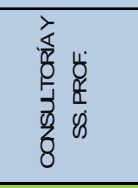 & 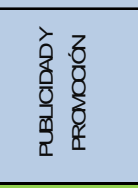 & 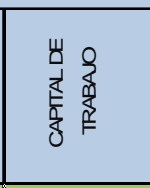 & \\
\hline \multirow{2}{*}{ A } & \multirow{2}{*}{$\begin{array}{c}\text { Estudio y } \\
\text { Diagnóstico de la } \\
\text { Situación }\end{array}$} & 1 & Resumen Ejecutivo y Descripción del Plan de Marketing & 1 & 1 & 1 & $x$ & & & & & & & & & & & & \multirow{2}{*}{$\$ 0.00$} \\
\hline & & 2 & Análisis e Investigación del Mercado y Análisis FODA & 1 & 1 & 1 & $\mathrm{x}$ & & & & & & & & & & & & \\
\hline \multirow{2}{*}{ B } & \multirow{2}{*}{\begin{tabular}{|c|} 
Análisis en Detalle \\
del Mercado \\
Argentino
\end{tabular}} & 1 & $\begin{array}{l}\text { Estudio de la Competencia, establecimiento de } \\
\text { estrategias y factores críticos de éxito }\end{array}$ & 2 & 2 & 1 & & $\mathrm{x}$ & & & & & & & & & & & \multirow{2}{*}{$\$ 0.00$} \\
\hline & & 2 & $\begin{array}{l}\text { Selección del Mercado Meta, Plan de Mercadeo y } \\
\text { Estrategia de Comercialización }\end{array}$ & 2 & 2 & 1 & & $x$ & & & & & & & & & & & \\
\hline \multirow{3}{*}{ c } & \multirow{3}{*}{$\begin{array}{l}\text { Estudio de } \\
\text { Factibilidad }\end{array}$} & 1 & $\begin{array}{l}\text { Establecimiento de Recursos e Inversiones y } \\
\text { Factibilidad Técnica del Proyecto (Logística y } \\
\text { Distribución Física Internacional) }\end{array}$ & 3 & 3 & 1 & & & $\mathrm{x}$ & & & & & & & & & & \multirow{3}{*}{$\$ 0.00$} \\
\hline & & 2 & $\begin{array}{l}\text { Factibilidad Económica (Ventas y Costos) y Financiera } \\
\text { (Cash Flow) }\end{array}$ & 3 & 3 & 1 & & & $x$ & & & & & & & & & & \\
\hline & & 3 & Indicadores Financieros y Análisis de Sensibilidad & 3 & 3 & 1 & & & $x$ & & & & & & & & & & \\
\hline \multirow{3}{*}{ D } & \multirow{3}{*}{$\begin{array}{l}\text { Ejecución del Plan } \\
\text { de Importación } \\
\text { (Primera Etapa) }\end{array}$} & 1 & $\begin{array}{l}\text { Evaluación y Selección de Proveedores (Fincas } \\
\text { productoras de flor en Colombia) y Selección de } \\
\text { Dersonal colaborador }\end{array}$ & 4 & 4 & 1 & & & $\mathrm{x}$ & $x$ & & & & & & $\$ 7.300 .00$ & & & \multirow{3}{*}{$\$ 32.970 .20$} \\
\hline & & 2 & $\begin{array}{l}\text { Instrumentación del Negocio (Inscripciones, Registros y } \\
\text { Licencias) - Publicidad y Promoción }\end{array}$ & 4 & 5 & 2 & & & 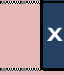 & $x \mid x$ & & & & & & $\$ 5.400 .00$ & $\$ 4.300 .00$ & & \\
\hline & & 3 & Equipamiento Oficina Comercial & 5 & 6 & 2 & & & & $x$ & $\mathbf{x}$ & & & & & & & $\$ 15.970 .20$ & \\
\hline \multirow{3}{*}{ E } & \multirow{3}{*}{$\begin{array}{c}\text { Ejecución del Plan } \\
\text { de Importación } \\
\text { (Segunda Etapa) }\end{array}$} & 1 & $\begin{array}{l}\text { Establecimiento ordenes de compra, negociación con } \\
\text { proveedores e instrumentación del medio de pago } \\
\text { (Carta de Crédito, Giro Directo. Cobranza) }\end{array}$ & 6 & 6 & 1 & & & & & $x$ & & & & & & & $\$ 28.779 .95$ & \multirow{3}{*}{$\$ 28.779 .95$} \\
\hline & & 2 & $\begin{array}{l}\text { Despacho del producto en el medio de transporte } \\
\text { seleccionado (Costo Implicito valor total de la impo) }\end{array}$ & 6 & 7 & 2 & & & & & $x$ & $\mathrm{x}$ & & & & & & & \\
\hline & & 3 & $\begin{array}{l}\text { Nacionalización y Distribución del Producto ((Cos to } \\
\text { Implicito valor total de la impo) }\end{array}$ & 7 & 7 & 1 & & & & & & $x$ & & & & & & & \\
\hline
\end{tabular}


Anexo $\mathbf{N}^{\circ}$ 2. Diagrama de Procesos para la Importación de Flor

\begin{tabular}{|c|c|c|c|c|}
\hline \multicolumn{5}{|c|}{ IMPORTACIÓN Y COMERCIALIZACIÓN DE FLOR COLOMBIANA EN ARGENTINA } \\
\hline \multirow[b]{2}{*}{ Fase } & \multirow{2}{*}{ Qué } & \multicolumn{3}{|c|}{ Quién } \\
\hline & & Importador/Distribuidor & Mayorista/Cliente & Productor/Exportador \\
\hline 1 & $\begin{array}{l}\text { Evaluación de los proveedores de flor } \\
\text { Colombiana (Calidad y Precio) }\end{array}$ & & & \\
\hline 2 & Relevamiento órdenes de compra & & & \\
\hline 3 & $\begin{array}{l}\text { Diseño del contrato de compraventa } \\
\text { internacional y emisión órden de } \\
\text { compra }\end{array}$ & & & \\
\hline 4 & $\begin{array}{l}\text { ¿El contrato es el adecuado para las } \\
\text { partes? }\end{array}$ & & & \\
\hline 5 & $\begin{array}{l}\text { Ejecución del pago de acuerdo con } \\
\text { las condiciones establecidas en el } \\
\text { contrato. (carta de crédito, cobranza) }\end{array}$ & & & \\
\hline 6 & Embarque de la mercadería & & & \\
\hline 7 & $\begin{array}{l}\text { Importación (pago de derechos), } \\
\text { despacho a plaza }\end{array}$ & & & \\
\hline 8 & Distribución & & & \\
\hline 9 & ¿Producto Conforme? & & & \\
\hline 10 & $\begin{array}{l}\text { Recepción del pago de las } \\
\text { mercaderías }\end{array}$ & & & \\
\hline 11 & $\begin{array}{l}\text { Evaluación final y correcciones } \\
\text { necesarias }\end{array}$ & & & \\
\hline & & & & FIN \\
\hline
\end{tabular}




\section{Anexo $\mathbf{N}^{\circ} 3$ Simulación del Embalaje y la Unidad de Carga}

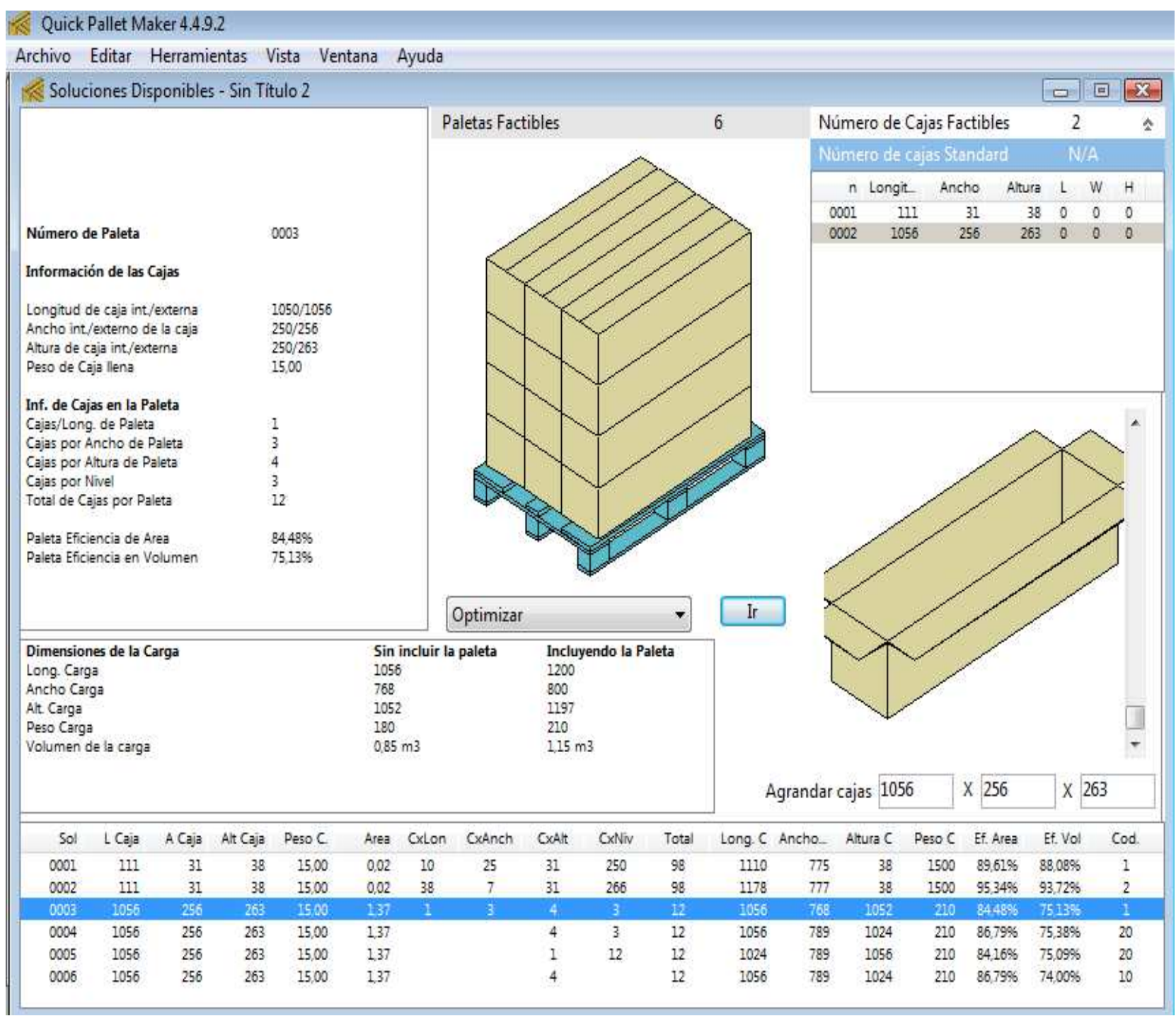


Anexo $N^{\circ} 4$ Frecuencias de Vuelos de Carga Bogotá-Buenos Aires

\begin{tabular}{|c|c|c|c|c|c|c|c|}
\hline \multirow{2}{*}{\multicolumn{8}{|c|}{$\begin{array}{c}\text { FRECUENCIAS AEREAS DE CARGA BOGOTA - BUENOS AIRES } \\
\text { Aerolínea : American Airlines / AMERICAN AIRLINES }\end{array}$}} \\
\hline & & & & & & & \\
\hline $\begin{array}{l}\text { Punto de } \\
\text { embarque }\end{array}$ & COLOMBIA & Conexiones & Frecuencias & $\begin{array}{l}\text { Número de } \\
\text { vuelos }\end{array}$ & Equipo & Clase & Observaciones \\
\hline \multirow{2}{*}{ BOGOTA } & \multirow{2}{*}{ BUENOS AIRES } & \multirow{2}{*}{$\begin{array}{l}\text { ESTADOS UNIDOS - } \\
\text { MIAMI }\end{array}$} & LU & 2 & \multirow{2}{*}{ BOEING 767} & \multirow[b]{2}{*}{$\mathrm{P}$} & \multirow{2}{*}{$\begin{array}{l}\text { Vuelan también con aviones Boeing } \\
\text { 757. y la conexión Miami - Argentina } \\
\text { se hace en un avión Boeing } 777\end{array}$} \\
\hline & & & MA-MI-JU-VI-SA-DOM & 2 & & & \\
\hline \multicolumn{8}{|c|}{ Aerolínea : CENTURION / CENTURION } \\
\hline $\begin{array}{l}\text { Punto de } \\
\text { embarque }\end{array}$ & COLOMBIA & Conexiones & Frecuencias & $\begin{array}{l}\text { Número de } \\
\text { vuelos }\end{array}$ & Equipo & Clase & Observaciones \\
\hline \multirow{2}{*}{ BOGOTA } & \multirow{2}{*}{ BUENOS AIRES } & \multirow{2}{*}{$\begin{array}{l}\text { ESTADOS UNIDOS - } \\
\text { MIAMI }\end{array}$} & LU & 1 & \multirow{2}{*}{ DC 10} & \multirow[b]{2}{*}{$\mathrm{F}$} & \multirow{2}{*}{ CAP. 62 TONS. } \\
\hline & & & MA-MI-JU-VI-SA & 1 & & & \\
\hline \multicolumn{8}{|c|}{ Aerolínea : COPA / COPA AIRLINES } \\
\hline $\begin{array}{l}\text { Punto de } \\
\text { embarque }\end{array}$ & COLOMBIA & Conexiones & Frecuencias & $\begin{array}{l}\text { Número de } \\
\text { vuelos }\end{array}$ & Equipo & Clase & Observaciones \\
\hline \multirow{4}{*}{ BOGOTA } & \multirow{4}{*}{ BUENOS AIRES } & \multirow{4}{*}{ PANAMA } & LU & 1 & \multirow{4}{*}{ BOEING 737} & \multirow{4}{*}{$\mathrm{F}$} & \\
\hline & & & MA-MI-JU & 1 & & & \\
\hline & & & $\mathrm{VI}$ & 1 & & & \\
\hline & & & SA-DO & 1 & & & \\
\hline \multicolumn{8}{|c|}{ Aerolínea : TACA / TACA } \\
\hline $\begin{array}{l}\text { Punto de } \\
\text { embarque }\end{array}$ & COLOMBIA & Conexiones & Frecuencias & $\begin{array}{l}\text { Número de } \\
\text { vuelos }\end{array}$ & Equipo & Clase & Observaciones \\
\hline \multirow{2}{*}{ BOGOTA } & \multirow{2}{*}{ BUENOS AIRES } & \multirow{2}{*}{ PERU - LIMA } & LU & 2 & \multirow{2}{*}{ AB-320 } & \multirow{2}{*}{$\mathrm{P}$} & \\
\hline & & & MA-MI-JU-VI-SA-DOM & 2 & & & \\
\hline \multicolumn{8}{|c|}{ Aerolínea : TAMPA / TAMPA CARGO } \\
\hline $\begin{array}{l}\text { Punto de } \\
\text { embarque }\end{array}$ & COLOMBIA & Conexiones & Frecuencias & $\begin{array}{l}\text { Número de } \\
\text { vuelos }\end{array}$ & Equipo & Clase & Observaciones \\
\hline BOGOTA & BUENOS AIRES & & LU-MI-VI-SA & 1 & BOEING 767 & $\mathrm{P}$ & \\
\hline \multicolumn{8}{|c|}{ Aerolínea : UPS / UPS } \\
\hline $\begin{array}{l}\text { Punto de } \\
\text { embarque }\end{array}$ & COLOMBIA & Conexiones & Frecuencias & $\begin{array}{l}\text { Número de } \\
\text { vuelos }\end{array}$ & Equipo & Clase & Observaciones \\
\hline \multirow{3}{*}{ BOGOTA } & \multirow{3}{*}{ BUENOS AIRES } & \multirow{3}{*}{$\begin{array}{l}\text { ESTADOS UNIDOS - } \\
\text { MIAMI }\end{array}$} & \multirow{2}{*}{ MA } & 1 & BOEING 757 & & \\
\hline & & & & 1 & BOEING 767 & $\mathrm{~F}$ & $\begin{array}{l}\text { CAP. } 35 \text { y } 52 \\
\text { respectivamente. }\end{array}$ \\
\hline & & & MI-JU-VI-SA & 1 & BOEING 757 & & \\
\hline
\end{tabular}




\section{Anexo $N^{\circ}$ 5. Análisis Financiero (Ventas y Costos Proyectados)}

\begin{tabular}{|c|c|c|c|c|c|c|}
\hline \multicolumn{7}{|c|}{ INGRESOS POR CONCEPTO DE VENTAS (Unidad en Ramos de Flores) } \\
\hline & CONCEPTO & Año 1 & Año 2 & Año 3 & Año 4 & Año 5 \\
\hline & Total Numero de Ramos a Importar & 12.960 & 13.867 & 14.838 & 15.877 & 16.988 \\
\hline 1 & Cantidad en Rosa (65\%) & 8.424 & 9.014 & 9.645 & 10.320 & 11.042 \\
\hline 2 & Cantidad en Clavel (30\%) & 3.888 & 4.160 & 4.451 & 4.763 & 5.096 \\
\hline 3 & Cantidad en Crisantemos (3\%) & 389 & 416 & 445 & 476 & 510 \\
\hline 4 & Cantidad en otros productos ( $2 \%)$ & 259 & 277 & 297 & 318 & 340 \\
\hline
\end{tabular}

\begin{tabular}{|c|c|c|c|c|c|c|}
\hline \multicolumn{7}{|c|}{$\begin{array}{l}\text { INGRESOS POR CONCEPTO DE VENTAS PROYECTADOS } \\
\text { IO ESTIMADO DE UN RAMO DE FLORES = Entre USD } 11 \text { y USD } 14\end{array}$} \\
\hline & CONCEPTO & Año 1 & Año 2 & Año 3 & Año 4 & Año 5 \\
\hline & os por Ventas Proyectadas & 154.224 USD & 171.953 USD & 191.409 USD & 212.746 USD & 236.132 USD \\
\hline 1 & Rosa & 100.246 USD & 111.770 USD & 124.416 USD & 138.285 USD & 153.486 USD \\
\hline 2 & Clavel & 46.267 USD & 51.586 USD & 57.423 USD & 63.824 USD & 70.840 USD \\
\hline 3 & Crisantemos & 4.627 USD & 5.159 USD & 5.742 USD & 6.382 USD & 7.084 USD \\
\hline 4 & Otros productos & 3.084 USD & 3.439 USD & 3.828 USD & 4.255 USD & 4.723 USD \\
\hline
\end{tabular}

\begin{tabular}{|c|c|c|c|c|c|c|}
\hline \multicolumn{7}{|c|}{$\begin{array}{l}\text { COSTO ESTIMADO DE UN RAMO DE FLORES = USD } 8^{\star} \text { (Según Matriz de Costos) } \\
\text { letes (Nacional, Internacional), Gastos e Impuestos de Nacionalización de mercadería incluida }\end{array}$} \\
\hline & CONCEPTO & Año 1 & Año 2 & Año 3 & Año 4 & Año 5 \\
\hline & s por Compras Proyectadas & 103.680 USD & 104.004 USD & 111.284 USD & 119.074 USD & 127.409 USD \\
\hline 1 & Rosa & 67.392 USD & 67.603 USD & 72.335 USD & 77.398 USD & 82.816 USD \\
\hline
\end{tabular}




\begin{tabular}{|c|c|c|c|c|c|c|}
\hline 2 & Clavel & 31.104 USD & 31.201 USD & 33.385 USD & 35.722 USD & 38.223 USD \\
\hline 3 & Crisantemos & 3.110 USD & 3.120 USD & 3.339 USD & 3.572 USD & 3.822 USD \\
\hline 4 & Otros productos & 2.074 USD & 2.080 USD & 2.226 USD & 2.381 USD & 2.548 USD \\
\hline
\end{tabular}

\begin{tabular}{|c|c|c|c|c|c|c|}
\hline \multicolumn{7}{|c|}{ OTROS GASTOS DE OPERACIÓN } \\
\hline & CONCEPTO & Año 1 & Año 2 & Año 3 & Año 4 & Año 5 \\
\hline & Otros Costos de Operación & 60.255 USD & 63.515 USD & 67.388 USD & 71.643 USD & 79.200 USD \\
\hline 1 & Recursos Humanos & 45.360 USD & 48.535 USD & 51.933 USD & 55.568 USD & 59.458 USD \\
\hline 2 & Gastos de Administración & 2.400 USD & 2.568 USD & 2.748 USD & 2.940 USD & 3.146 USD \\
\hline 3 & Gastos Comercialización & 3.645 USD & 3.337 USD & 3.385 USD & 3.540 USD & 3.702 USD \\
\hline 4 & Gastos Financieros & 6.600 USD & 6.600 USD & 6.600 USD & 6.600 USD & 9.600 USD \\
\hline 5 & Otros gastos no incluidos & 2.250 USD & 2.475 USD & 2.723 USD & 2.995 USD & 3.294 USD \\
\hline
\end{tabular}


Anexo $\mathbf{N}^{\circ}$ 6. Presupuesto Financiero Proyectado (Flujo de Caja)

\begin{tabular}{|c|c|c|c|c|c|c|}
\hline CONCEPTO & Periodo 0 & Año 1 & Año 2 & Año 3 & Año 4 & Año 5 \\
\hline \multicolumn{7}{|l|}{ Gestión Operativa } \\
\hline Ingresos por Venta de Mercadería & 0 USD & 154.224 USD & 171.953 USD & 191.409 USD & 212.746 USD & 236.132 USD \\
\hline Otros Ingresos & 0 USD & 0 USD & 0 USD & 0 USD & 0 USD & 0 USD \\
\hline SUBTOTAL DE INGRESOS & 0 USD & 154.224 USD & 171.953 USD & 191.409 USD & 212.746 USD & 236.132 USD \\
\hline Egresos por Compras de Mercadería & 0 USD & 103.680 USD & 104.004 USD & 111.284 USD & 119.074 USD & 127.409 USD \\
\hline Recursos Humanos & 0 USD & 45.360 USD & 48.535 USD & 51.933 USD & 55.568 USD & 59.458 USD \\
\hline Gastos Administración & 0 USD & 2.400 USD & 2.568 USD & 2.748 USD & 2.940 USD & 3.146 USD \\
\hline Gastos Comercialización & 0 USD & 3.645 USD & 3.337 USD & 3.385 USD & 3.540 USD & 3.702 USD \\
\hline Gastos Financieros & 0 USD & 6.600 USD & 6.600 USD & 6.600 USD & 6.600 USD & 9.600 USD \\
\hline Otros gastos no incluidos & 0 USD & 2.250 USD & 2.475 USD & 2.723 USD & 2.995 USD & 3.294 USD \\
\hline SUBTOTAL DE EGRESOS OPERACIÓN IVA incluido & 0 USD & 163.935 USD & 167.519 USD & 178.673 USD & 190.717 USD & 206.609 USD \\
\hline Bienes de Capital a Adquirir & 0 USD & 0 USD & 0 USD & 0 USD & 0 USD & 0 USD \\
\hline Infraestructura (Equipamiento Oficina Comercial) & 4.160 USD & 0 USD & 0 USD & 0 USD & 0 USD & 0 USD \\
\hline Consultorías y Servicios Profesionales & 4.430 USD & 0 USD & 0 USD & 0 USD & 0 USD & 0 USD \\
\hline Mercadería (Primeras importaciones) & 8.640 USD & 0 USD & 0 USD & 0 USD & 0 USD & 0 USD \\
\hline Otros Recursos & 0 USD & 0 USD & 0 USD & 0 USD & 0 USD & 0 USD \\
\hline SUBTOTAL INVERSIONES & 17.230 USD & 0 USD & 0 USD & 0 USD & 0 USD & 0 USD \\
\hline TOTAL ACUMULADO INVERSIONES Y EGRESOS & 17.230 USD & 163.935 USD & 167.519 USD & 178.673 USD & 190.717 USD & 206.609 USD \\
\hline \multicolumn{7}{|l|}{ Gestión Financiera } \\
\hline Aporte de Socios & 6.510 USD & 0 USD & 0 USD & 0 USD & 0 USD & 0 USD \\
\hline Otras fuentes de Ingreso & 0 USD & 0 USD & 0 USD & 0 USD & 0 USD & 0 USD \\
\hline SUBTOTAL DE INGRESOS POR RECURSOS & 6.510 USD & 0 USD & 0 USD & 0 USD & 0 USD & 0 USD \\
\hline FLUJO DE CAJA POR PERIODO & -10.720 USD & -9.711 USD & 4.434 USD & 12.736 USD & 22.029 USD & 29.523 USD \\
\hline FLUJO DE CAJA ACUMULADO & -10.720 USD & -20.431 USD & -15.997 USD & -3.261 USD & 18.768 USD & 48.291 USD \\
\hline
\end{tabular}




\begin{tabular}{|r|c|}
\hline VAN (USD) $=$ & 34.581 USD \\
\hline TIR (\%) $=$ & $41 \%$ \\
\hline Periodo de Recuperación de Inversión (días) $=$ & 1.149 \\
\hline Periodo de Recuperación de Inversión $=$ & 3 Años, 1 Mes, 24 Días \\
\hline
\end{tabular}




\section{Anexo $N^{\circ}$ 7. Premisas y Estimaciones Utilizadas para la Proyección de los Flujos de Fondos Netos}

\section{Criterios generales}

- Los flujos de fondos proyectados corresponden a aquellos generados por los tipos de flor objeto del presente proyecto.

- La apertura de un flujo de fondos se realiza para 5 años

- Las inversiones se detallan en la sección 6.1.

- Los flujos de fondos se estimaron conforme a las premisas que se describen más adelante.

- No se incluyen los flujos de fondos que se espera ocasionen:

a. Las futuras inversiones que ocasionen mejoras en la capacidad de servicio.

b. Los resultados generados por operaciones financieras, reestructuraciones y contingencias varias.

c. Los pagos del impuesto a las ganancias.

- Los flujos de fondos esperados fueron expresados en USD

\section{Ingresos por ventas}

\section{Volumen de venta de flor}

Para las cantidades se tuvo en cuenta los volúmenes manejado por los actuales importadores de flor a la República Argentina (Tabla No. 10) donde el importador que menos cantidades importo fue IKEBANA S.A: con un total 328.698 tallos de flor. Teniendo en cuenta esto, la proyección de la importadora apunta a importar en volumen aproximadamente el $50 \%$ en tallos con respecto a este último, lo cual en un inicio es una proyección conservadora mientras se conoce a totalidad el mercado. Este presupuesto entonces corresponde a un presupuesto estimado en número de tallos a importar de aproximadamente 155.000 tallos de flor (Corresponde a 12.960 ramos). En inicio se proyecta un aumento anual en volúmenes importados de acuerdo al crecimiento del sector antes mencionado del $6 \%$. 
En todos los casos, se asumió el cobro de las ventas en el mismo mes de despacho.

\section{Precio de venta}

Para las ventas se tuvo en cuenta como referencia el Precio del cliente Final (Consumidor) determinado en la Matriz de Precios (Tabla No. 14) donde el valor de un ramo está entre de US\$11 y US\$ 14 aproximadamente, dependiendo si el cliente es un mayorista o un detallista respectivamente. En el paso del tiempo puede estimarse un aumento de los precios de acuerdo a la inflación general del país.

\section{Gastos fijos de administración y comercialización}

\section{Mercadería:}

Para los costos se tuvo en cuenta como referencia el Valor DDP determinado en la Matriz de Precios (Tabla No. 14) donde el valor de un ramo nacionalizado en Argentina, es de US\$ 8 aproximadamente. A futuro con un aumento de cantidades puede estimarse un descuento por volumen por parte del proveedor colombiano.

\section{Recursos Humanos.}

Respecto al primer año, los sueldos, jornales y contribuciones se estiman sobre una dotación de tres personas abocadas la labor administrativa, de marketing y distribución. Se proyectan aumentos de sueldos anuales, de acuerdo a la estimación del promedio de inflación de Argentina

\section{Gastos Administrativos.}

Se incluyen en este rubro el valor correspondiente al alquiler y gastos (expensas, servicios), de la oficina comercial ubicada en Capital Federal.

\section{Gastos de Comercialización}

Hacen alusión a la adquisición del host y mantenimiento de la página de internet, así como material publicitario propuesto en el plan de mercadeo. 


\section{Otros Gastos}

El rubro otros gastos, se corresponde con los imputados a imprevistos, papelería y material gráfico.

\section{Gestión Financiera}

\section{Gastos Financieros}

Utilizando una simulación de leasing ofrecida por la entidad financiera bancolombia.com, se obtuvieron los valores de cuotas por periodo. Lo anterior para la adquisición del camión adaptado que cumplirá la labor de distribución desde el aeropuerto a cada uno de los clientes.

\section{Aportes}

Se prevé la capitalización en US\$6.500, rol que ejercerán los accionistas, en este sentido es aportar los fondos para el pronto emplazamiento, que en una relación costo-beneficio repercutirá favorablemente a la vez, en la rentabilidad del negocio en el corto y mediano plazo. 


\section{Anexo $N^{\circ}$ 8. Diseño Preliminar Página de Internet}

IMPORTADORA DE FLORES COLOMBIANAS

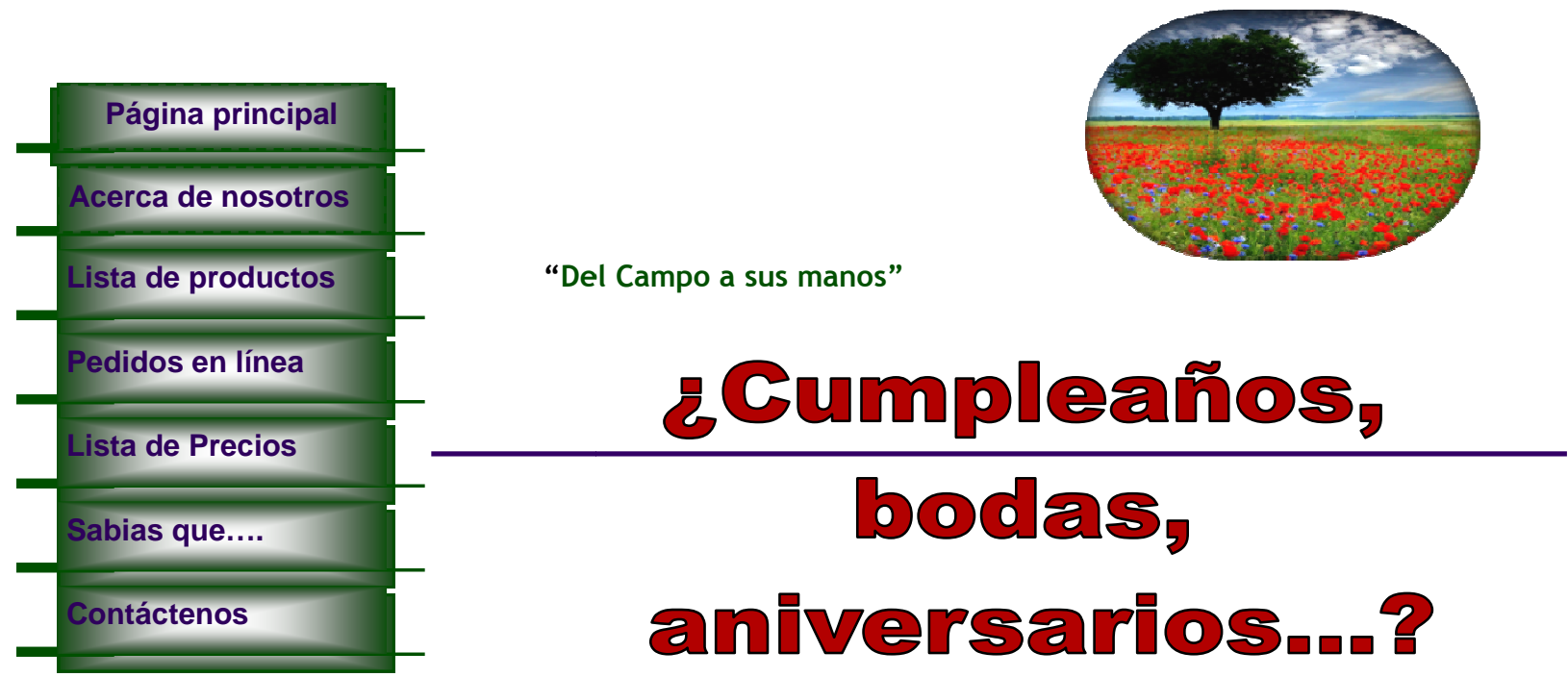

Información de contacto:

IMPORTADORA DE FLORES

COLOMBIANAS

Acuña de Figueroa 118

TELEFONO

4982-7292

Correo: Imporflorcolombiana@gmail.com
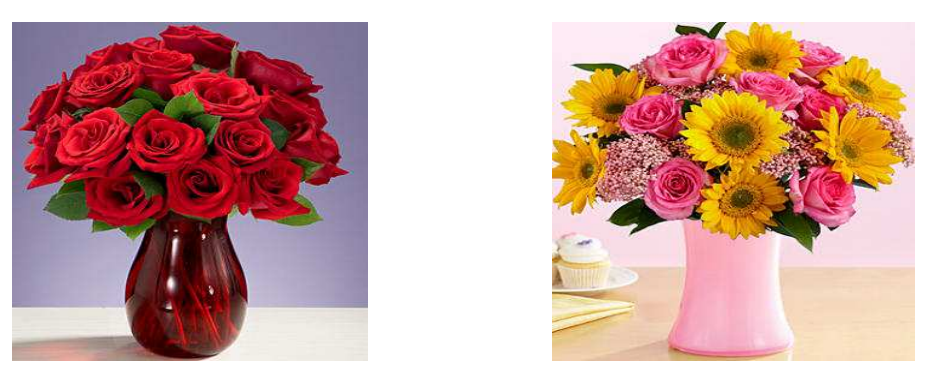

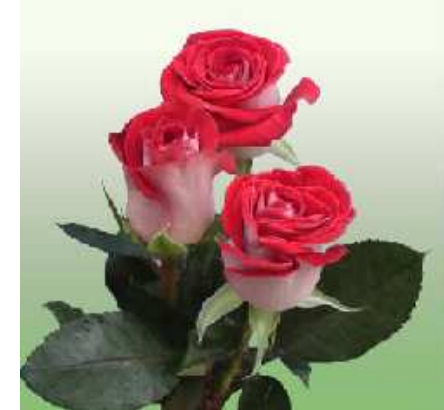

¿Conoces el significado de las Rosas?... Encuéntralo en sabias qué...!!

Página principal | Acerca de nosotros | Info. de contacto | Lista de productos | Lista de servicios | Lista de proyectos | Vínculos | Acerca de nosotros | Lista de productos | Acerca de nosotros 


\section{ACLARACIÓN}

Yo aseguro que esta tesis fue elaborada por mí, que no utilicé ningún otro material que no haya dado a conocer en las referencias y que no utilicé frases o párrafos de otros autores, que este trabajo de tesis nunca ha sido presentado ante un comité de evaluación de tesis y que no trasgreda derechos de terceros. 